\title{
LANGUAGE VARIATION, SOCIALIZATION AND ATTITUDES: \\ A SOCIOLINGUISTIC INVESTIGATION OF SCHOOL-AGED BIDIALECTAL ENGLISH SPEAKERS
}

by

Nicola M. Dove

Bachelor of Arts (Honours), Psychology and Linguistics, Carleton University, 2011

Graduate Certificate, Communicative Disorders Assistant, Durham College, 2012

\author{
A Major Research Paper \\ presented to Ryerson University \\ in partial fulfillment of the \\ Master of Arts \\ in the program of \\ Early Childhood Studies
}

Toronto, Ontario, Canada, 2014

(C) Nicola M. Dove 


\begin{abstract}
Author's Declaration
I hereby declare that I am the sole author of this MRP. This is a true copy of the MRP, including any required final revisions.

I authorize Ryerson University to lend this MRP to other institutions or individuals for the purpose of scholarly research

I further authorize Ryerson University to reproduce this MRP by photocopying or by other means, in total or in part, at the request of other institutions or individuals for the purpose of scholarly research.

I understand that my MRP may be made electronically available to the public.
\end{abstract}




\title{
LANGUAGE VARIATION, SOCIALIZATION AND ATTITUDES: \\ A SOCIOLINGUISTIC INVESTIGATION OF SCHOOL-AGED BIDIALECTAL ENGLISH SPEAKERS \\ (C) Nicola M. Dove
}

Masters of Arts

in the program of

Early Childhood Studies

\begin{abstract}
The original purpose of this investigation was to determine the relationships between dialect, cultural identity, and literacy for Jamaican-Canadian Creole speakers (JCS), but was expanded to focus more broadly on language socialization due to low recruitment. Fourteen participants (5 children, aged 5-6 and 9 adults) from JCS families within the Toronto area were recruited for this study. Language attitudes and use measures: questionnaire, interview, and Matched-Guise Test. Language and literacy measures: Diagnostic Evaluation of Language Variation and Assessment of Literacy and Language. Child results showed that language dominance was Standard English for both use and exposure, and to date, language and literacy results are only described due to small sample size. In relation to identity and Creole use, interpretation of qualitative measures revealed that language attitudes were not always reflected in language use. However, findings provide initial insights regarding the relationship between language, identity, and literacy that warrant deeper investigation.
\end{abstract}

Keywords: sociolinguistics, dialect, Jamaican Creole, bidialectal, cultural identity, Jamaican-Canadian, language, literacy 


\section{Acknowledgements}

My biggest realization in this academic journey is that no man is an island. Beyond my own writing and research efforts, I could not have completed this project on my own. I would like to take a moment to express appreciation to others.

First and foremost, I am most grateful to God who has provided me with a path and a purpose. Truly, words are insufficient in expressing my gratitude to God. It is because of Him that I will continue to do what I do with purpose.

I am forever grateful to the women who inspired me to pursue higher education, my mother and grandmother. Mom, you have demonstrated that with hard work and perseverance, one can achieve their goals in spite of any challenges. Thank you for the many prayers along the way and the constant reminder to keep my eye on the prize. Your efforts in this journey have not gone unnoticed and are greatly appreciated. Although the memory of my grandmother lives on in

my heart and mind, I can still hear her saying, "If at first you don't succeed, try, try, try again." I hope I have made you both proud.

To my MRP advisor, Dr. Kathleen Peets, your enthusiasm about my research has been inspiring and motivating. You have gone above and beyond to mentor, guide, challenge, and support me in this process. It has been a pleasure completing my MRP under your supervision.

To the MA ECS program director, Dr. Mehrunnisa Ahmad Ali, thank you for your support, encouragement, and helpful advice along the way. I have always left your office with a feeling of motivation and clarity of mind.

To my second reader, Dr. Sejal Patel, thank you for taking the time to provide detailed feedback on my MRP and checking in with me on my progress throughout the school year. 
I would like to thank all the members of my MRP defense committee, Dr. Kathleen Peets, Dr. Sejal Patel, and Dr. Angela Valeo, for their review of my MRP and helpful advice to ensure its successful completion.

To those who have encouraged me along the way, family, friends, and my fellow cohort... Thank you! Even the smallest gestures have had great impact. I will refrain from listing names here, as there are far too many individuals who have been and continue to be positive lights in my life. For that, I am extremely grateful.

To the participants who were involved in my study, your interest in my research and willingness to share it with others was inspiring. Thank you for your time and effort.

Lastly, as much as I am grateful for the blessings, I am also grateful for the trials along the way. For without them, I could not have challenged my limits and I would not have grown. 


\section{TABLE OF CONTENTS}

AUTHOR'S DECLARATION $\quad$ ii

$\begin{array}{ll}\text { ABSTRACT } & \text { iii }\end{array}$

ACKNOWLEDGEMENTS iv

LIST OF TABLES $\quad$ viii

LIST OF APPENDICES $\quad$ ix

CHAPTER 1: INTRODUCTION 1

CHAPTER 2: THEORETICAL AND CONCEPTUAL FRAMEWORK 4

Social Identity Construction $\quad 4$

$\begin{array}{ll}\text { Socialization through Language } & 8\end{array}$

Creole Language Systems: Status and Value 11

Inequity in Canadian Society and Education: Theoretical Insights 19

Identity and Achievement: Racial, Cultural, and Dialectal Considerations 22

CHAPTER 3: LITERATURE REVIEW 27

$\begin{array}{ll}\text { Social Identity } & 27\end{array}$

$\begin{array}{ll}\text { Language and Language Socialization } & 30\end{array}$

Creole Language Systems 36

Inequity in Canadian Society and Education: Empirical Insights 42

Identity and Achievements: Perceptions and Realities 44

$\begin{array}{ll}\text { CHAPTER 4: METHODOLOGY } & 49\end{array}$

$\begin{array}{ll}\text { Participants } & 49\end{array}$

$\begin{array}{ll}\text { Procedures } & 51\end{array}$

$\begin{array}{ll}\text { Measures } & 52\end{array}$ 
CHAPTER 5: RESULTS $\quad 59$

Child Findings $\quad 59$

$\begin{array}{ll}\text { Adult Findings } & 67\end{array}$

$\begin{array}{ll}\text { CHAPTER 6: DISCUSSION } & 78\end{array}$

$\begin{array}{ll}\text { Child Data } & 78\end{array}$

$\begin{array}{ll}\text { Adult Data } & 82\end{array}$

Methodological Insights: Contributions and Challenges 86

$\begin{array}{lr}\text { Future Directions } & 88\end{array}$

CHAPTER 7: CONCLUSION 89

$\begin{array}{ll}\text { APPENDICES } & 91\end{array}$

$\begin{array}{ll}\text { REFERENCES } & 149\end{array}$ 


\section{List of Tables}

TABLE 1

Child Assessment Results for the Diagnostic Evaluation of Language Variation (DELV) and the Assessment of Language and Literacy (ALL).

TABLE 2

Child Language Use as Reported by parents.

TABLE 3

Likert Scale Matched-Guise Responses (Detective Dog and the Disappearing Doughnuts)

TABLE 4

Likert Scale Matched-Guise Responses (X-ray for Xylophone Fish)

TABLE 5

Number of Adult Participant Questionnaire Responses for Questions Concerning Standard English.

TABLE 6

Number of Adult Participant Questionnaire Responses for Questions Concerning Jamaican Creole.

TABLE 7

Parental Language Views Likert Scale Average Ratings and Ranges. 


\section{LIST OF APPENDICES}

APPENDIX A: Recruitment flyer $\quad 91$

$\begin{array}{ll}\text { APPENDIX B: Consent form } & 92\end{array}$

$\begin{array}{ll}\text { APPENDIX C: Assent form } & 98\end{array}$

$\begin{array}{ll}\text { APPENDIX D: Consent form (focus group) } & 101\end{array}$

APPENDIX E: Parent-Child information form and questionnaire 106

APPENDIX F: Matched-Guise test 112

$\begin{array}{ll}\text { APPENDIX G: Information sheet for study } & 120\end{array}$

$\begin{array}{ll}\text { APPENDIX H: Focus group script } & 124\end{array}$

$\begin{array}{ll}\text { APPENDIX I: Inclusion/Exclusion checklist } & 127\end{array}$

$\begin{array}{ll}\text { APPENDIX J: Order of English sound acquisition } & 128\end{array}$

APPENDIX K: Interview responses and coding 129

APPENDIX L: Individual adult responses (language views) 148 


\section{Chapter 1: Introduction}

There appears to be an ongoing, systemic issue in education. Past and present statistics suggest that a disproportionate number Black students are underachieving in Toronto public schools (Brathwaite, 2010; Cummins, 1997; Colour of Poverty Campaign - Colour of Change Network, 2011; Dib, Donaldson, \& Turcotte, 2008; Ferguson, Tilleczek, Boydell, Rummens, Cote, \& Roth-Edney, 2005; Gordon \& Zinga, 2012; Royal Commission on Learning, 1994). This finding is problematic. The term 'Black' is a homogeneous assumption, and is often used to describe diverse groups and subgroups of the African diaspora. Within these subgroups lie further diasporic subgroupings and a vast array of cultural groups. Therefore, 'Black' represents very large and diverse groups of people. Racial studies have pointed to systemic justice issues, such as inequalities in education, but generally do not discuss any sociolinguistic related issues. Additionally, when findings related to academic performance and achievement are explained on grounds of race, it racializes a problem that is not racially determined.

The trend of Black students underachieving in Canadian schools remains, but this investigation will consider factors other than race. In addition, children of Caribbean backgrounds are also underachieving in Toronto schools (Coelho, 1991; 1988; Smith, Schneider, \& Ruck, 2005). Previous studies have identified the influence of nonstandard dialects on aspects of emergent literacy development and literacy performance (Labov, 2001 as cited in Labov, 2010; Terry, 2012). This study explores the role of dialect in the academic underachievement of Black students in Canada, specifically among Black Canadian students who speak a dialect that differs from Standard English.

Statistics Canada (2011) reported that $22.8 \%$ of Black Canadians are of Jamaican heritage. The Organization for Economic Cooperation and Development (OECD) provided a 
profile of the Jamaican diaspora, and reported that Canada was the third main destination for Jamaican emigrants, with the United Kingdom being the second and the United States being the first (OECD, 2012). Jamaica is a Caribbean island with a unique language history: as a result of colonialism, European and West African languages merged as a pidgin language, which overtime formed what is known today as the Jamaican Creole dialect (Akers, 1981; Deuber \& Hinrichs, 2007; Millar, 2007). Spoken to varying degrees, the Jamaican Creole dialect can be placed on a Creole Continuum, which is dependent on numerous geographical and sociological factors (Akers, 1981; Clacher, 2004; Harry, 2006; Wigglesworth, Billington, \& Loakes, 2013). Therefore it can be assumed that in Canada, many Jamaican immigrants speak Jamaican Creole, but in varying degrees (monodialectal English speakers), and in some cases in addition to Standard English (bidialectal English speakers). Although the root language (also known as the lexifier) is not specified, Statistics Canada indicated that Creole-speaking populations in Canada reporting the use of Creole in the home environment increased by $42 \%$ between 2006 and 2011 (Statistics Canada, 2012). It is possible that linguistic barriers may explain achievement differences of some Black Canadian students, particularly those of Jamaican heritage. More specifically, could these language barriers impact emergent literacy skills achievement?

Language is a symbolic medium through which identity is asserted and culture is expressed and transmitted (De Fina, 2007; Gardiner \& Kosmitzki, 2011; Migge, 2007). Language views and attitudes determine how a language is used, and purposes and contexts in which the language is used (Baker, 2006; De Fina, 2007; Paradis, Genesee, \& Crago, 2004; Schecter \& Bayley, 2004; Watson-Gegeo, 2004). Consider Creole languages, which often exist in what can be described as a diglossia where language prestige influences language use (Baker, 2006; Irvine, 2004; Mair, 2002; Mühleisen, 2005). Creole languages are often restricted to oral 
form and are thus considered low prestige languages (Mühleisen, 2005). This is the language situation in Jamaica (Polinsky \& Kagan, 2007; Winford, 1997). However, developments reflective of positive attitude shifts toward the Jamaican Creole language are occurring in Jamaica (Carpenter \& Devonish, 2010; Kouwenberg et al., 2011; Mair, 2002). In addition, polarity persists as evidenced by traditional practices reflective of negative attitudes towards the Jamaican Creole language in Jamaica (Deuber and Hinrichs, 2007; Hall, 2010; Irvine, 2004; Mair, 2002; Smith-Edwards, 2013). These attitudes are transferred to diasporic contexts (Ager, 1999). As language and cultural identity are closely related, it is possible that cultural barriers may also explain some achievement difference for Black Canadian students, particularly those of Jamaican heritage.

In performing an extensive review of literature, I was unable to find the following: a) the impact of Jamaican Creole on Standard English literacy achievement and, b) the impact of Jamaican cultural identity on emergent literacy. Instead of focusing on race with regard to academic achievement and performance, the current study addresses a systemic problem with a theoretically informed research question. My research question is, do dialect and cultural identity affect the literacy performance of Jamaican Canadian Creole speakers?

As a member of the Jamaican diaspora by descent residing in Canada and having experienced academic challenges of my own in the past, this area of research is of particular interest to me. To answer this research question, I include literature concerning identity construction and language socialization. I move away from homogeneous assumptions, and explore the experiences of members of the Jamaican diaspora in Canada. Relevant theories and concepts frame this investigation, some of which include Social Identity Theory, Presence Caribbean, Language Socialization Theory, Assimilation, private language planning. To 
understand Creole in the diasporic context, one must consider Creole in its native context, therefore, I also include and describe existent language views and practices in Jamaica and related concepts such as diglossia, language prestige, decreolization, and language status and standardization. In discussing views and attitudes toward the language, I use post-colonialism and linguistic imperialism to frame my argument. As the Canadian context is of importance to answering my research question, I discuss how the orientation of Canadian society allows for both equity and inequity to exist and how the inequities in wider society are reflected in education. Lastly, I consider the relationship between ethnicity and academic achievement. To further examine the influence of group membership on academic achievement, I also consider the relationship between dialect and achievement, specifically language as a predictor of literacy performance. Concepts of Linguistic Insecurity and Interference Perspective provide a conceptual framework for this section. In combination with literature, I utilize a variety of preliminary exploratory research methodology in an effort to answer my research question. In consideration of previous empirically supported tools, measures were chosen (and in some cases adapted) to assess aspects of language variation, use, attitudes, and literacy performance for the purposes of addressing my research question.

\section{Chapter 2: Theoretical and Conceptual Framework}

\section{Social Identity Construction}

The question of whether we as individuals impact our environment, or whether we are individually impacted by our environment has long existed in social sciences disciplines. The Human Agency Perspective (also referred to as the Individualist View) considers our individual role in impacting our environment, whereas the Social Structures Perspective (also referred to as the Structuralist View) considers the impact of our environment on us (Wotherspoon, 2009). 
Double Involvement, a merge of these two perspectives, is a concept that posits that "we create society at the same time as we are created by it" (Wotherspoon, 2009, p. 7). Similarly, one's behaviors influence the practices of a collective group within wider society, by which individuals are also shaped (De Fina, 2007).

In consideration of individual identity with respect to a group, Social Identity Theory (SIT) explores individual identity with respect to their collective group membership (Benwell \& Stokoe, 2006; Ellemers \& Haslam, 2012; Schwartz, Luyckx, \& Vignoles, 2011). Identification with a particular social group(s) requires some form of membership. Membership in social groups is fluid, and can either be chosen or assigned (Gardiner \& Kosmitzki, 2011; De Fina, 2007; Howard, 2000). This membership thus determines our social identity, but where does this all begin and what are the influencing factors? Identity formation begins early in development and social identity development is influenced by context (Gardiner \& Kosmitzki, 2011). SIT takes into account the influence of context in identity formation, including cultural influences which shapes social identity development (Ellemers \& Haslam, 2012; Gardiner \& Kosmitzki, 2011).

The dimensions of social identity include race, ethnicity, gender, class, to name a few (Howard, 2000). Ethnicity is an anthropological concept whereas race is a biological concept (Yinger, 1985). Ethnicity is based on one's cultural origins and describes one's position within wider society, as either that of the minority or the majority (Gardiner \& Kosmitzki, 2011; Phenice \& Griffore, 2000). Ethnic identity is framed by several components, such as language and race (Yinger, 1985 as cited in Phenice \& Griffore, 2000). The formative years are imperative to one's identity development. There are three stages of ethnic identity development, as outlined by Gardiner and Kosmitzki (2011). The first stage is marked by an unawareness of one's cultural 
or ethnic identity and thus, there is no participation or exploration of one's identity in relation to ethnic background (Gardiner \& Kosmitzki, 2011). The second stage is marked by the emergence of awareness of one's ethnic identity and participation in activities that are related to one's culture (Gardiner \& Kosmitzki, 2011). The third and final stage consists of internalization of one's ethnic identity, however, the resulting social behaviors and practices vary from person to person (Gardiner \& Kosmitzki, 2011). At this point, internalization influences whether one chooses to participate in ethnically-related social activities or not. Although identity formation takes place primarily in adolescence, it is greatly impacted by context of our formative years in which the concept of self emerges (Gardiner \& Kosmitzki, 2011).

In diverse environments, the process of social identity development has an added complexity, and we see the formation of multicultural identities due to exposure to multiple cultures (Gardiner \& Kosmitzki, 2011). Metropolitan cities across Canada may serve as examples of spaces where multicultural identities exist. When self-identifying, heterogeneous and specific terms are usually used (Plaza, 2004). However, ethnic groups are too often homogeneously classified, particularly by members of wider society, in the Canadian context (Plaza, 2004). Quite unfortunately, negatively-based assumptions and stereotypes are attached to these homogenous labels (Plaza, 2004).

When describing the experiences of Caribbean diaspora in Canada, race and ethnicity must be considered (Allahar, 2011). A diaspora can be described as individuals who have migrated from their native country, voluntarily or involuntarily (Allahar, 2011). Among immigrant groups, patterns of assimilation differ, and thus the process of identity construction also differs across these groups (Plaza, 2006). Plaza (2004; 2006) mentions two types of Assimilation: Linear and Segmented. Linear Assimilation involves identifying with the new culture overtime, whereas 
Segmented Assimilation involves identifying and maintaining one's identities with both the native and the new culture.

Collective cultural identity can be understood by shared characteristics. Woodall (2007) explains that for the Black Caribbean identity, the shared characteristics are those marked by discontinuity, beginning with colonization to present day migration. Woodall (2007) presents the concept of "Presence Caribbean" as the understanding of cultural identity of Black Caribbean individuals framed by "rupture and transportation" (p. 120), which also steps away from the understanding of cultural identity as solely "grounded in both race and cultural expressions" (p. 120). The author explains, "presence Caribbean is not a fixed and continuous signifier guaranteed by the presence of black skin" (p. 120). Presence Caribbean is a fairly new way of understanding Caribbean identity in the Canadian context, and is a concept that places emphasis on the fluidity and continuous negotiation and reconstruction of Black Caribbean identity. Black Caribbean identity in the Canadian context is constantly being negotiated and reconstructed (Wooddall, 2007).

Hall (2010) discusses theoretical perspectives on identity construction for members of the Jamaican diaspora, particularly those in the United States. The author describes how the movement of people away from their native land changes the way a culture is framed and understood, which ultimately influences the transmission of that culture, which is often the case for members of the Jamaican diaspora (Hall, 2010). The author uses post-colonialism to describe the colonial impact on group and individual identity negotiation. Furthermore, "the essence of how Jamaicans negotiate a transgressive Black identity on the island is continually reinforced and recreated for Jamaican immigrants to the United States by their regular immersion in the homeland" (p. 136). Highlighting similar complexities of members of the Jamaican diaspora in 
Canada, Plaza (2006) argued that in Canada, "Multiculturalism policies...have encouraged many young Caribbean Canadians to live between two worlds where national boundaries, national cultures, and national identities are flexible" (Plaza, 2006, p. 213-214).

Identity development begins in early development and identity construction is a continuous process in adulthood. Individual membership with respect to a group is influenced by numerous contextual factors, culture being one. Identity construction takes into account aspects of both self-identity and identity as perceived by the wider society. For members of the Caribbean diaspora in Canada, particularly Jamaican Canadians, the process of identity construction is further complicated by group patterns of assimilation and continuous reconstruction and negotiation of identity. Although notions of Caribbean culture are reframed away from the native context, the native notions of culture remain as influencing factors in the process of identity construction in the diasporic context.

\section{Socialization through Language}

The relationship between language and identity has long been discussed in sociolinguistics (Benwell \& Stokoe, 2006). A branch of sociolinguistics, variationist sociolinguistics, explores aspects of language use in relation to social identity (Benwell \& Stokoe, 2006). Identity construction takes place through one's social practices (De Fina, 2007). Language is a social behaviour and is considered to be a symbolic means through which socialization in child development occurs, that is, a child learns social practices, ideologies, beliefs of their culture(s) and ethnicity (De Fina, 2007; Gardiner \& Kosmitzki, 2011; Labov, 1968). Second language acquisition fields are increasingly adapting the Language Socialization perspective, which is centered on the notion of enculturation taking place through language practices (Watson-Gegeo, 2004). Although the present investigation is centered on dialect, terms and concepts related to 
bilingualism will also be included, as numerous authors have made clear the similarities between bidialectal and bilingual settings (De Fina, 2007; Winford, 1997).

Similar to the question of our impact as individuals on wider society versus the impact of wider society on us as individuals, lies the question of the impact of language on cultural knowledge versus the impact of culture on language development. The forces of socialization through language take place in meaningful contexts, particularly, contexts in which one engages in activities that are "embedded in cultural meaning systems" (Watson-Gegeo, 2004, p. 340).

Vygotsky's concept of "Talking to Learn" describes social interactions as means by which children use language to understand the world around them (Gardiner \& Kosmitzki, 2011). In families where more than one language exists, parents consciously make language choices that guide the linguistic path of their children (Baker, 2006). This is referred to as private language planning, which places emphasis on the role of the parents in determining where the language was acquired, where it is used, and the purposes of its use may be important for their children (Baker, 2006; Pavlenko, 2004; Piller, 2001). For the purposes of this paper and in discussing the forces of socialization, I will be focusing on the meaningful contexts in which most verbal interactions takes place; within the home, outside the home (in the community, for example), and at school.

Language attitudes towards a particular language also influence the language choice of its speakers (Baker, 2006). Language attitudes can be described as, "internal models about the nature of things which the process of socialization in our own culture induce in each of us" (Le Page, 1988, p. 26). Personal language choice may be guided by views and attitudes held in wider society. Due to lack of language prestige in wider society and as preferred by speakers and listeners of the language, minority languages (such as Creoles, for example) are often confined to 
private settings (Baker, 2006). In subtractive contexts, maintenance of minority languages are discouraged, whereas maintenance of home and additional language(s) are encouraged in additive contexts (Baker, 2006; Paradis, Genesee, \& Crago, 2004).

In some cases, the context allows individuals to choose between using the majority or the minority language (Schecter \& Bayley, 2004). It is likely that additive contexts allow for this freedom of language choice. Maintenance of minority language influences the process of language socialization (Schecter \& Bayley, 2004). In relation to linguistic minority populations, Schecter and Bayley (1997) highlight the complexity of identity construction: "In their daily negotiations between dominant and minority cultures they confront questions of the discreteness and synthesis of linguistic code at many junctures and levels of self- and other-defining decision making" (p. 514). It is within subtractive contexts, in which minimal opportunities of engagement in minority language are presented, that components of cultural identity associated with minority languages are likely to be lost (Paradis, et al., 2004). Arguably, Canada's pluralistic orientation allows for both subtractive and additive spaces to exist beyond the confines of the home space, but remains restricted to designated spaces. In other words, native language use may be welcome in some but not all spaces in Canadian society, and thus arguably allows for both preservation and loss of one's cultural identity depending on the space.

One's bilingual competence may be concerned with language ability (productive and receptive), language use, and other dimensions as described by Baker (2006). Delpit (2006a) explains that oral-based languages are learned in various contexts of communication. In this case the circumstances under which one becomes bidialectal should be considered. For bilingual individuals, there are two within-individual determinants of acquiring bilingual competency: bilingualism was by choice (also known as elective bilingualism) and bilingualism by exposure 
(also known as circumstantial bilingualism) (Baker, 2006). For the case of individuals living in a context where Standard English is the majority language and a minority language is spoken at home, acquisition of the language may occur through mere exposure (circumstantial), and thus language ability is likely to be primarily receptive rather than productive.

In early development, parent language choices guide the language socialization path of their child/ren. Language choice is shaped by existing language views and attitudes. Often, negative views of minority languages lead to their confinement to private spaces. However, maintenance of minority language influences the process of language socialization, including identity construction and enculturation, of those belonging to the associated culture. For minority languages, such as Creoles, opportunities for language maintenance may exist in spaces beyond the home but remain limited in the Canadian context. To better understand these complexities, one must consider the existing views and resulting practices of Creole language, as well as the historical forces that have shaped them.

\section{Creole Language Systems: Status and Value}

Creole languages were developed under unique sociohistorical conditions, which began with contact between multiple languages (Bakker, Daval-Markussen, Parkvall, \& Plag, 2011). Consider the English-speaking Caribbean, where numerous forms of English-lexified Creole languages exist: English-based Creole dialects in the Caribbean are the result of contact between West African languages and the English language, in particular during the period of European colonization that occurred four to five hundred years ago (Clacher, 2004; Hall, 2010; Wigglesworth, Billington \& Lakes, 2013; Winford, 1997). Consequently, English-based Creole languages in the Caribbean have been shaped grammatically and orthographically by British English and grammatically by West African languages (Clacher, 2004). Winford (1997) 
describes Caribbean English Creoles as having "stable grammars, conditioned by social and situational factors" (p. 233).

Related to Post-colonialism is the concept of Linguistic Imperialism by which we understand English to be the language of global dominance (Baker, 2006; Irvine, 2004; Khan, 2013). Under this notion, other languages may be considered inferior to the English language. A diglossia is present when two languages co-exist in a society, one being considered a minority language and the other a majority language, which are labels that are dependent on purpose and context (Baker, 2006; Mair, 2002; Mühleisen, 2005). Within a diglossic setting, there is a distinct separation of minority and majority languages, or what Mair (2002) described as a "strict separation of a high and a low code according to functional domain" (p. 36). The high code language is primarily present in written form while the low code is primarily present in oral form, each form being context-dependent (Mühleisen, 2005). Within a diglossic setting, Creoles exist "in functional complementary distribution with either a lexifier or other established standard languages" (Mühleisen, 2005, p. 3). In recognition of the subordinate position of Creole languages, DeGraff (2005) argued that “Creole languages remain, in Alleyne's (1994: 8) phrase, among 'the most stigmatized of the world's languages' for reasons that can be traced back to now-defunct race theories of the colonial era" (p. 534).

Mühleisen (2005) discussed the ways in which Creole languages gain status and standardization through writing. It is through writing that languages gain prestige (Mühleisen, 2005). As Creole languages are often restricted to oral form and as a result, these languages have low language prestige (Mühleisen, 2005). However Bentolila (1987), who explored the use of Haitian Creole in the Haitian education system, describes the challenges associated with transitioning from oral to written form such as the traditional notions of language not being 
upheld; "the didactic use of Creole, its being written down, requires a necessary distancing of the traditional social situation in which the forms and behavior of communication of the unilingual are forged" (Bentolila, 1987, p. 85). Bentolila (1987) also warned, "when the language of an oral civilization enters the field of communication from which it has always been excluded, linguistic and sociological problems arise whose extent and complexity have not been measured" (Bentolila, 1987, p. 85). Although in reference to Haitian Creole, the concepts presented by Bentolila (1987) can be applied to other Creole languages.

Increasingly, we are seeing an emergence of Creole languages in the written form and efforts towards standardization (Bentolila, 1987; Pigott, 2011; University of the West Indies, 2014). One may interpret these developments as a move towards linguistic empowerment, in which post-colonial societies reclaim their identity through language. Creole remains a major component of Haitian identity in spite of its minority position and lack of language prestige (Bentolila, 1987). These sentiments are shared with other Creole-speaking nations, including the English-based Creole-speaking nation of Jamaica.

Jamaican Creole. Early in history, what existed in Jamaica were two language extremes where both African and English languages played influencing roles in Jamaican society (Winford, 1997). The post-emancipation period presented conditions for language evolution due to increased social and locational mobility between members of different language groups (Winford, 1997). Creole languages consist of language varieties that closely resemble the lexifier as well as varieties that present with differences as compared to the lexifier, as is the case with Jamaican Creole (also referred to as Patois or Patwa) as an English-lexified language (Polinsky \& Kagan, 2007). Speakers tend to use language forms that resemble varieties furthest away from the lexifier in home environments (Polinsky \& Kagan, 2007). 
Jamaican Creole (Patois) speakers can be placed on what is commonly referred to as a Creole Continuum, where speech-types range from basilect or "conservative Creole" (Clacher, 2004, p. 155), mesolect or "intermediate creolized varieties of English" (Clacher, 2004, p. 155), and acrolect or "standard variety of English" (Clacher, 2004, p. 155) varieties (Clacher, 2004; Harry, 2006). It is important to note that variations in the Jamaican Creole dialect can also be explained by various geographic and sociological factors (Harry, 2006; Irvine, 2004; Wigglesworth, Billington, \& Loakes, 2013).

The language situation in Jamaica is described as diglossic, as there are two varieties perceived by speakers: Jamaican Creole (Patois) and English (Irvine, 2004). The language variation presented by the creole continuum creates settings that are similar to those encountered in bilingualism (Winford, 1997). Decreolization, a term introduced by Whinnom (1971), also influences language variance. Under the assumption of decreolization, fewer identifying traits of Creole languages are displayed over time (Bolton \& Kachru, 2006; Irvine, 2004). What influences these changes? LePage (1988) explained that languages views held by speakers influence the way in which speakers use a language; "linguistic change is a function of social choice" (Le Page, 1988, p. 35).

Bolton and Krachru (2006) describe the "post-independent Jamaica" (p. 7), where polarized language views exist. The first view upholds traditional ideals, which fail to recognize Jamaican Creole as a language, but rather see it as a degenerate form of English meant for those who are uneducated and of lower social socioeconomic class. The second recognizes the diglossic language situation in Jamaica and the social and cultural significance of the Jamaican Creole language. It is for this reason that I will engage in two discussions regarding Jamaican Creole: one which is framed around the notion of Jamaican Creole being considered a degenerate 
and the other which is framed around the notion of Jamaican Creole being considered a language.

Patois as a degenerate. Globally, English is considered a language of prestige (Baker, 2006; Irvine, 2004; Khan, 2013). Jamaican Creole is not an official language in Jamaica, while English is. However, Jamaican Creole remains significant in the day-to-day lives of Jamaicans. Language prestige is determined by educational level and socioeconomic status (Baker, 2006). This is the case in Jamaica, as speakers of different forms of Jamaican Creole are determined by education level and socioeconomic class (Harry, 2006; Irvine, 2004; Wigglesworth, Billington, \& Loakes, 2013). It can be argued that the language presents power differentials in wider Jamaican society determined by language use.

Numerous circumstances present challenges for obtaining language prestige of the Jamaican Creole language. Firstly, an established standardized orthographical system for Jamaican Creole does not exist (Deuber \& Hinrichs, 2007; Mair, 2002). In addition, the use of Jamaican Creole remains influenced by traditional views and attitudes. Many Jamaicans hold language views that are colonial in nature, describing Jamaican Creole as a "despised corruption of the colonial language" (Mair, 2002, p. 31). In reference to the remnants of colonialism, Hall (2010) refers to the colonial nature in the purpose and use of the language:

If one remembers that the slaves to mask the speaker's communicative intent from the slave-master, created the Jamaican Patois, then it already becomes clear that this perspective of the language argues for the fact that the speakers of the language continue to socially construct Patois to mark and reinforce an insider versus outsider status. (Hall, 2010, p. 134) 
These colonial attitudes guide political decisions, affecting the everyday lives of Jamaicans. In 2013, it was announced that the Ministry of Education in Jamaica will introduce English language testing to evaluate the oral competence for elementary and high school students as of 2016 (Smith-Edwards, 2013). In justifying the decision, the Jamaica's Minister of Education stated, "Whatever your job is, if you are fluent in English, you have an advantage. English is the universal language of professionalism. No matter where you are in the world, competence in English is prized" (Smith-Edwards, 2013, para. 8).

Decreolization can be described as "contact-induced changes that take place in creolesboth 'basilect' and 'intermediate', under pressure from varieties closer to the acrolect" (Bolton \& Kachru, 2006, p. 37). Sociological factors determine whether one language may be considered more prestigious and preferred than another. This can be applied across different forms of Jamaican Creole; "differential competence of successive generations of speakers, not just the existence of basilectal, or other lects" (Rickford, 1987 as cited in Bolton \& Kachru. 2006, p. 37). There also appears to be a recent shift in the language structure, and considerations of what is considered Standard English in Jamaica. Traditionally, British English was the language of English influence, however lately, American English influence is increasingly present in Jamaican English (Mair, 2002). It can be argued that under the sociological pressures of persistent traditional views of the language, changes may take place and the language, a marker of the identity, could eventually be lost.

Patois as a language. In spite of not being officially recognized as a language in Jamaica, Jamaican Creole remains present in Jamaican society (Kouwenberg, et al., 2011). There appears to be a current shift and changing of language views in Jamaica. Mair (2002) describes the 
change as shifting from "symbol of powerlessness and degeneracy (to) symbol of solidarity, truth, and connection to Afro-creole folk tradition" (Mair, 2002, p. 31).

Firstly, there appears to also be new developments in Jamaica concerning the language situation. Brown-Blake (2008) wrote a response article to the Joint Select Committee of Parliament's proposal to "include language as a basis upon which discrimination should be prescribed in the Constitution of Jamaica" (p. 32). The author highlights that consideration of this proposal at the political level is indicative of the changing views of the Jamaican Creole language in Jamaica.

Secondly, since 2002, the Jamaica Language Unit (JLU) at the University of the West Indies has been putting in effort towards the standardization Jamaican Creole in the written form (University of the West Indies, 2014). To date, texts of significance, such as the Bible, have been translated into Jamaican Creole language (Pigott, 2011).

Thirdly, the Ministry of Education, Youth and Culture (MOEYC) Language Education Policy in Jamaica expressed concerns regarding the absence of standardized written form of Jamaican Creole in the school context (MOEYC, 2001 as cited in Carpenter \& Devonish, 2010). In response, the Bilingual Education Project (BEP) was launched in Jamaica for students in the first through fourth grade levels, which sought to incorporate both Jamaican Creole and Standard Jamaican English in academic instruction (Carpenter \& Devonish, 2010).

Patois in diasporic contexts. Morgan (2014) describes the concept of speech community very clearly; "language represents, embodies, constructs, and constitutes meaningful participation in society and culture" (Morgan, 2014, p. 1). In describing the role of language within a speech community, she stated, "it is within speech communities that identity, ideology, and agency are actualized in society" (Morgan, 2014, p. 2). Secondly, "It also assumes that a 
mutually intelligible symbolic and ideological communicative system must be at play among those who share knowledge and practices..." (Morgan, 2014, p. 1).

In discussing the language choices and views of Jamaicans, Irvine (2004) describes the speech community as a space within which speakers' views of standard and non-standard forms of a language are shaped. What about speech communities away from the native setting, such as diasporic contexts? As part of the concept of speech community, Morgan (2014) suggests, "as people relocate away from families and home communities and build others, relationships and interactions continue and change, and are sustained" (Morgan, 2014, p. 1).

The use of language in contexts away from the native contexts can be influenced by one's Linguistic Insecurity. A term introduced by Labov (1968), Linguistic Insecurity refers to language variation reflected in one's speech in which one chooses to utilize the prestigious form of speech, a choice determined by existing social factors. Linguistic Insecurity can also be referred to as insecurity regarding one's proficiency in a particular language or lack of confidence regarding the use of their language or dialect, including purpose and contexts of its use (Ager, 1999). Linguistic Insecurity can be explained by the language's social place due to lack of prestige and their command of the socially prestige language, and is often observed amongst speakers of language and dialects that have lower social status (Ager, 1999). Speakers may view patois as "not a 'real' language, that the word or expression they use is 'patois' and not 'real' English" (Ager, 1999, p. 9). The result of Linguistic Insecurity is language shift and even language disappearance (Ager, 1999). If Linguistic Insecurity is inhibited, the language may be preserved thus resulting in a preserved identity (Ager, 1999).

It can be argued that Linguistic Insecurity inhibits the preservation of one's identity. In in an environment where one may feel uncomfortable with their language use, for example 
immigrants whose language may be perceived as negative in their new country of residence, there is a risk for identity reconstruction. As language is a central component to cultural identity, this identity reconstruction may lead to a loss of identity. One can imagine that in a diasporic context, there are multiple factors working together to influence language use, including existing views and attitudes in one's native country as well as those existing in the new country of residence and reconstructed views of immigrants.

In Jamaica, the views about Patois are polarized. These polarized views influence language practices in the diasporic context, these language practices are closely related to identity construction. In a diasporic setting, this may have further implications related to identity reconstruction and loss.

\section{Inequity in Canadian Society and Education: Theoretical Insights}

In consideration of Canada's orientation, Canada can be described as a society marked by individualism, liberalism, pluralism (Allahar, 2011; Berry, 1984; Henslin, Glenday, Duffy \& Pupo, 2007; Dib, Donaldson, \& Turcotte, 2008; Wotherspoon, 2009). Each of these terms imply self-sufficiency, free choice, and cohesion which is idealistic and picturesque. Canada's Multiculturalism policy:

seeks to improve intergroup harmony by encouraging all ethnic groups in Canada to develop themselves as vital communities, and by further encouraging their mutual interaction and sharing; the assumption, which is quite explicit in the policy, is that such group development will lead to a personal and collective sense of confidence, and this in turn will lead to greater ethnic tolerance. (Berry, 1984, p. 353)

The orientation of Canada paints an overly optimistic picture as compared to the realities and experiences in Canadian society. In spite of Canada's orientation, inequity persists in 
Canadian society. It can be argued that Canada's orientation, while it contributes to the existence of cohesion and peace in Canadian society, also contributes to the existence of inequity (Wotherspoon, 2009). Canada as an individualist society fails to challenge existing negative assumptions existing within social structures, such as those concerning race (Wotherspoon, 2009). Allahar (2011) sums up the problem with this idealistic notion of Canada:

Canada is a liberal democratic, capitalist country in which social inequality is portrayed as normal and natural, but at the same time the dominant institutions cannot be too blatant in the exclusion and denial of opportunities to some immigrants while enhancing those of others. The twin ideologies of liberalism and individualism are invoked and come to play a key role in controlling the perceptions of the public, so the official Canadian policy of multiculturalism was devised to tell immigrants that they too were equal parts of society. But as a capitalist society where social inequality is a structural feature of the wider economy and polity, and also as a society in which systemic racism is an acknowledged reality, the ideology of multiculturalism clashes with the lived racism experienced by working-class immigrants of color, and it is in this context that leaders of the Caribbean diaspora in Canada have based calls for the creation of a Black-focused school. (Allahar, 2011, p. 57)

In spite of existing multicultural and anti-racism policies, inequity and discrimination on the basis of racial and ethnic group membership persists within Canadian contexts (Wotherspoon, 2009). Allahar (2011) described Canada as a "racist society" (p. 55). Aguiar, McKinnon, and Sookraj (2011) highlight the racialization of Jamaicans racial and cultural intolerance in British Columbia, Canada. Dragasevich (2012) discusses the multicultural policy put in place in 1971, and the role of the Canadian Ethnocultural Council in the face of a changing 
social fabric. Dragasevich (2012) identifies that although multiculturalism has been long valued in Canada at various levels (policy, societal), there are appears to be a shift in attitude toward multiculturalism and thus, a need to "revisit the policy of multiculturalism" (p. 233) periodically.

By way of Cultural Transmission, societal values and practices are reflected and replicated within the educational context (Codjoe, 2001; Henslin et al., 2007; Wotherspoon, 2009). For example, individualism is very much a central part of the education system, as emphasis is placed on individual student accomplishments and achievement rather than accomplishments and achievements as a group (Henslin et al., 2007). Arguably, individualism encourages competition which may create a hostile learning environment for some students. This is one of many ways in which the inequities present in wider society are reflected and maintained within the school environment (Cummins, 1997; Wotherspoon, 2009).

Brathwaite (2010) explores the role of racism in the curriculum and discusses strategies of reducing discriminatory practices within schools, specifically in the curriculum. Although they have the potential to not reflect the negative effects of wider held beliefs and practice, Canadian schools, historically and presently, reflect racially discriminatory practices that persist in wider society, and has played a significant role in the marginalization of Black students (Brathwaite, 2010; Wotherspoon, 2009).

One of the ways in which wider societal inequities show presence in the classroom is through dichotomous power relations. The power relations that exist outside of education, "influence both the ways in which educators define their role and the types of structures that are established in the educational system" (Cummins, 1997, p. 425). Delpit (2006a) coined the term Culture of Power to describe power relations within schools. Delpit (2006a) presents numerous dichotomic forms through which power relations are established within the classroom. Some of 
these dichotomies include teacher versus student, and individual/group versus another individual/group's intelligence or normalcy. There are rules that govern participation in the "Culture of Power". These rules are rooted in wider society and belong to the culture of power, and therefore the more that one adheres to these rules and acquires the culture of power, the greater one's academic success may be. Those who have more power are less aware of its existence compared to those who do not have the power, who faced challenges related to the power differentials. Cummins (1997) argues that in order to promote the academic success among minority students, there has be a change in power relations between teachers and students.

Canada's orientation, although it promotes equity, also promotes inequity. These inequities are reflected in the educational context and promote the existence of unequal power relations. This is especially problematic for minority students, as this directly impacts their academic success. One must therefore further consider the impact of identity and achievement.

\section{Identity and Achievement: Racial, Cultural, and Dialectal Considerations}

One's group membership as well as negative societal perceptions of that group can serve both positive and negative roles in student outcomes, as highlighted by Wright (2011); "group connectedness and pride, as well as awareness of societal discrimination, can play protective and enhancing roles in youth development" (Wright, 2011, p. 613). However, what appears to be evident is the perpetual continuation of ethnicity and the associated negative assumptions held by wider society playing a negative role in schools. Cummins (1997) describes it as, "a historical and current pattern of coercive relations of power in which African Canadian student identities have been constructed as deficient and actively devalued in classroom activities" (p. 426). 
Henry (1993) calls for a reconceptualization of what it means to be a Black student in education. She explains,

Within the language of dominance lurks a racialized discourse of pathology, deviance, and deficiency concerning Black people. Those of us who would construct an alternative world must rethink, deconstruct, reconstruct the language of theorization. Without challenging dominant social science paradigms and categories, we easily acquiesce in our own oppression as African people. (Henry, 1993, p. 209)

As one's group membership and negative societal perceptions of that group may influence student outcomes, language group membership should be considered. In education, many assumptions are held regarding language groups. Schecter and Bayley (2004) provide an insightful explanation in this regard:

Underlying mainstream policy makers' precipitous attempts to control the variation and difference that characterize modern, urban classrooms, we find traditional notions of socialization - to the effect that, 'People who speak this language and who are located in this social space and geographical place to this, so children who speak that language and are located in that social space and geographic place learn that.' (Schecter \& Bayley, 2004, p. 621)

Clacher (2004) indicated that there is a lack of knowledge in the education system with respect to English-based dialects, and thus the misplacement of these students in language programs that do not help. Caribbean students in Canada have been faced with linguistic prejudice, or differential treatment on the bases on language. At present, there appears to be an absence of language supports for students of different dialectical backgrounds in the Toronto District School Board (TDSB) schools. Coelho (1988) explains, 
Divergence from Standard English usage by Caribbean students is usually not regarded with the same tolerance as errors made by students who are learning English as a Second Language, because Caribbean students are generally not regarded as language learners. They are regarded as English speakers who are careless with the language. (Coelho, 1988 as cited in Siegel, 1999a, p. 510)

Wigglesworth and colleagues (2013) also identified negative views of Creole languages, specifically those in education settings, and the resulting lack of research where Creole-speaking students are concerned. As a result of being marginalized, Creole-speaking students face disadvantageous educational conditions; "such judgments can affect the way Creole speakers feel about their own language and how they engage with the language used in school and whether they see Creole as having a role in education" (p. 389).

Wigglesworth, Billington and Lakes (2013) identified gaps in research with respect to Creole-speaking children, specifically in the area of "measuring the normal language development of children who are growing up acquiring Creoles" (p. 390). Although Cumming (2013) focused on post-secondary students, this article provided insights regarding the existing trend of students from various language backgrounds experiencing challenges in areas of academic achievement, including literacy.

As an attempt to reconceptualize the notion of nonstandard dialect speakers, Wigglesworth and colleagues (2013) recommended the implementation of language diversity awareness programs to "normalize non-standard (language) varieties" (p. 395), as well as address the educational needs and resolve the gap in performance of bilingual children. Clacher (2004) explains that globalization has resulted in the increased Caribbean student population seen in North American schools and presented the increased need for, "specialized pedagogical 
strategies" (p. 163). Furthermore, "alternative pedagogical approaches...for Creole-Englishspeaking students, research is needed to better understand the linguistic characteristics of their language acquisition" (Clacher, 2004, p. 153).

There are numerous arguments against the use of dialects in academic settings. Siegel (1999a) describes three: (1) the time-on-task argument, (2) the ghettoisation argument, and (3) the interference argument. The time-on-task argument assumes that time is positively related to achievement (Snow, 1990 as cited in Siegel, 1999a). In other words, the amount of time spent instructing student in the standard language directly related to educational achievement in the standard language. The ghettoisation argument assumes that the inclusion of nonstandard language in the classroom will prevent student from receiving the economic advantages that a standard language provides beyond the classroom (Snow, 1990 as cited in Siegel, 1999a).

The interference argument posits that incorporating non-standard languages in the educational settings is disadvantageous to students, as it may present challenges for students in the acquisition of the standard language variety (Siegel, 1999a; 1999b). The interference perspective posits that non-standard dialects may negatively impact the acquisition of the standard dialect (as in the case of African American Vernacular English and Standard American English) (Siegel, 1999b). Through critical analysis of the interference viewpoint, Siegel (1999b) concludes that incorporating non-standard dialects in education may positively impact students' acquisition of the standard dialect.

There is a need for more programs that promote awareness and positive perspectives of non-standard language varieties in schools (Siegel, 1999b). The benefits of Creole in education are clear. Siegel (1999a) discloses the benefits of incorporating Creole and other non-standard language varieties in the classroom, specifically the "educational, social, and psychological 
advantages" (p. 508). Bialystok and Peets (2010) present their view of schooling as a space that facilitates the building of knowledge, experiences, and competencies such as those of different languages. In addition, Schecter and Bayley (1997) explain that the beneficial results of such practices,

The provision of opportunities to engage in such negotiations (identity negotiations), then, may well prove more fundamental to the success of culturally diverse students that the implementation of any multicultural curriculum taking the form of group descriptions, no matter how sensitively the latter are drawn. (Schecter \& Bayley, 1997, p. 539) What place do non-standard dialects, such as Jamaican Creole, have in education? To support my argument, I would like to draw a parallel with an argument presented by Lisa Delpit regarding language diversity and responsive pedagogical practices. In response to the "Ebonics Debate", that is, whether or not children should be permitted to incorporate home dialect (in this case, African American Vernacular English, a nonstandard American English dialect) in the classroom, Delpit (2006b) claims that she is neither for it nor against it. She further explained that standard and non-standard language forms serve specific purposes in different contexts, and children should be aware of this. However, she argues that access to one dialect and not the other presents challenges. Those with access to the non-standard dialect have close connections with their cultural identity. Those with access to the standard dialect will likely avoid economic failure. She argues that content rather than form with regard to language should be the focus in the educational context. By focusing on language form one may exclude the fact that "the student had to have comprehended the sentence in order to translate it into her own language" (Delpit, 2006b, p. 99). Additionally, it "will only confuse the child, leading her away from those intuitive understandings about language that will promote reading development” (Delpit, 2006b, p. 99). 
The school's role is to recognize and celebrate linguistic diversity amongst their student body and provide access to the standard language forms. Dialect should be included as a reflection of culture in schools.

The consequences of group membership, race-based or language-based, can be both positive and negative. The way in which racial and language groups are constructed influence their outcomes. Therefore, reconceptualization of the construct should be provided is needed and space for identity negotiation in places such as the classroom.

\section{Chapter 3: Literature Review}

\section{Social Identity}

The question of cultural identity among Jamaican-Canadians lies within the context of race and society. This distinction between race and culture is often not made in the literature and the term 'Black' is used instead, usually with an assumption of homogeneity of culture held by researchers, specifically with identity-related research. Aboud and Doyle (1995) use homogenous ethnic terms throughout, which fail to acknowledge the ethnic and cultural diversity with the 'Black Canadian' group. Baffoe (2011), although they use the term 'Black', they include the broad cultural group of "African". Although Chioneso (2007) makes a distinction between African and Caribbean populations, the researcher is drawing on a framework in which African social practices are being compared to non-African practices (with a non-African social context). Boatswain and Lalonde (2000) provides a description of the groups within the 'Black' identity.

Aboud and Doyle (1995) compared the racial attitudes of Black Canadian children in kindergarten to those in the third grade. Findings from their investigation show that while preschoolers were found to be confused by racial labels, the older children possessed stronger 
racial biases. These findings suggest that in early school-age, children begin to discover the meaning of racial labels and their associated biases.

When describing the experiences of Caribbean immigrants in Canada, race and ethnicity must be considered (Allahar, 2010). The label 'Black' carries varied meanings among those who are defined by the label. When studies have addressed the question of race versus culture among Afro-Canadians, the results have shown a stronger tendency toward cultural (not racial) identification. Boatswain and Lalonde (2000) investigated the preferred labels of Black individuals residing with the Greater Toronto Area. Most participants included were of Caribbean descent. Results suggest that while 'Black' was the preferred label among participants, a great amount of variability was found among participants particularly those of Caribbean descent who preferred to be identified by the label associated with their Caribbean heritage (Boatswain \& Lalonde, 2000). Variability in preferred ethnic labels may suggest that not only do the labels mean something different to the groups defined by the label, but may also suggest variation in the experiences associated with the label.

Identity construction for members of the African diaspora must be taken into consideration. As context plays an important role in identity construction, one must account for lived experiences. Baffoe (2011) considered the lived experiences of Black immigrants, specifically new immigrants and refugees, in Canada. Baffoe (2011) identifies that a reconstruction of one's identity in the new social context takes place for immigrants. We must take into account the social environment in social identity construction.

In combination with lived experiences, the surrounding social structure serves a central role in identity construction. Chioneso (2007) examined the influence of cultural orientation of a society on individual cultural orientation expressed by members of the African diaspora, 
specifically Jamaican and Ghanaian immigrants within the Canadian context. Interviews consisted of open-ended question regarding in-group membership, and in-group solidarity, and were presented to Jamaican and Ghanaian immigrants residing in Toronto. Results demonstrate that immigrants maintained their native cultural orientation, and also integrated their new cultural orientation. This suggests that they underwent a process of reconceptualization of their identity.

Increasingly, empirical investigations are moving away from homogenous groupings and closely examining issues related to Caribbean identities and experiences, particularly in the Canadian context. Thompson and Baeuer (2003) performed a quantitative investigation on aspects of identity construction and changes for Jamaican immigrant families who migrated to Canada, as well as Britain and the United States. In their examination of life-story interviews from Jamaican immigrant families, the authors found there to be a continuation of seeing oneself as Jamaican, in spite of their new citizenship status (British and Canadian) and expression of less opposition to their countries than those in the United States. Thus in comparison to the United States, Canada and Britain allowed for a more flexibility of one's identity. The authors conclude that elements of the social structure (marginalization, discrimination) may present forces that shape one's identity, as well as personal experiences within those social structures (sense of belonging).

Additionally, in moving away from homogenous assumptions and focusing on the specific experiences of Caribbean immigrants in the Canadian context, Plaza (2004) examined the similarities and differences in values and norms of Afro- and Indo-Caribbean groups, specifically in terms of family structure, living arrangements, and home ownership. The author explored the role of their native culture in shaping their reconstructed diasporic Caribbean 
identity in Canada; Plaza (2004) concluded, "Although Caribbean immigrants did not exactly reproduce their old cultural patterns when they moved to Canada, these patterns continued to have a powerful influence" (p. 261).

Speaking to the complexity of identity development, Plaza (2006) later investigated identity construction of one-and-a-half and second generation Caribbean Canadians, specifically Afro- and Indo-Caribbean Canadians. Findings from this study suggest that based on their arrival in Canada identity development for one-and-a-half and second generation Caribbean Canadians is complex and fluid process. He explains that the process of ethnic identity development is "characterized by constant shifting and assembling of new hybridized identities, ones that are based primarily on physical appearance and closeness to the dominant group in terms of social and cultural capital" (Plaza, 2006, p. 227).

Race and ethnicity are important to discuss when describing the experiences of Caribbean Canadians. The discovery of racial labels and their associated biases comes early in life. Race is often homogeneously discussed and fails to capture the experiences of cultural groups. One's cultural identity is shaped by context and experiences. Research is increasingly recognizing the Jamaican Canadian identity and associated experiences, and the complexity of identity construction in the diasporic context.

\section{Language and Language Socialization}

Language is a means through which socialization and enculturation in child development occurs, that is, a child learns social practices, ideologies, beliefs of their culture(s) largely through language (Gardiner \& Kosmitzki, 2011). Many researchers have examined language socialization practices of various diasporic groups. Pavlenko (2004) administered a web-based questionnaire regarding language choice, preference, and emotionality to over a thousand 
multilingual participants. The results from this investigation revealed that beyond language dominance or prestige, there are other factors that determine language choice, such as emotionality of the language as perceived by its speakers. In other words, views of a language determine language choice.

Schecter \& Bayley (1997) investigated the impact of language socialization practices on cultural identity and language use. Participants consisted of 40 Spanish-speaking families, with a minimum of one member of Mexican heritage by birth, residing in the United States. Parental cultural identification and language use were found to influence the cultural identification and language use of their children. The parents determined the context (where, when, and with whom) that the native language can be used. Thus, it is clear that parents play a central role in determining the path of language socialization for their child(ren).

Schecter and Bayley (2004) later examined language socialization by focusing on home language practices of Spanish-speaking immigrants residing in the United States. The authors provided narratives of two women of Mexican origin residing in California. These narratives provided detailed accounts of their language choice and use, the resulting challenges and experiences, and the impact of language choice on their identity. This demonstrates how parents' views of language influence their language practices, which are then transferred to the child.

Focusing on the relationship between language and identity construction, De Fina (2007) examined identity construction for first-, second-, and third-generation Italian male immigrants. Findings from this analysis revealed that language socialization, in this case the use of codeswitching, played a pivotal and continuous role in individual and collective identity construction. These results support the idea of the way that we use language or learned to use language through socialization impacts the processes of identity formation and construction. This is also 
true for Creole language speakers. Migge (2007) examined patterns of language variation in code-switching used by Creole languages speakers in Suriname and French Guiana within the Easter Maroon community, and found that language choice and variation or code-switching was used as a means of asserting group membership in relation to one's identity. Thus in this context, language socialization practices determines one's position of identity with respect to group membership, as the Social Identity Theory would likely predict.

Researchers have also considered language socialization for young Jamaican Creole speakers. Best, Tyler, Gooding, Orlando, and Quann (2009) explored cross-dialect word recognition for children 15- and 19-months of age. All participants, who were American English speakers (Connecticut variety), were presented with 12 pre-recorded words in their native dialect and non-native dialect (Jamaican Creole of the masolect variety). They found that the 19-month old participants were able to recognize unfamiliar pronunciations (words pronounced in the nonnative dialect) of familiar words. These findings support the emergence of phonological awareness in the early stages. Based on this finding, and to further understand the groundwork of language socialization, current research on language acquisition for bilingual and bidialectal children will be considered for this investigation.

Patterns of language development for bilingual and bidialectal children. For the purposes of this investigation, empirical findings for the following language groups were considered: monolingual, bilingual, monodialectal, bidialectical. The bilingual and bidialectal groups included those who were in the process of acquiring Standard English as a second language or a second dialect.

Monolingual versus bilingual. Empirical evidence suggests that in comparison to their monolingual peers, bilingual children have smaller English vocabulary sizes. The large-scale 
study by Bialystok, Luk, Peets and Yang (2010) measured the English vocabulary differences in monolingual (English) and bilingual (English and non-English language) children. They considered previous research that investigated the differences in language performance between monolingual children and bilingual children. Over a thousand participants were included in this study with 772 being monolingual and 966 being bilingual (Bialystok, et al., 2010). The Peabody Picture Vocabulary Test (PPVT-III) was administered where participants were asked to match drawn pictures to words. Results of this study show that bilingual children obtained overall lower scores than monolingual children across all age groups (ages 3 to 10 years). This suggests that bilingual (English and non-English language) children have smaller English vocabulary sizes than monolingual (English) children.

What does having a smaller English vocabulary size mean for bilingual children? Well, according to Bialystok et al. (2010), it is "not an overall disadvantage but rather an empirical description that needs to be taken into account in research designs" (Bialystok et al., 2010, p. 530). Furthermore, they state, "the vocabulary deficit (in English) is almost certainly filled by knowledge of (non-English words), making it likely that the total vocabulary for bilingual children is in fact greater than that of monolinguals" (Bialystok et al., 2010, p. 530). They considered the differences in vocabulary sizes, suggesting that there are two separate vocabularies for home and school. "Bilingual children are not typically disadvantaged in academic and literacy achievement... or academic uses of spoken language...because the linguistic basis of those activities is well established" (Bialystok et al., 2010, p. 530). Bialystok and colleagues (2010) did not consider speakers of English-based dialect speakers in their study.

Monodialectical versus bidialectical. Empirical evidence suggests that there are differences in patterns of language in monodialectical and bidialectical children. Pearson, 
Velleman, Brant \& Charko (2009) compared the phonological milestones of typically developing children from two dialectical English-based language groups: Mainstream American English (MAE) and African American English (AAE). Their focus was on MAE acquisition for AAE speakers, and on phonological challenges that may arise with AAE speakers. Pearson and colleagues (2009) predicted that although the acquisition differences between the groups will be more salient at older ages, a difference in developmental language patterns would present around four years old. Results reveal that there are differences in rate and order of sound acquisition (see Appendix $\mathbf{J}$ for chart of English sound acquisition order) and that it was slower for MAE learners for AAE speakers.

Terry (2012) examined the relationship between language development and literacy performance (specifically, emergent literacy skills in Standard English) for prekindergarten-aged children whose native dialect was nonmainstream American English (NMAE). Tests included a vocabulary assessment, a measurement of dialectical differences, and a literacy screening administration. Results found that children who used NMAE speech forms did not perform as well on literacy tasks as children who used fewer NMAE speech forms. Furthermore, Terry (2012) suggests that this difference may be due to a mismatch in language and print. Terry (2012) explained, "linguistic mismatches between NMAE and MAE may be more critical to achievement among older children, especially if they have weaker metalinguistic awareness skills" (p. 74). Similarly, language mismatch can be examined with other dialects with regard to academic performance. Although this study considered socioeconomic status and racial variation in selecting their participants, they did not take into account the regional differences in dialects.

It is interesting that both articles make a clear distinction between the language that is considered to be mainstream versus the language that is not considered to be mainstream (the 
English dialect). This may be reflective of the negative views of English-based dialects held by many, as suggested by current researchers (Wigglesworth, Billington, \& Lakes, 2013).

\section{English as a Second Language (ESL) versus English as a Second Dialect (ESD).}

Numerous studies have compared patterns of language acquisition of individuals who are ESL and ESD. Clacher (2004) compared patterns of language acquisition, in particular tense-aspect morphology (perfective and progressive markers) in English, of two groups: English as a Second Language (ESL) speakers and English as a Second Dialect (ESD) speakers. All participants were in the ninth and tenth grades, and resided in the United States for no more than two years. All participants, based on their academic writing performance, participated in writing programs designed for ESL speakers. Subjects' placement on the Creole continuum was considered in this study, which provides fairly complete and accurate linguistic profiles of these speakers. Participants were asked to complete a written story-retell task to assess their narrative skills. Results showed that Creole speakers of the basilect and acrolect varieties did not show similar patterns of language acquisition as ESL speakers. However, Creole speakers of the mesolectalacrolectal varieties (intermediate to standard varieties of English) did show similar patterns of language acquisition as ESL speakers. As participants were recruited from both Jamaica and Guyana, there were likely linguistic variations between speakers from both countries. Regional differences of Creole speakers within each country were not considered, which may be indicative of an underlying assumption of homogeneity among Creole speakers.

Mousa (2014) considered the differences in English language learning used by English dialect speakers and English language learners. Participants included Jamaican Creole speakers and the Arabic speaking participants were from a previous study (Moussa, 1994). Participants were asked to pronounce a list of English words and sentences, and were audio-recorded and 
later transcribed. Mousa (2014) found that both Jamaican Creole speakers and the Arabic speakers replaced the labio-dental fricative sound /v/ with another sound; /b/ or / $\beta$ / for Jamaican Creole speakers and /f/ for Arabic speakers. In other words, both English as a Second Language and English as a Second Dialect speakers displayed sound replacements for the same sound, which supports the notion of bidialectalism and bilingualism being similar.

While there is a lack of research comparing dialectal speakers, it is clear that bidialectal and bilingual language speakers share many language development features. As explained by Miggie (2007), Creole speakers are similar to bilingual speakers in that they,

creatively and strategically draw on these meanings in their everyday interaction to manage their self-presentation and their relationships with their interlocutors. This gives rise to different kinds of interaction between these varieties that may, but do not have to, lead to the emergence of new bilingual codes. (Migge, 2007, p. 70)

Although the central research question of this present investigation focuses on bidialectal (English and Jamaican Creole) speakers, there appears to be a lack of existing literature in this area. Nonetheless, an additional language and dialect influences aspects of language acquisition and development.

\section{Creole Language Systems}

There appears to be an underlying theme of assumed homogeneity of Creole dialects and Creole dialect speakers. Wigglesworth and colleagues (2013) use the term "Creole" throughout their paper in referral to Creole dialects across multiple languages (English, French, and Spanish). Additionally, in investigating aspects of language acquisition for Creole speakers, Clacher (2004) did not specify the English-based Creole dialect considered and included participants from two different English-based Creole dialects (Jamaica and Guyana). 
Although Wigglesworth and colleagues (2013) used the term "Creole" as a blanket term to discuss Creole dialects across multiple languages, Creole dialects in general are often not considered to be mainstream or standard languages (Terry, 2012; Pearson et al., 2009;

Wigglesworth, et al., 2013). Wigglesworth and colleagues (2013) explain, "negative judgments about Creoles are widely held by policy makers, educators, and the general public in many countries where Creoles are not spoken” (p. 389). Attitudes towards Creole languages and implications for education will be further discussed at a later point in this paper.

Jamaican Creole in the Jamaican context. Empirical findings support the existence of the Jamaican Creole continuum. Schneider and Wagner (2006) investigated the presence of the Creole Continuum by examining a literary piece written by a Jamaican author. They performed an analysis on the piece and found that there was a presence of basilect, masolect and acrolect varieties of Jamaican Creole throughout.

Empirical evidence continues to support the existence of the Creole continuum as observed in linguistic features use by Jamaican Creole speakers. Deuber (2009) examined the variation in morphological and syntactic features of the speech of Jamaican Creole (acrolect) speakers (referred to as well-educated), and identified subtle transitions as compared to both the basilect and mesolect forms and English. Irvine (2004) also identified the phonological variation in speakers of the acrolect form of Jamaican Creole, in particular features used and avoided by Jamaican Creole speakers employed in situations governed by specific language expectations.

Harry (2006) compared speech forms from two basilectal Jamaican Creole speakers. This case-study highlights phonological features, with respect to consonant and vowel sounds as well elements of word prosody and intonation. Both participants reside in Eastern regions of Jamaica and appear to differ in terms of social factors (level of education, socioeconomic status). This 
finding is significant, as social factors impact the dominant form of Jamaican Creole spoken by an individual. Details regarding Jamaican Creole and its different forms will be further discussed in the proceeding section. Similar to the variety of linguistic forms that exist in Jamaica within the overarching existence of two languages (Jamaican Creole and Jamaican English), literature also presents findings that support the polarized views of the Jamaican Creole language.

Patois as a degenerate. Research supports the existence of language views and use that are colonial in nature. Deuber and Hinrichs (2007) considered Jamaican Creole and Nigerian Pidgin languages in their investigation, both being English-based oral languages. Written forms of both languages are vastly different than their spoken forms. In 2005, the Jamaica Language Unit at the University of the West Indies conducted a questionnaire with a thousand respondents. Consistent with traditional notions of the language, more than half the respondents indicated that they perceived English speakers as more intelligent and educated that Jamaican Creole speakers (Jamaica Language Unit, 2005).

Irvine (2004) examined spontaneous speech samples from government agency employees in Jamaica, specifically frontline and non-frontline workers. Frontline workers were those described as employees appointed by senior management staff based on language use, personality, and educational qualifications. Irvine (2004) found that in comparison to the nonfrontline staff, frontline staff avoided numerous phonological features identified and Jamaican Creole language features. In some cases, there were linguistic features that the frontline staff presented with that were not present in Creole or Standard English, which the author suggests is an altogether disconnect from Jamaican Creole. These findings support the decreolization argument, which suggests disappearance and distancing from features of the language. Arguably, 
negative language views drive this language change, thus a change in language views and attitudes may prevent language change or even disappearance.

Deuber and Hinrichs (2007) considered Jamaican Creole and Nigerian Pidgin languages in their investigation, both being English-based oral languages. Written forms of both languages are vastly different than their spoken forms. Researchers suggest that this discrepancy may not only continue but also widen if steps are not taken towards closing the gap.

Regarding new developments of the language in Jamaica, Mair (2002) examined text from community members posted in a discussion board on www.jamaicans.com. This investigation provided two major contributions. Firstly, the investigation provided evidence of increased American English influence and decreased British English for Jamaican Creole speakers. Secondly, Jamaican Creole (Patois) was found to serve a minimal role in written form. Kouwenberg and colleagues (2011) discuss the language views held by Jamaicans, most of which appear to be negative. With regard to environments in which the use of Jamaican Creole may be deemed acceptable, one speaker stated that Jamaican Creole was "a broken form of English... this 'broken form' was acceptable at home and in informal domains but not allowed in formal settings" (Kouwenberg et al., 2011, p. 389). With regard to social status, one speaker explained, "Patwa as a means of communication in daily interactions was for the unlearned only" (Kouwenberg et al., 2011, p. 388). In terms of the use of Jamaican Creole in the educational context, one speaker warned, "let us keep patois out of our schools. It should remain what it is, a street language" (Kouwenberg et al., 2011, p. 390). Suggesting that it may prevent progress, a speaker argues that Jamaican Creole "does not help us in mastering that which is crucial to our moving forward smoothly, both academically and vocationally" (Kouwenberg et al., 2011, p. 390). Suggesting that there is no place for Jamaican Creoles in education and speaking to the low 
level of prestige and value of the language held for some speakers, one speaker expresses disbelief in a fellow Jamaican's quest for maintenance of the Jamaican Creole language; “I can't believe someone as educated as yourself is actually advocating that we maintain our abject ignorance and stupidity via the perpetuation of our bilious so-called 'language' patois. 'Stupid talk for stupid people"” (Kouwenberg et al., 2011, p. 395).

Patois as a language. In spite of empirical evidence of traditionalistic approaches to the language, the move towards standardization of Jamaican Creole continues. Research supports the existence of contemporary views of the Jamaican Creole language. Results from the language survey conducted in 2005 demonstrate a shift in views of Jamaican Creole. Most respondents viewed Jamaican Creole as a language and recognized themselves as bilingual citizens (Jamaica Language Unit, 2005). Most respondents also indicated support of Jamaican Creole being recognized as an official language with English in Jamaica (Jamaica Language Unit, 2005).

Kouwenberg and colleagues (2011) discussed narratives regarding language attitudes if Jamaican Creole speakers in Jamaica that were positive. The authors included the opinions of Jamaicans on language that were positive. Although traditionalist perspectives have played a formative role in how Jamaican Creole speakers view their language, it may be through reflection and questioning that they come to new realizations about Jamaican Creole. One speaker reflects, "what followed was, for me, a paradigm shift. Through my own research, I came to realize that Jamaican (Patwa) bears its own vibrancy, creativity, linguistic structure and intricacies, having all the features that make a language" (Kouwenberg et al., 2011, p. 393). Furthermore, one speaker expresses understanding of the mobility that the language allows; "being an educated Jamaican meant for me that I spoke/understood Jamaican Creole and English and was able to manipulate both based on their different roles and what I hoped to achieve. It 
meant that I was bilingual" (Kouwenberg et al., 2011, p. 393). Recognizing that the language goes beyond linguistic terms, but is also related to identity, one speaker explains, "our language is our identity, it helps us to belong" (Kouwenberg et al., 2011, p. 394). In the educational context, there are those who have attempted to bring light to its existence in education:

After over 10 years in the formal education system, being taught that Jamaican Patwa was 'bad' English and its use was not encouraged, at the University (the pinnacle of learning and education that I believed should be using the 'Queen's English') those views were opposite. (Kouwenberg et al., 2011, p. 392)

Another speaker expressed, "Jamaican Creole was indeed a language in its own right — a notion I dare to suggest in Early Education and was thoroughly put down and called narrow-minded by a colleague educator" (Kouwenberg et al., 2011, p. 395).

Although negative language views persist, there appears to be a shift occurring and moving toward positive language views held by Jamaican Creole speakers. As recognized by the Ministry of Education, Youth and Culture (MOEYC) Language Education Policy, there is an absence of a standardized written form of Jamaican Creole in Jamaican education (MOEYC, 2001 as cited in Carpenter \& Devonish, 2010). The Bilingual Education Project (BEP), which incorporated both Jamaican Creole and Stand Jamaican English in academic instruction, was launched in Jamaican schools and proved to be a success with students (Carpenter \& Devonish, 2010). This study will be discussed in further detail in the Dialect and Achievement section of this paper.

In spite of influencing colonial views of the language that have long existed in the Jamaican context, a shift of views is occurring. Speakers are increasingly recognizing the value of the language. Furthermore, the current language situation of Jamaican is being recognized at 
the policy level. New developments at the social and political levels are taking place, and it will not be long before positive language views and attitudes are adapted by Jamaican Creole speakers island-wide.

\section{Inequity in Canadian Society and Education: Empirical Insights}

The existence of discrimination on the basis of race in the Canadian context has been found in literature. Joseph and Kuo (2009) explored coping strategies used by Black Canadians in Ontario in response to racial discrimination. They found that Black Canadians use a wide range of coping strategies. Results from these studies are suggestive of the existing racism that persists in Canadian society, particularly in Ontario.

Furthermore, Dion and Kawakami (1996) investigated the perception of discrimination among visible and white minority ethnic groups in the City of Toronto. Participants who were considered to be white minorities were of Italian, Jewish, or Portuguese ethnicity, whereas participants who were considered to be visible minorities were of Black, Chinese, or South Asian ethnicity. Black and South Asian ethnicities were further sub-grouped. Most Black participants were of Caribbean ethnicity, with the second highest number of participants were of Jamaican ethnicity. With close to a thousand respondents, Dion and Kawakami (1996) found that subjects who belonged to Black minority groups perceived higher levels of discrimination, at the personal and group levels, than the other minority groups. The researchers explained, "Perceptions of discrimination do, nevertheless, represent an important psychological reality for immigrants and ethnic minority group members, regardless of their statues or adequacy as social indicators of 'actual' discrimination of tolerance” (Dion \& Kawakami, 1996, p. 204).

Past and present statistics suggest that Black students are underachieving in Toronto public schools in comparison with students of other ethnic backgrounds (Brathwaite, 2010; 
Cummins, 1997; Colour of Poverty Campaign - Colour of Change Network, 2011; Dib, Donaldson, \& Turcotte, 2008; Ferguson, Tilleczek, Boydell, Rummens, Cote, \& Roth-Edney, 2005; Gordon \& Zinga, 2012; The Royal Commission on Learning, 1995). In addition, children of Caribbean backgrounds are also underachieving in Toronto schools (Coelho, 1991; 1988; Smith, Schneider, \& Ruck, 2005). Smith and colleages (2005) found that Black students in Canada, including those of Caribbean nationality and descent residing in Toronto, were academically underachieving in spite of their positive beliefs about academic achievement. These findings more than likely includes students of bidialectal language groups. High school drop-out rates are highest among students belonging to visible minority groups that other ethnic groups in Canada (Dib, Donaldson, \& Turcotte, 2008). Schools in Ontario consist of the highest amount of racialized individuals in their student body were found to have the highest drop-out rates (Colour of Poverty Campaign - Colour of Change Network, 2011).

The reasons for this underachievement have also been discussed in research. Findings suggest that the school climate may be a major contributing factor (Ferguson et al., 2005). Immigrant and first generation Canadian students are presented with numerous risk factors for dropping out of school, including major differences between their home culture and the culture of their school and of wider society (Ferguson et al., 2005). For students who belonging to visible minority groups, it was identified that "school climate(s) in which stereotypes, prejudice, racism, and differential treatment were common and left unchallenged" (Ferguson et al., 2005, p. 33). It is notably apparent that the Toronto District School Board (TDSB) does not presently provide language supports specifically for students of different dialectical backgrounds. As school climate plays a major contributing role in student achievement, the gap between home and school cultures needs to be sutured. 


\section{Identity and Achievement: Perceptions and Realities}

The relationship between ethnicity and achievement have been examined in research. Chavous and colleagues (2003) examined the relationship between identity and achievement amongst African American students at the twelfth academic grade-level. They found that students with the lowest level of academic attainment were more likely to have lower group affiliation and were found to identify with a group that was more negatively perceived socially. These findings revealed that group membership and societal perceptions of the group with which students identify may impact their achievement. Major differences in Grade Point Average (GPA) were not found amongst participants, suggesting that identity does not directly impact academic outcomes. However, racial identity was found to influence students' educational beliefs, and racial centrality and was found to have a positive relationships with school relevance and school efficacy.

What importance does identity serve in the school setting? Wright (2011) examined the relationship between identity (racial and ethnic) and academic success for African American male students in the eleventh and twelfth grades. The author moves away from focusing on underachievement, and instead focuses on the determinants related academic success for these students. Findings suggest that a healthy identity (racial and ethnic) enables students to function effectively between different cultural environments of school and home which influences their success in both environments (Wright, 2011). Therefore, "a healthy racial-ethnic identity is critical to success in school" (Wright, 2011, p. 633).

Codjoe (2001) highlighted the experiences of academically successful Black students in Canada, specifically Edmonton, Alberta. Utilizing qualitative research methodology, Codjoe (2001) examined the narratives 12 Black students, which included Caribbean-born, African (by 
birth and descent), and Canadian-born participants. The researcher outlines 6 prevailing themes regarding the students' experiences within their schools (barriers to academic success): "differential treatment by race; negative racial stereotyping; the lack of representation of Black/African perspectives, histories, and experiences; low teacher expectations; and what can be describes as a hostile school environment" (Codjoe, 2001, p. 349). Reflecting on the difficulty of the educational experience as an immigrant, one participant commented, "adjustment was difficult when I first came here...I was the only Black girl in my school...I was called names and stuff like that...I almost did not graduate" (Codjoe, 1997 as cited in Codjoe, 2001, p. 359). One student was warned, “...they said something about how teachers weren’t fond of Black students” (Codjoe, 1997 as cited in Codjoe, 2001, p. 357). Highlighting the disconnect between them and the school environment, one respondent mentioned, "there was nothing on anything that was Black-related or Black successful in the academic area" (Codjoe, 1997 as cited in Codjoe, 2001, p. 357).

Dunn (1993) examined several studies that investigated the learning styles of students in the third to twelfth grades, as well as high school graduates. Cultural groups within and outside of the United States, including Jamaicans. Findings suggest that there are differences in learning styles that are statistically significant across cultural groups. However, it is possible that these results can be explained by factors external to culture, such as disconnect between the learning styles of the students and the school curriculum presented.

One's identity does not determine academic success, but rather widely held perceptions of the group with which one identifies has the potential to influence academic perceptions of students and thus impact things factors associated with academic success, such as engagement. A healthy identity, that is not seeing the negative perceptions as true, is imperative for academic 
success. As school reflects wider society, if discriminatory views persist in the educational context, they can be barriers of success, these barriers are very much alive in the Canadian schools. While I have briefly focused on minority racial and ethnic groups, I would like to refocus this investigation on dialect and academic achievement.

Dialect and achievement. A theme encountered in my literature search is the importance of language in predicting the literacy performance in early childhood. Aspects of language development, such as vocabulary size and phonological acquisition patterns, are considered to be predictive of literacy performance in children (Bialystok, Luk, Peets \& Yang, 2010; Pearson, Velleman, Brant \& Charko, 2009). As Clacher (2004) explained, literacy performance also "provide(s) insight into how learners process the meaning-bearing information... which in turn fosters an understanding of the early difficulties that students encounter as they develop writing skills" (p. 157).

Oral language skills are often used as a guide for children as they acquire emergent literacy skills and transition into reading and writing (Terry, 2012). Quite often, variations in oral language skills are seen in children and as Terry (2012) explained, "variation appears to be related, at least in part, to characteristics of the family, home, school, and classroom environments" (p. 67). Linguistic diversity plays an important role in language development and literacy development because "children rely heavily on their oral language skills while learning how to read and write, it is important to investigate sources of variation in these skills... Linguistic diversity is one such source of variation" (Terry, 2012, p. 67).

Children from diverse backgrounds experience literacy challenges due to the mismatch of the oral language learned and the print language (Bialystok et al., 2010; Clacher, 2004; Terry, 2012). Existing research has identified the academic disadvantages associated with speaking a 
non-standard dialect. Labov (2001 as cited in Labov, 2010) performed an analysis of 287 students in the second, third, and fourth grade levels across 3 states within the United States. Students were African American Vernacular English speakers and identified as experiencing difficulty with literacy. Results were as follows: "A moderate but significant correlation between reading errors and those features that are specific of AAVE" (p. 19). Additionally, the researcher identified, "a global relationship between the use of AAVE and decoding problems. The relationship is not necessarily a direct one, as there are many intervening factors that are likely to be responsible for a high use of AAVE and low performance in decoding” (p. 20).

The benefits of bilingual education are undeniable. Garcia and Bartless (2007) presented a case study of a bilingual high school with a student body that was primarily composed of Spanish-speaking students who were learners of English. The researchers employed the Speech Community Model of Bilingual Education, which provided students with means of acquiring English in an environment where competition from native speakers is removed. This study highlights the benefits of home language incorporation in the academic space, as the school was found to have a "drop-out rate significantly lower than the local average for comparable students, a graduation rate significantly higher than the local average for comparable students, and an excellent attendance record and college acceptance rate" (Garcia \& Bartlett, 2007, p. 1). Results from this study suggest that students are likely to be more engaged in academic environments where their home language was embraced rather than avoided.

Creole languages have been used as a tool in literacy education. In Carriacou, Kephart (1992 as cited in Siegel, 1999a) used an English-based Creole as a medium for teaching Standard English literacy to Creole speaking students (12 years of age). Findings suggest that Creole facilitated Standard English literacy learning. Results were not conclusive, but showed promise 
for the use of Creole in education. Although Creole was shown to be neither beneficial nor detrimental to Standard English literacy performance, incorporation of Creole in literacy education resulted in improved the engagement of students as observed in their increased enjoyment and enthusiasm towards Creole reading materials (1992 as cited in Siegel, 1999a).

In an effort to improve literacy outcomes and overall academic outcomes of Jamaican students, the Bilingual Education Project (BEP) was launched in Jamaica for students in the first through fourth grade levels (Carpenter \& Devonish, 2010). This project was created in response to concerns raised about the use of Jamaican Creole in education, as presented in the Language Education Policy of the Jamaican Ministry of Education and Culture (Carpenter \& Devonish, 2010). The BEP was a dual language program that incorporated both Jamaican Creole and Standard Jamaican English languages as part of literacy instruction in schools, and ran for four years between 2004 and 2008. As compared to students who received monolingual Standard English instruction, the students in this program performed better in English literacy by the third year.

Bialystok and colleagues (2010) advise that it is important not to confuse literacy performance with academic achievement. While literacy does not represent overall academic achievement, it provides a glimpse of how alternative strategies can be used to facilitate literacy earning. Even though non-standard dialects may present as disadvantageous for literacy learning, studies have also shown their benefit. In particular, Creole languages have been incorporated in the classroom resulting in improved performance and engagement in English literacy. These findings challenge the misconceptions held in education regarding the use of nonstandard dialects in education, and instead supports idea that Creole can be used as tools in formal education. 
To further challenge these misconceptions regarding dialect, my research question seeks to explore the relationship between language, identity, and achievement. For the sake of not focusing on race, my research question focuses on a specific cultural group, Jamaican Canadians. My preliminary research question is, do dialect and cultural identity impact the literacy performance of Jamaican Canadian Creole speakers? My revised research question is, for Jamaican Canadians, what is the relationship between dialect use, cultural identity, and attitudes towards education?

\section{Chapter 4: Methodology}

\section{Participants}

A total of 14 participants from Jamaican Creole-speaking families within the Greater Toronto Area were recruited for this study; 5 child participants ( 4 males; 1 female) between the ages of 5 and 6 years (M=69.2 months) and 9 adult participants ( 6 females; 3 males). Adult participants included parents ( 3 mothers; 3 fathers), grandparents ( 1 grandmother), and family members ( 2 cousins) of 5-6 year old children. Among the participants, 4 adults engaged in study participation in the absence of children, but indicated that the target child with whom they spoke Jamaican Creole was between the ages of 5 and 6. Due to the social factors surrounding Jamaican Creole and its use, such as level of education and socioeconomic status, participants in this study were from a range of socioeconomic backgrounds, with education levels ranging from high school to post-secondary education.

The selection criteria used in the present study required all participants to be Jamaican- or Canadian-born (of Jamaican descent) monodialectal or bidialectal Jamaican Creole speakers, or monodialectal English speakers who live in environments where there is frequent exposure to Jamaican Creole, at home or in the community (see Appendix I for Inclusion/Exclusion 
Checklist). Child participants attended schools in Canada since kindergarten, with English being the language of educational instruction. For children who had not attended school in Canada since kindergarten, they received educational instruction in a Standard English dialect since kindergarten. Children with no previously diagnosed language or literacy-related delays or difficulties were eligible to participate. Participants whose language of exposure in their home environment was a non-English language or dialects of English other than Jamaican Creole were not eligible to participate in this study.

Participants were recruited from a variety of school-based and community-based sources. School-based sources included Early Childcare Centres and the Ryerson University community. Community-based sources included community centres, immigrant services, and Jamaican associations based in Toronto (Jamaican Canadian Association, Jamaican Alumni Association). The primary methods of recruitment for this study included direct contact and advertising (see Appendix A), as well as snowball and convenience sampling. As part of snowball sampling, participants were asked to share information about this research study with those who may be interested in participating. Convenience sampling involved contacting individuals based on distant and relational proximity to the investigator.

The initial stages of recruitment were slower than expected. A cash incentive was implemented in an effort to encourage participation in the study. Adult participants had the opportunity to receive an incentive of up to 30 dollars, depending on their levels of participation in the study. Specifically, they were offered 10 dollars for completion of the questionnaire, 10 dollars for the involvement of a child in the study, and 10 dollars for participation in the interview. Recruitment increased after implanting monetary compensation for participation in the present study. 


\section{Procedures}

As part of the initial screening process to determine eligibility for this study, it was requested that potential participants provide responses to 11 questions concerning their current place of residence, child's birthplace, place of educational instruction, and home language practices. The screening questions are described in Appendix I. A total of 3 individuals who were interested in participating were not included in the study mostly because they did not meet the inclusion criteria. Two individuals, one of whom was a Jamaican Creole speaker, did not have frequent contact with children between the ages of 5 and 6 who lived in environments where there was frequent exposure to Jamaican Creole. One individual was not included because she was neither Jamaican- nor Canadian-born (of Jamaican descent) and was not a monodialectal or bidialectal Jamaican Creole speaker. A total of 4 participants who were eligible to participate in the present study were not included. Two adult participants did not complete the parent questionnaire despite frequent efforts of follow-up. Two participants, an adult and child, were not included due to frequent scheduling conflicts.

As part of the assent process, child participants were verbally informed of what their participation entailed, risks and benefits of the study, and their right to refuse to participate at any time. They provided assent by informing the researcher of whether they wanted to participate in the study and writing their name on the assent form. The adult by whom they were accompanied also provided consent for their participation. After providing assent, child participants were asked to complete language and literacy assessments and activities, which will be described further in the measures section. Children were provided with multiple breaks during the session. If needed, this portion of the study could also take place over 2 sessions. An optional interview took place where the investigator and the adult participants gathered for an hour and a half to 
have a discussion centered on specific target questions (see Appendix H). Interviews were audio recorded and transcribed by the investigator (see Appendix K).

As part of the consent process, adult participants were provided with a description of the aims, procedures, risks, and benefits of study participation. Any questions that they had regarding the form were addressed in person at the time of signing. After providing consent, adult participants were asked to complete an information sheet and language questionnaire. Participants had the option of completing the questionnaire during the time data was being collected from the accompanying child participants, prior to the time data was being collected from the child participants, or after the time data was being collected from the child participants.

In all reports of the data, pseudonyms replaced all participant names for the purposes of maintaining anonymity and protecting the privacy of all participants. Child and adult pairings were given pseudonyms with the same initial letter.

\section{Measures}

A total of four instruments were used to measure language attitude, dialectal differences, and language and literacy performance. Instruments used with child participants included the Diagnostic Evaluation of Language Variation (DELV) (Seymour, Roeper, \& de Villers, 2003), the Assessment of Literacy and Language (ALL) (Lombardino, Lieberman, Brown, 2005), and the Matched-Guise Test (adapted from conventions used by Edwards, 1977; Lambert, 1960; Loureiro-Rodrigues, Boggess and Goldsmith, 2012; Reynolds-Keefer, Johnson, Dickenson, \& McFadden, 2009). Instruments used with adult participants included the parent questionnaire and an interview. The rational for the use of each instrument is described in the Child Measures and Adult Measures sections to follow.

\section{Child Measures.}


Dialectal Difference. The Diagnostic Evaluation of Language Variation (DELV) is a criterion-referenced test that was developed by speech-language pathologists for the purposes of having a non-biased measure of language impairment (Seymour, Roeper, \& de Villers, 2003). This language assessment tool was designed for school-aged children between 4 and 12 years of age to assess various aspects of a child's Standard American English language including syntax, semantics, pragmatics, and phonology (Pearson Education Incorporated, 2008; Seymour, Roeper, $\&$ de Villers, 2003). Previous studies have used the DELV as a measure in comparing speakers of two different American English dialects (Pearson, et al., 2009; Terry, 2012). As seen in investigations by Terry (2012) and Pearson, Velleman, Brant \& Charko (2009), the DELV was utilized in this investigation to assess the presence and degree of dialectal variations for the monodialectal and bidialectal children in this study, specifically among speakers of African American English Vernacular (AAEV). Although AAEV is not the focus of the current study, one of the authors, Tom Roeper, indicated that its relevance extends beyond this population and is currently being used in a study of dialect use in South Africa (personal communication, 2014). Therefore, this study will be the second to use this assessment outside of the United States, and the first to use it among people of Caribbean descent.

The DELV is a two-part assessment that consists of a screening portion and a diagnostic portion. The diagnostic portion of the test is utilized for language disorder diagnosis (Pearson Education Incorporated, 2008). The screening portion is a norm-referenced test that determines the presence of dialectical variation as compared to the American English dialect (Pearson Education Incorporated, 2008). This portion of the DELV was designed to decrease bias, specifically cultural and linguistic biases in testing (Seymour, Roeper, \& de Villers, 2003). For the purposes of this investigation, the diagnostic portion was not used, however, the screening 
portion of the DELV was used to assess the form of language use for child participants (Pearson Education Incorporated, 2008). The duration allotted this assessment was a maximum of 15 minutes per participant.

Scoring. Subsections for the DELV include the DELV A, which tested for nonstandard English features and DELV B, which tested for Standard English features. The categories of the DELV include: Mainstream American English (MAE), some variation from MAE, and strong variation from MAE. Scoring within the MAE category indicates that the participant produced linguistic features, specifically morphosyntactic and phonological features that are consistent with MAE speakers, or speakers of other standard varieties of American English (Seymour, Roeper, \& de Villers, 2003). Scoring within the variation from MAE category indicates that the participant may produce linguistic features that vary from MAE speakers, or speakers of other standard varieties of American English.

Language and Literacy. The Assessment of Language and Literacy (ALL) is a normreferenced assessment tool that is used to identify emergent literacy and language deficits in school-aged children at the preschool and first grade levels (Pearson, 2014). This tool has been used in one previous investigation by Peets and Milburn (2012), who used the ALL as a measure of language comprehension, in preschool-aged children. While this measure is not widely used, it was selected for its naturalistic listening comprehension subtest in which participants hear a passage and are asked open-ended questions as opposed to "true or false" statements or cloze format questions (Peets \& Milburn, 2012).

For the purposes of this investigation, four subtests was administered to child participants: (1) Basic Concepts, (2) Parallel Sentence Structure, (3) Elision, and (4) Listening Comprehension. The Basic Concepts subtest "assesses a child's knowledge of concepts of size, 
number, location, shape, position, and comparison" (Lombardino, Lieberman, Brown, 2005, p. 14). During the Basic Concepts subtest, each child participant was asked to point to a picture item that represents the words provided by the investigator (Lombardino, et al., 2005). The Basic Concepts subtest measures linguistic concepts that are irrespective of grammar. The rationale for including this subtest was based on its lack of macrolinguistic features where bidialectal children would be expected to perform well. The Parallel Sentence Structure subtest assesses the syntactic and morphological components of spoken language (Lombardino, et al., 2005).

During the Parallel Sentence Structure subtest, the investigator presented child participants with a description of a picture. Participants were asked to describe similar pictures with similar grammatical features as used by the investigator. The Elision subtest assesses a child's ability to manipulate sounds and syllables (Lombardino, et al., 2005). During the Elision subtest, the investigator presented child participants with a word and asked them eliminate a portion of the word. Responses were generated with and without a picture prompt. These two subtests were both selected due to the differences that exist at the syntactic and phonological levels between Jamaican Creole and Standard English.

The Listening Comprehension subtest assesses language comprehension through story retell tasks. During the Listening Comprehension subtest, the investigator read a story to the child participants who were then asked to retell the story presented. Responses were generated with and without a picture prompt. The duration of this assessment was a maximum of 60 minutes. This subtest measures early literacy abilities, so it informs the research question regarding the possible relationship between language/dialect and literacy performance/readiness.

Language Attitude. The Matched-Guise Technique, originally developed by Lambert (1960) as a measure of language attitudes, was used to measure language attitudes in adolescent 
participants, specifically towards French-speakers by English Canadian speakers in Quebec. This technique has also been used in research to measure language attitudes of adults. Edwards (1977) used this technique to measure language attitudes towards English-based Irish dialect in adults. Quite recently, Loureiro-Rodrigues, Boggess and Goldsmith (2012) used this technique to measure language attitudes towards the Spanish-based Galacian dialect in adolescents. The current study is the first to administer the Matched-Guise test to kindergarten-aged children. The Likert-scale design of the Matched-Guise test was adapted to be suitable for young children. A pictorial Likert-scale with words describing each category of choice was used in place of the traditional numerical format (see Appendix F; adapted from Reynolds-Keefer, Johnson, Dickenson, \& McFadden, 2009). Each choice was presented verbally to each participant during testing along with each question regarding attribute.

Audio recordings included 2 stories spoken by speakers of 2 English dialects: Jamaican Creole (of the basilect variety) and Canadian English. The Jamaican Creole speaker was born in Jamaica and the Canadian English was born in Canada (as a first generation Canadian of Jamaican descent). The 2 stories read by the speakers were X-ray for Xylophone fish and Detective Dog and the Disappearing Doughnuts. Child participants were presented with a total of 4 audio recordings; each story recording of an age-appropriate story read in the Jamaican Creole speaker (of the basilect variety) and a Standard Canadian English speaker. The stories were counter-balanced for dialect to avoid a story or speaker effect in their performance on the task. Following each story, the child participants were presented with 7 questions concerning language attitude to which they gave responses using a 4-point Likert-scale. The duration of this assessment was a maximum of 15 minutes.

\section{Adult Measures.}


Language attitudes and use. Numerous methods were used in this current investigation to gain dimensions of perceptions of language attitudes and use. The 3-page parent questionnaire measured language views and use of the adult and child, as stated by the adult (see Appendix E). The questionnaire consists of single-select 5-point scale questions and closed-ended questions. A subset of the questions included in this questionnaire were adapted from the Language Attitude Survey of Jamaica presented by the Jamaican Language Unit (2005) at the University of West Indies. There are 4 sections in this questionnaire: Parent Language Use, Parent language Opinions, Child Language Use, and Child Language Opinions. In each of these sections, there are 8-12 questions requesting that participants provide ratings for each response as they apply.

The parental information form included with the parent questionnaire requests that adult participants provide biographical information regarding their and their child's birthplace and education. Specifically, city and country of birth, level education, current employment position, and location of education institutions from which they received their education.

A focus group was initially planned for the present study. However, due to recruitment challenges and scheduling conflicts, I conducted interviews with the adult participants. The interviews were conducted either individually or in dyads with adult participants. The purpose of this was to gain more in-depth information regarding language use, perceptions of children's abilities to succeed academically, and perceptions of educators' attitudes. Open- and closedended questions were included (see Appendix $\mathrm{H}$ ), although further discussion was permitted if participants felt it necessary. Interviews were audio recorded, and then later transcribed by the investigator. The maximum length of the interviews was 30 minutes.

As part of analysis of interview data, an issue-focused approach was taken, which focuses on "what could be learned about specific issues...from any and all respondents" (Weiss, 1995, p. 
154). Furthermore, it is "likely to move from discussion of issues within one area to discussion of issues within another, with each area logically connected to the others" (Weiss, 1995, p. 154). The issue-focused approach was taken in the present investigation in an effort to retrieve perspectives on group membership and achievement. In coding the data, linkages were made between what participants said in the interview to concepts and themes in the theoretical and conceptual framework of this investigation. This approach was similar to the approach taken by Codjoe (2010), in which the themes present in student narratives were highlighted and discussed in relation to the broader theoretical and empirical supporting information. Sorting involved recognizing recurring themes that arose in the interviews. As part of local integration, which involved interpretation of interview materials and developing a method to integrate these materials in the report, I highlighted major themes presented in the interviews (see Appendix K). Finally, as part of inclusive integration, I identified themes across all interviews and incorporated these findings in my report. 


\section{Chapter 5: Results}

\section{Child Findings}

Presented are the findings of all 5 child participants. This small sample size presented limitations for the research, which will be further discussed in the Discussion section of the paper.

Language and Literacy. As previously stated, the categories of the DELV include: Mainstream American English (MAE), some variation from MAE, and strong variation from MAE. As presented in the table below (see Table 1), there was one child who obtained showed non-Standard English features (Alice), and another child who showed Standard English feature (Dan). Overall DELV assessment results revealed that Alice scored within the MAE range, while Dan scored within the range of some variation from MAE.

As previously stated, four subtests of the Assessment of Language and Literacy (ALL) was included: Basic Concepts, Parallel Sentence Structure, Elision, and Listening Comprehension. As previously described, the Basic Concepts subtest assesses for linguistic concepts generated by picture prompts. The Parallel Sentence Structure subtest measures syntax and morphology generated by picture prompts. The Elision subtests assesses sounds and syllable manipulation generated with and without picture prompts. The listening comprehension subtest measures text-based (i.e., stories and descriptions) language comprehension with and without picture prompts.

All the scores reported in the table below (See Table 1) are standard scores, and total range from 1-19 with a standard deviation (SD) of 3. A total of 9 scores fall within the low average range, while 3 scores are slightly above average. Seven scores are 1 SD below the mean 
$(\mathrm{M}=10)$, therefore some children are doing poorly in some areas. Four scores are greater than 1 SD below the mean, all were obtained from Standard English speakers.

On the measure of linguistic concepts (Basic Concepts subtest), 2 children scored in the low average range (Alice and Carl), and 1 child scored more than one SD below the mean (Dan). All participants scored within the average (Alice and Bert) to low average (Carl, Dan, and Ed) range on the syntax and morphology measure (Parallel Sentence Structure subtest). On the sound and syllable manipulation measure (Elision subtest), there was a lot of variation with some scoring in the average range, slightly above the average range, and below the average range. Specifically, Carl scored $1 \mathrm{SD}$ below the average range, and Alice scored below $1 \mathrm{SD}$ below the average range. On the measure of language comprehension (Listening Comprehension subtest), 2 Standard English speakers (Bert and Dan) scored below 1 SD below the average range. 
Table 1.

Child Assessment Results for the Diagnostic Evaluation of Language Variation (DELV) and the Assessment of Language and Literacy (ALL).

\begin{tabular}{|c|c|c|c|c|c|}
\hline & Alice & Bert & Carl & Dan & $\mathrm{Ed}$ \\
\hline \multicolumn{6}{|c|}{ Diagnostic Evaluation of Language Variation (DELV) } \\
\hline $\begin{array}{r}\text { Nonstandard English } \\
\text { features } \\
(\mathrm{DELV}-\mathrm{A})\end{array}$ & 0 & 2 & 6 & 6 & 7 \\
\hline $\begin{array}{r}\text { Standard English features } \\
\text { (DELV-B) }\end{array}$ & 12 & 10 & 2 & 4 & 1 \\
\hline Dialect Category & Standard & Standard & Dialect & Standard & Dialect \\
\hline \multicolumn{6}{|c|}{ Assessment of Language and Literacy (ALL) } \\
\hline $\begin{array}{r}\text { Basic Concepts/ } \\
\text { Linguistic Concepts } \\
(\mathrm{M}=10, \mathrm{SD}=3)\end{array}$ & 7 & 9 & 7 & 5 & 9 \\
\hline $\begin{array}{l}\text { Parallel Sentence/Syntax } \\
\qquad(\mathrm{M}=10, \mathrm{SD}=3)\end{array}$ & 10 & 10 & 7 & 7 & 9 \\
\hline $\begin{array}{r}\text { Elision/Sound and } \\
\text { Syllable manipulation } \\
(\mathrm{M}=10, \mathrm{SD}=3)\end{array}$ & 5 & 11 & 7 & 9 & 12 \\
\hline $\begin{array}{r}\text { Listening/Language } \\
\text { Comprehension } \\
(\mathrm{M}=10, \mathrm{SD}=3)\end{array}$ & 8 & 6 & 9 & 6 & 11 \\
\hline
\end{tabular}

Note. For the purposes of maintaining anonymity and protecting the privacy of all participants, pseudonyms replaced all participant names in reports of the data.

Language use. In addition to the language use data reported above, parent report data were also included on child language use. On a scale of 1 to 5, parents were asked to rate frequency in response to 10 questions as listed in the table below. The response scale is interpreted as follows: $1=$ Never, $2=$ rarely, $3=$ occasionally, $4=$ almost all the time, $5=$ all the 
time. A summary of the responses collected and organized by language and context are presented in the table below (See Table 2).

While adult participants indicated that all the children understood Jamaican Creole, there are only 2 children for whom there was a high level of understanding (Bert and Ed). In terms of language use, at home and outside of home, all of the children were reported as low except for Ed. In terms of Standard English, again, Ed is differentiated from the rest of the sample of occasional use although he also shows strong understanding of Standard English. Overall, the use of Standard English was stronger than Jamaican Creole use across contexts, however, Ed showed stronger use for Patois than Standard English across contexts. 
Table 2.

Child Language Use as Reported by Parents.

\begin{tabular}{|c|c|c|c|c|c|}
\hline & $\begin{array}{l}\text { Alice } \\
\text { (Anne) }\end{array}$ & $\begin{array}{c}\text { Bert } \\
\text { (Bob) }\end{array}$ & $\begin{array}{c}\text { Carl } \\
\text { (Cara) }\end{array}$ & $\begin{array}{c}\text { Dan } \\
\text { (Dennis) }\end{array}$ & $\begin{array}{c}\text { Ed } \\
(\text { Eve })\end{array}$ \\
\hline \multicolumn{6}{|l|}{ Creole/Patois: } \\
\hline understands & 3 & 4 & 2 & 2 & 5 \\
\hline home use & 2 & 2 & 1 & 1 & 4 \\
\hline use with parent & 1 & 2 & 1 & 1 & 4 \\
\hline use outside home & 2 & 2 & 1 & 1 & 4 \\
\hline school use & 1 & 2 & 1 & 1 & 4 \\
\hline \multicolumn{6}{|l|}{ Standard English: } \\
\hline understands & 5 & 4 & 5 & 5 & 5 \\
\hline home use & 4 & 5 & 5 & 5 & 3 \\
\hline use with parent & 5 & 4 & 5 & 5 & 3 \\
\hline use outside home & 5 & 4 & 5 & 5 & 3 \\
\hline school use & 5 & 4 & 5 & 5 & 3 \\
\hline
\end{tabular}

Note. For the purposes of maintaining anonymity and protecting the privacy of all participants, pseudonyms replaced all participant names in reports of the data.

Language attitude. See Tables 3 and 4 for the ratings given to each speaker by child participants, as part of the Matched-Guise test. For ease of summarizing the results, numbers were assigned to each rating. $4=$ really, $3=$ kind of, $2=$ not really, and $1=$ no.

For the attribute of smartness, ratings were found to be the same for both the Standard English and Jamaican Creole speakers in Story 1 and Story 2, with the exception of Bert, Dan, and Ed. In Story 1, Dan and Ed rated the Jamaican Creole speaker as kind of smart and the Standard English speaker as really smart. In Story 2, Bert rated the Jamaican Creole speakers as 
kind of smart and the Standard English speaker as really smart, while Dan rated the Standard English speaker as kind of smart and the Jamaican Creole as really smart.

In both stories, all participants assigned the same ratings to both the Standard English speaker and the Jamaican Creole speaker, with the exception of Alice, Ed and Dan. In Story 1, Alice rated the Patois speaker as really kind and the Standard English speaker as kind of kind. In Story 2, Dan rated the Patois speaker as kind of kind and the Standard English speaker as not really kind. Unlike Dan and Alice who rated the Patois speaker as higher in the attribute of kindness, Ed gave a lower rating to the Patois speaker (not really kind) than the Standard English speaker (kind of kind).

On the attribute of niceness, participants rated both the Jamaican Creole and Standard English speakers as really nice with the exception of Ed. In Story 1, Ed rated the Patois speaker as not nice and rated the Standard English speaker as really nice.

Participants assigned the same ratings for the Creole speaker across both stories on the attribute of friendliness. For Story 1, participants gave higher ratings on the attribute of friendliness to Standard English speakers. Specifically, Carl and Dan who rated Standard English speakers as really friendly and Creole speakers as kind of friendly. For Story 2, participants gave higher ratings on the attribute of friendliness to Creole speakers. Specifically, Dan rated Creole speakers as kind of friendly and Standard English speakers as not friendly. Bert rated Creole speakers as really friendly and Standard English speakers as kind of friendly.

In Story 1, no variance was found across ratings as each participant rated the Creole and Standard English speakers as really funny. Each Participant gave the same ratings on funniness for both Patois and Standard English speakers in Story 1. For Story 2, there is more variability in the ratings particularly given to Creole speakers. For Story 2, all participants gave the same 
ratings on funniness for Patois and Standard English speakers with the exception of Bert, who rated the Patois speaker as not really funny and the Standard English speaker as really funny.

In both stories, all participants rated the Patois and Standard English speakers as equally polite, with the exception of Bert and Carl. In both stories, Bert rated the Patois speakers as kind of polite and the Standard English speakers as really polite. In Story 1, Carl rated the Standard English speaker as really polite and the Patois speaker as kind of polite. In Story 2, Carl rated the Patois speaker as really polite and the Standard English speaker as kind of polite.

For both stories, each participant gave the same rating for both speakers on the attribute of working hard. Scores across participants were found to be consistent with a few exceptions. Alice assigned a higher score for the Creole speaker on the attribute of kindness in Story 1. Bert gave higher ratings to the Standard English speaker on attributes of smartness and funniness in Story 2, and politeness in Story 1 and 2. He rated the Patois speaker higher than the Standard English speaker on the attribute of working hard in Story 1. Carl gave higher ratings to Patois speakers on the attribute of kindness in Story 1. Ed gave higher ratings to the Standard English speaker on the attribute of smartness, kindness, and niceness. Dan displayed the most variation in his ratings, as he rated the Patois speaker as less friendly and smart than the Standard English in Story 1 and the Standard English speakers as less smart and kind than the Patois speaker in Story 2.

In observing the averages, ratings on the attribute of working hard were same for both speakers in each story. Similarly, all speakers assigned the same ratings on the attribute of working hard across both stories. Overall, the ratings were not that different between speakers. 
Table 3.

Likert Scale Matched-Guise Responses (Detective Dog and the Disappearing Doughnuts)

\begin{tabular}{|c|c|c|c|c|c|c|}
\hline & Alice & Bert & Carl & Dan & $\mathrm{Ed}$ & Mean \\
\hline \multicolumn{7}{|l|}{ Patois speaker: } \\
\hline Smart & 4 & 4 & 4 & 3 & 3 & 3.6 \\
\hline Kind & 4 & 3 & 3 & 4 & 2 & 3.2 \\
\hline Nice & 4 & 4 & 4 & 4 & 1 & 3.4 \\
\hline Friendly & 4 & 4 & 3 & 3 & 4 & 3.6 \\
\hline Funny & 4 & 4 & 4 & 4 & 4 & 4 \\
\hline Polite & 4 & 3 & 3 & 4 & 4 & 3.6 \\
\hline Works hard & 4 & 1 & 4 & 4 & 4 & 3.4 \\
\hline \multicolumn{7}{|l|}{ Standard English speaker: } \\
\hline Smart & 4 & 4 & 4 & 4 & 4 & 4 \\
\hline Kind & 3 & 3 & 3 & 4 & 3 & 3.2 \\
\hline Nice & 4 & 4 & 4 & 4 & 4 & 4 \\
\hline Friendly & 4 & 4 & 4 & 4 & 4 & 4 \\
\hline Funny & 4 & 4 & 4 & 4 & 4 & 4 \\
\hline Polite & 4 & 4 & 4 & 4 & 4 & 4 \\
\hline Works hard & 4 & 1 & 4 & 4 & 4 & 3.4 \\
\hline
\end{tabular}

Note. For the purposes of maintaining anonymity and protecting the privacy of all participants, pseudonyms replaced all participant names in reports of the data. 
Table 4.

Likert Scale Matched-Guise Responses (X-ray for Xylophone Fish)

\begin{tabular}{|c|c|c|c|c|c|c|}
\hline & Alice & Bert & Carl & Dan & $\mathrm{Ed}$ & Mean \\
\hline \multicolumn{7}{|l|}{ Patois speaker: } \\
\hline Smart & 4 & 3 & 4 & 4 & 4 & 3.8 \\
\hline Kind & 4 & 3 & 3 & 3 & 4 & 3.4 \\
\hline Nice & 4 & 4 & 4 & 4 & 4 & 4 \\
\hline Friendly & 4 & 4 & 3 & 3 & 4 & 3.6 \\
\hline Funny & 4 & 2 & 4 & 3 & 4 & 3.4 \\
\hline Polite & 4 & 3 & 4 & 4 & 4 & 3.8 \\
\hline Works hard & 4 & 1 & 4 & 3 & 4 & 3.2 \\
\hline \multicolumn{7}{|l|}{ Standard English speaker: } \\
\hline Smart & 4 & 4 & 4 & 3 & 4 & 3.8 \\
\hline Kind & 4 & 3 & 3 & 2 & 4 & 3.2 \\
\hline Nice & 4 & 4 & 4 & 4 & 4 & 4 \\
\hline Friendly & 4 & 3 & 3 & 1 & 4 & 3 \\
\hline Funny & 4 & 4 & 4 & 3 & 4 & 3.8 \\
\hline Polite & 4 & 4 & 3 & 4 & 4 & 3.8 \\
\hline Works hard & 4 & 1 & 4 & 3 & 4 & 3.2 \\
\hline
\end{tabular}

Note. For the purposes of maintaining anonymity and protecting the privacy of all participants, pseudonyms replaced all participant names in reports of the data.

\section{Adult Findings}

Presented are the findings of all 9 adult participants. Interviews were conducted with a total of 5 out of the 9 adult participants.

Language use. The first set of questions that adult participants responded to in the questionnaire were concerned with parental language use. On a scale of 1 to 5, they were asked 
to rate frequency in response to 8 questions as listed in the table below. The response scale is interpreted as follows: $1=$ never, $2=$ rarely, $3=$ occasionally, $4=$ almost all the time, $5=$ all the time. A summary of the responses collected for the current study are presented in the tables below (See Table 5 and Table 6), which includes average responses and range of responses for each question.

Standard English. Frequency of responses to questions concerning use of Standard English are presented in Table 5 below. All adult participants reported that they understand Standard English all the time. Regarding home language use, 5 out of 9 adult participants reported that they never Standard English at home almost all the time. Two out of 9 adult participants reported that they speak Standard English at home all the time. Two out of 9 adult participants reported that they speak Standard English at home occasionally.

Regarding use of language with the target child, 4 out of 9 adult participants reported that they speak Standard English to their child or children occasionally. Four out of 9 adult participants reported that they speak Standard English to their child or children almost all the time. One out of 9 adult participants reported that they speak Standard English to their child or children all the time.

For language use outside the home, 7 out of 9 adult participants reported that they speak Standard English outside the home almost all the time. Two out of 9 adult participants reported that they speak Standard English outside the home all the time.

Overall, all participants indicated that they understand Standard English all the time. Most participants indicated that they speak Standard English at home and outside the home almost all the time. Lastly, most participants were split between speaking Standard English to their child occasionally and almost all the time. 
Table 5.

Number of Adult Participant Questionnaire Responses for Questions concerning Standard English.

\begin{tabular}{|c|c|c|c|c|c|}
\hline & Never & Rarely & Occasionally & $\begin{array}{l}\text { Almost all } \\
\text { the time }\end{array}$ & $\begin{array}{l}\text { All the } \\
\text { time }\end{array}$ \\
\hline I understand Standard English & & & & & 9 \\
\hline I speak Standard English at home & & & 2 & 5 & 2 \\
\hline $\begin{array}{l}\text { I speak Standard English to my } \\
\text { child/children }\end{array}$ & & & 4 & 4 & 1 \\
\hline $\begin{array}{l}\text { I speak Standard English outside the } \\
\text { home }\end{array}$ & & & & 7 & 2 \\
\hline
\end{tabular}

Jamaican Creole. As reported in the table below, 5 out of 9 adult participants reported that they understand Patois all the time. Four out of 9 adult participants reported that they understand Patois almost all the time. In terms of Patois use in the home, 5 out of 9 adult participants reported that they occasionally speak Patois at home. Three out of 9 reported that they speak Patois at home almost all the time. One out of 9 adult participants reported that they never speak Patois at home.

In terms of speaking Patois to the target child, 6 out of 9 adult participants reported that they occasionally speak Patois to their children. One out of 9 adult participants reported that they speak Patois to their children almost all the time. One out of 9 adult participants reported that they rarely speak Patois to their children. One out of 9 adult participants reported that they never speak Patois to their children.

Three out of 9 adult participants reported that they speak Patois outside the home almost all the time. Three out of 9 adult participants reported that they occasionally speak Patois outside 
the home. Two out of 9 adult participants reported that they rarely speak Patois outside the home. One out of 9 adult participants reported that they never speak Patois outside the home.

Most participants indicated that they understand Jamaican Creole all the time, however most participants indicated occasional use of Jamaican Creole in the home context and with children. Participants were split between using Jamaican Creole outside the home occasionally and almost all the time.

Table 6.

Number of Adult Participant Questionnaire Responses for Questions Concerning Jamaican Creole.

\begin{tabular}{|c|c|c|c|c|c|}
\hline & Never & Rarely & Occasionally & $\begin{array}{l}\text { Almost all } \\
\text { the time }\end{array}$ & $\begin{array}{l}\text { All the } \\
\text { time }\end{array}$ \\
\hline I understand Patois/Patwa & & & & 4 & 5 \\
\hline I speak Patois/Patwa at home & 1 & & 5 & 3 & \\
\hline $\begin{array}{l}\text { I speak Patois/Patwa to my } \\
\text { child/children }\end{array}$ & 1 & 1 & 6 & 1 & \\
\hline $\begin{array}{l}\text { I speak Patois/Patwa outside the } \\
\text { home }\end{array}$ & 1 & 2 & 3 & 3 & \\
\hline
\end{tabular}

Language attitude. The second set of questions that adult participants responded to in the questionnaire was concern with parental language views. On a scale of 1 to 5, participants were asked to rate their level of agreement in response to 12 questions presented, beginning with "When you hear a person speaking Patois/Patwa and another person speaking Standard English..." The response scale is interpreted as follows: 1= strongly disagree, $2=$ disagree, 3=neither agree/disagree, 4= agree, 5= strongly agree. A summary of the responses collected for the current study are presented in the tables below (see Table 7), which includes average responses and range of responses for each question (see Appendix L for individual responses). 
As seen in the differences in average ratings for attributes of intelligence, honesty, education, friendliness, money, Patois speakers were ranked higher than Standard English speakers. For the attribute of helpfulness, both groups received the same average scores. Average ratings for Creole speakers on honesty and friendliness were particularly high as compared to other average ratings.

Table 7.

Parental Language Views Likert Scale Average Ratings and Ranges.

\begin{tabular}{lcc}
\hline Questions & Average & Range \\
\hline You think the person speaking Patois/Patwa is more intelligent & 2.56 & $1-4$ \\
You think the person speaking Standard English is more intelligent & 2.22 & $1-3$ \\
You think the person speaking Patois/Patwa is more honest & 3.11 & $2-4$ \\
You think the person speaking Standard English is more honest & 2.33 & $1-3$ \\
You think the person speaking Patois/Patwa is more educated & 2.44 & $1-3$ \\
You think the person speaking Standard English is more educated & 2.33 & $1-3$ \\
You think the person speaking Patois/Patwa is more friendly & 3.56 & $1-4$ \\
You think the person speaking Standard English is more friendly & 2.44 & $1-3$ \\
You think the person speaking Patois/Patwa has more money & 2.11 & $1-3$ \\
You think the person speaking Standard English has more money & 2 & $1-3$ \\
You think the person speaking Patois/Patwa is more helpful & 2.67 & $1-4$ \\
You think the person speaking Standard English is more helpful & 2.67 & $1-4$ \\
\hline
\end{tabular}

The final set of questions that adult participants responded to in the questionnaire was concerned with child language views. On a scale of 1 to 5, participants were asked to rate their level of agreement in response to 12 questions presented, beginning with "When your child hears a person speaking Patois/Patwa and another person speaking Standard English..." The response 
scale is interpreted as followed: $1=$ strongly disagree, $2=$ disagree, $3=$ neither agree/disagree, $4=$ agree, $5=$ strongly agree. A summary of the responses collected for the current study are presented in the tables below, which includes average responses and range of responses for each question. A majority of scores fell between 1-3 ranges, with a few 3-scores. 5 were never indicated.

Interview data. The results are considered in the order of the three topics covered by the interview questions: language use, perceptions of children's abilities to succeed academically, and perceptions of educator attitudes. Adult participants presented perspectives of their personal experiences. Interviews were conducted with a total of 5 out of the 9 adult participants.

Brief participant profiles. Ann is a Canadian-born Jamaican Creole speaker. Ann has completed post-secondary education and is currently employed as a Special Needs Coordinator. Ann is the mother of Alice. Cara and Dennis are the parents of Carl and Dan. Cara is a Canadianborn Jamaican Creole speaker who has completed post-secondary education and is presently a Homemaker. Dennis is a Canadian-born individual who does not speak Jamaican Creole, but is of Jamaican descent. He was completed some post-secondary education and is currently employed as a Locator. Hal is a Canadian-born Jamaican Creole speaker who chose to not indicate his profession. He has completed high school education.

Language use. Within the responses concerning language use, the following themes emerged: group connectedness, language planning, and communicative limitations. In discussing language use, all parents indirectly referred to identity and group connectedness as driving forces behind the use of the language. Dennis stated that, "by family background, I'm familiar with Patois.” Ann explained, "It's just something that I grew up with so it's almost like a force of habit so at home my mom spoke patois to me and I've just grown up around it so I end up 
speaking it." Hal explained his use of Jamaican Creole as providing his child with the ability "just to associate with her family members."

All parents seemed to have engaged in some form of language planning as part of language socialization. In addition, all interviewees provided details regarding the contexts, purposes, and individuals with whom their children are or would be permitted to utilize Jamaican Creole. For example, Hal provided a detailed account of the contexts in which Jamaican Creole is used outside the home: "Usually family events, outings, when we go out to dinner together. We go out to another family member's house. Around the same nationality people... Jamaica day, stuff like that." Ann explained, "if she's speaking in a playground, I don't see a problem with it (use of Creole with non-Jamaican friends." Cara indicated specific moments where her use of Jamaican Creole is naturalistic: “Only when I'm frustrated and I need to get that expression out, it comes out." Dennis detailed, "The most I... (use Patois) outside of a house setting, joking around with ..Friends at... odd times." Ida indicated that she chooses to use Jamaican Creole minimally with the child across contexts "Because she won't understand. Too much explanation.”

The classroom was mostly perceived as a setting in which Jamaican Creole was not permitted for use by their children for various reasons including concerns related to speakers' inability to communicate effectively and respectfully when using the language. Ann protested, “not when she's in class, I don't think it's appropriate." Hal justified his position on the matter, "Outside the classroom is totally fine, maybe the play yard or with her friends or whatever, but not to a teacher. Not to an authority figure." Ida explained, "Not at school because it's going to be all about the same thing... Others not understanding what she's saying." Dennis spoke to the use of Jamaican Creole in the classroom, but with caution: "I would assume that when it came to 
certain stuff, grammar, pronunciation, that might end up being somewhat of an issue, maybe. I don't know, I'm just kind of surmising, but I wouldn't see it as a problem." However, Cara spoke to the importance of different cultures being represented in the classroom through language use. She explained that for students,

“...coming into the classroom where maybe English is not their first spoken language... the teacher still has ... to relate to that student to understand... where they're coming from. So for me, I see no difference if our child was to speak Patois in the classroom." Perceptions of children's abilities to succeed academically. With responses concerning perceptions of children's abilities to succeed academically, the following themes emerged: bilingualism and language interference.

All interviewees indicated that their child's language or language background has no relation to academic performance and success, but few assumed that exposure to Jamaican Creole would yield similar benefits as bilingualism. Hal explain,

"Patois adds another level... I mean if you think of it this way, someone that speaks another language, they're considered bilingual. So they can identify with someone speaking to them in their language. So it would be beneficial to her."

Ann explained that her child, "does extremely well in her language components in school... so I definitely don't see any type of barrier." She further explained, "whether it's languages... or whether it's just even a different dialect...to differentiate between the two and (figure out) exactly what they need to put down on paper not just say, I think it's definitely a positive." However, Ann reflected, "If she wasn't doing well, I think... I could see it (language and culture) being perceived by others as being a negative attribute to her not doing well in school." 
Responses to questions concerning Jamaican Creole use in the classroom were all quite different. Ann indicated that she is open for exploring the use of Jamaican Creole in the classroom;

"I'm an advocate when it comes to exploring different cultures in the classroom, especially because Canada is so multicultural... if there was an activity, I think that would be great... to experience different cultures and I think that may also take away some of the stigma associate with it."

Ida expressed that Patois should be incorporated in the classroom "we're living in a diverse community... I think we should all learn to get along with everybody else and understand that... we're the same." Hal was adamant about the exclusion Patois in classroom; "You wouldn't incorporate North American slang into academics, so I think Patois should be treated as slang because that's what it is."

Regarding the incorporation of Patois in specific classroom activities, language interference seemed to be a major concern that arose. Cara emphasized the lack of need for Jamaican Creole in the classroom;

"if teachers were getting a lot of students from a Jamaican culture background and there was a greater or high need for it, then I would assume then that for sure, they could incorporate something like that. But I think there's no real need right now. It wouldn't be necessary."

Making inference to possible language interference, Dennis explains, "I don't think it would do any damage to them outside of maybe.. Once again, with English. Mainly because they're younger." Hal argues that "it (Jamaican Creole in class) would probably hurt it (child's academic performance)... I don't see why they would be incorporating... that type of language in the 
classroom.” Ann provided details concerning her stance against Jamaican Creole as part of instruction;

"If they are teaching them how to speak in English and she's learning how to write in certain English...especially at this age, I think just for them to continue to develop literature in the English language, I think it would be better for her not to do it in the classroom."

Ida held a different opinion concerning the use of Jamaican Creole in the classroom from the other interviewees. She explained, "I would think it would help because at least they'd know that okay, that's a part of her background."

Perceptions of educators' attitudes. Negative school climate was the prevailing theme that arose from this section. Ann explained,

"I had to remove her from the school she was at last year based on the way she was being treated because of the fact that she was Black and there was a lot of racist things that was going on at the school."

She further explained,

"none of the kids were playing with her and this is something that I brought up to the teachers (and) principals... being Black, she was definitely in the minority...I was just told 'well it's because they share the same language why the other kids aren't playing with her."”

Speaking to the magnitude of this issue, Ann concludes, "I took it to the actual school district and this is a problem that has been happening a lot... a certain survey that goes out to every single parent... because it is such a big problem." Hal mentioned a similar negative schools experience, "because (her preschool) was predominantly Asian, they actually geared towards 
accommodating the Asian language more than they would accommodate any other language which I found really weird." Hal provided details of other parents sharing the same sentiments; 'She's like 'listen to them speak in their mother tongue'...it's like you're giving a little bit more attention to those students because you're able to communicate with them... identify with their language. It feels kind of biased." Cara describes previous events associated with school climate; "the teacher was really targeting him a bit based on his language... I felt like she was targeting him a bit, but then I found out that she targeted certain students in general." Cara provided further description of the events, "she would call me every other day telling me of incidents he was in and nothing major. He wouldn't hurt anybody." Ann specified that this teacher targeted “other students of different cultures. So, I didn't feel like it was only me." Dennis added that, "we learned later on that she taught a higher grade class and I think the transition was just... what she was able to handle was children who are... more well-mannered because they were older." He further explained, “Outside of that, I don't think there anything specific to the language or culture to say well there was a specific target in that regard."

In relation to negative school climate and in reference to specific parent-related issues that arose, there were a few noteworthy responses. Cara, Dennis, and Ida responded with a resounding "no", when asked if they felt that they were treated differently by teachers due to their language or cultural background in comparison to parents from other culture or language backgrounds. Ann explained that the existence of discriminatory practices in the school overtime was enough to make her feel differentially treated; "I just felt like it was a problem that was obviously going on in the school for a bit of time. So to me, just that alone is them treating me different." Hal recounted a specific incident in which he felt targeted on the basis of race; "I was at an award show...I was wearing a hat and this was an outside event... one of the parents turned 
to me and said "take your hat off". And I felt totally offended by that." He continued, "it could be a generational thing, but I more took it as...because I was Black. I was literally the only Black person at that ceremony... So, I felt offended by that."

\section{Chapter 6: Discussion}

My overall analysis drew on a variety of methodological approaches in combination with theoretical and empirically supported concepts and strategies. Some of these methods have provided insights in my small sample, but others showed limitations. As a result, I include here a discussion of the contributions and limitations of the methods used in this exploratory study. Findings from this study revealed a few important patterns regarding language, identity, and literacy related to Jamaican Canadian children that warrant further investigation with a larger sample.

\section{Child Data}

Overall, the child participants totaled five, therefore it was not possible to draw conclusions, or even to reliably interpret, the language and literacy data. Instead, the current study offered an opportunity to explore the use of various measurement tools for use with a larger sample in future. Here I report descriptively on the findings related to the five child participants.

Language and Literacy. On the Diagnostic Evaluation of Language Variance (DELV) screening test, most children (3 out of 5) scored within the Mainstream English range. However, 2 of the 5 children were found to have variation from MAE speakers, or speakers of other standard varieties of American English. This indicates that these 2 participants produced linguistic features (specifically morphosyntactic and phonological features) with some variation as compared to Mainstream American English (MAE) speakers, or speakers of other standard 
varieties of American English (Seymour, Roeper, \& de Villers, 2003). Factors related to language use, such as code switching, can be possible influences of this variation (Seymour, et al., 2003). The degree of variation remains unknown.

Across the Assessment of Language and Literacy (ALL) subtests, Basic Concepts, Parallel Sentence, Elision, and Listening Comprehension, the lower scores were among children who were Standard English speakers. It is interesting to note that the 2 participants who scored in the low average range (Dan and Alice) were both Standard English speakers. Carl, a Standard English speaker who was found to have dialectal variation in the DELV screening test, was included in this group.

I initially hypothesized that bidialectal children would be expected to do well on the Basic Concepts subtest. However, the scores that were among the lowest were obtained on the Basics Concepts subtest across participants with Dan being the lowest. Alternatively, adult participants were asked during the screening process to confirm whether or not the children were previously diagnosed with language or literacy-related delays or difficulties.

Performance on language and literacy measures show that the children who scored below average were not consistent with dialect form. In other words, there appears to be no pattern in the findings related to dialect. With a small sample size, the relationship cannot be determined, but general scores were within the average range. Although it is not possible to assess the impact of Jamaican Creole language on Standard English achievement in this investigation, it was noteworthy that the only Jamaican Creole-speaking child (Ed) in the sample achieved a high level of performance on language and literacy measures. Due to mismatch of oral language and print language, children from diverse backgrounds have been found to experience literacy challenges (Bialystok et al., 2010; Clacher, 2004; Terry, 2012). Previous studies have 
highlighted the benefits associated with Creole use in education, including increased engagement and improved literacy-related outcomes (Carpenter \& Devonish, 2010; Kephart, 1992). Conclusions cannot be made in this regard. More participants are needed to see if Ed's performance is replicated with other Jamaican Creole-speaking participants.

Language use. Due to the small sample of quantitative child data, adult data (both qualitative and quantitative) were also considered. Overall, it appears that Standard English is the dominant language used across contexts by children, as reported by parents. Carl's parents indicated that he understands and uses Standard English more than he understands and uses Jamaican Creole. However, DELV scores revealed that he produced linguistic features (specifically morphosyntactic and phonological features) with some variation as compared to MAE or speakers of other standard varieties of American English. Ed was the only child whose use of Jamaican Creole exceeded use of Standard English across all contexts. Interestingly, Ed's ALL scores across subtests exceeded the scores of the other participants.

There appears to be more exposure to and use of the Standard English across different contexts. Social Identity Theory takes into account the influence of culture in identity development. As language is a symbolic means through which identity is asserted and enculturation in child development occurs (De Fina, 2007; Gardiner \& Kosmitzki, 2011; Migge, 2007), this finding provides some insight regarding identity assertion through language socialization practices across Jamaican families in the Canadian context. Vygotsky's concept of "Talking to Learn" describes social interactions as a means by which children use language to understand the world around them (Gardiner \& Kozmitzki, 2011). For individuals living in additive environments where a dialect is spoken at home, acquisition of the language is through circumstantial (through exposure) and thus language ability may likely be receptive rather than 
productive (Baker, 2006; Genesis et al., 2004). It is likely that Creole-speaking parents engaged in Segmented Assimilation, which involves maintaining practices related to one new and cultures (Plaza, 2004; 2006). This is not surprising, as Canada is a context within which members of the Caribbean diaspora undergo continuous identity negotiation (Wooddall, 2007), and thus this is likely reflected in their language practices across different contexts.

Language attitude. It is important to note that most of the child ratings were positive and hence, it is difficult to interpret the perspectives of this small sample. One participant, Ed, may have overstated ratings due to his association of the Jamaican Creole speaker with a popular dancehall artist from Jamaica.

Ratings appear to be relatively consistent between speakers with the exception of a few items. Alice rated the both speakers as the same on all attributes, with the exception of kindness for which she gave the Jamaican Creole speaker a higher rating in Story 1. Across both stories, there were inconsistencies for ratings on politeness, for which Bert gave the Jamaican Creole speaker a higher score in Story 2 and a lower score in Story 1. Across both stories, there were inconsistencies for ratings on friendliness, for which Carl gave the Jamaican Creole speaker a higher score in Story 2 and a lower score in Story 1. Across both stories, there were inconsistencies for ratings on friendliness, for which Dan gave the Jamaican Creole speaker a lower ratings in Story 1 and 2. In Story 1, Ed gave mostly low scores to the Jamaican Creole speaker in Story 1. Ratings were the same between speakers in Story 2 with the exception of friendliness for which Ed rated the Jamaican Creole speaker as higher. Interestingly, the ratings for the attribute of working hard were the same between speakers in each story.

Overall, there was a pattern of participants giving more positive ratings to the Jamaican Creole speaker for Story 2 and lower ratings to the Jamaican Creole speaker for Story 1. Stories 
and dialect were selected randomly to avoid effects of story or dialect. There are a number of factors that could have contributed to this occurrence. The ability of the Likert scale to accurately depict what the child feels is dependent on the child's understanding of word meanings.

Reynolds-Keefer and colleagues (2009) identified that children favoring specific images may impact the accuracy of measurement when using a pictorial Likert scale with children.

Conducting an interview with children would provide more information to support their language views.

Insufficient child data was present, therefore the current investigation relied on additional qualitative and quantitative data from adult participants. Due to the small sample size, it was not possible to investigate the relation between language and literacy scores and Creole use. A larger sample size and a higher number of Creole speakers would be needed to make statistical comparisons

\section{Adult Data}

Language use. Overall, there appears to be high ratings by adult participants on the dimension of understanding both Standard English and Jamaican Creole. However, Standard English remains the language of dominance in terms of use across contexts. However, 1 participant (Dennis) reported never speaking Jamaican Creole across all contexts. Although Dennis is of Jamaican descent, he is different from other participants because he is the spouse of a Jamaican Creole speaker.

Evidence of private language planning amongst all interviewees was present, as parents provided detailed accounts of their language socialization practices, specifically regarding the contexts, purposes, and individuals with whom their children are or would be permitted to utilize Jamaican Creole. Similar to empirical evidence of the polarized views of the Jamaican Creole 
language in the literature, there appears to be some evidence of this as observed amongst the participants of the present investigation. While participants indirectly referred to group connectedness as driving forces behind their use of Jamaican Creole, internalization of Jamaican Creole being substandard is evident, particularly with concerns raised by adult participants regarding the effectiveness of the language in communicating respectfully. This may also be evidence of what Labov (1968) described as Linguistic Insecurity. As a result, parents primarily support the use of Jamaican Creole in informal settings such as the playground, rather than formal settings such as the classroom. Code-switching into Jamaican Creole in the home context may reflect a value of the dialect as a part of personal identity or the language of "heart and home".

Similarly, perspectives on Jamaican Creole use in the classroom also reflected polarity. As recognized in research (De Fina, 2007; Winford, 2007), participants recognized the similarity of bidialectalism to bilingualism and potential beneficial influence of Jamaican Creole if used in the classroom. However, use of Jamaican Creole in specific activities within the classroom yielded mixed responses. Language interference, that is the non-standard language presenting challenges in acquiring skills in the standard language variety, was a major concern in this area. Cara, who displayed a strong sense of sociolinguistic insight, spoke to the importance of different cultural and language groups being represented in the classroom. Delpit (2006b) also spoke to the importance of different language groups being represented in the classroom, as it is the school's role to provide access to both standard and nonstandard forms of language.

In discussing concerns related to differential treatment, both race and language emerged. However for the most part, perceived differential treatment on the basis of race did not appear to be common. Two participants (Ann and Hal) described differential treatment that seemed to be 
as race-based. Ann, specifically, made a connection between culture and race and differential treatment on the basis of both. Differential treatment was not experienced by all participants, which contradicts Allahar's (2011) bold statement of Canada being a "racist society" (p. 55). Relevant are the findings by Boatswain and Lalonde (2000) that Caribbean Canadians preferred to be identified by their ethnic label, which may explain why race was not a predominating theme that emerged in the present study. In addition, perceptions of racism should be considered, as they were in the study by Dion and Kawakami (1996). It is important to emphasize that although actions may not be with discriminatory intent, perceived discrimination, "represents an important psychological reality for immigrant and ethnic minority group members" (Dion \& Kawakami, 1996, p. 204). Nonetheless, these experiences of discrimination do exist in education for some which have the potential to negatively impact student outcomes (Wright, 2011). Researchers have also highlighted the role of school climate in contributing to academic underachievement (Ferguson et al., 2005). Interestingly, while race cannot be ignored, it is culture and language that are meaningful in this investigation, not only to me, but to the participants.

Language attitudes. It is likely that the scale inaccurately captured language attitudes of participants. A 5-point scale allowed participants to neither agree nor disagree, which was the midpoint value of " 3 " on the scale, and the most commonly chosen rating for all questions across participants. Child language views as reported by parents were mostly neutral, which likely indicates that the measure is not valid, and will not be further discussed. That is, the measure is making a connection between dialect use and dimensions that are entirely unrelated. This suggests that the measure should not be used in a larger investigation concerning perceptions of 
child language views. Instead, child language views were solely extrapolated from the MatchedGuise Test.

Although there is a pattern with all of the responses to Jamaican Creole questions ranking more positively, with this sample size, it is not possible to derive a meaningful or valid interpretation based on the results. All of the questions except for one question were ranked in the lower end of the scale, meaning most people did not believe that these attributes were related to language. The only difference is ratings of Jamaican Creole speakers for the attribute honesty, for which the average rating is above the neutral ranking of 3 . Five participants responded with a score of 3 and above, while 4 participants responded with a score below 3. Although the content of the questionnaire was adapted from a measure on language attitudes in Jamaica (Jamaica Language Unit, 2005), it appears it is not valid for this population. Nonetheless, this is an interesting pattern, considering that in a previous investigation on perceived attributes of Jamaican Creole and English speakers, ratings of honesty were found to have no relation to language in Jamaica (Jamaica Language Unit, 2005).

In terms of language views, higher ratings were found among Jamaican Creole speakers than Standard English speakers across attributes with the exception of helpfulness for which both speakers received equal average ratings. Interestingly with child participants, variation was found among all attributes and speakers with the exception of the attribute or working hard. This finding, although found amongst a small number of participants, could demonstrate the strength and significance of parental influence on children by way of socialization, more specifically the parent to child transfer of views and attitudes. A larger sample size will afford the opportunity to explore this question further. In consideration of alternative explanations for findings, some participants may have had either highly negative language views or highly positive language 
views for many reasons including preconceived perceptions of group or how outsiders' perception of group, which would be reflected in interview and questionnaire data.

\section{Methodological Insights: Contributions and Challenges}

For the purposes of informing future research, I would like to provide reflections on my methodological insights which emerged from challenges faced in this research process.

Specifically, I will address the process of recruitment and measurement tools used.

Initial challenges with recruitment provided me with numerous insights. Firstly, the time available for recruitment was limited. An earlier commencement on recruitment would have likely increased the number of participants recruited for this study. Secondly, in expecting participants to be available and present for an extended period, monetary compensation was necessary and resulted in increased interest in study participation. Compensation, in a way, highlights the importance of the role of participants in this study and the importance of the study overall.

Child measures provided ample methodological insights. The Diagnostic Evaluation of Language Variation (DELV) assessment tool was incorporated in the study based on the recommendations of one of the authors, Tom Roeper. Having utilized the tool on a small sample, it is apparent that this tool provides information regarding the presence of dialectal variation features. This is a tool that I would not only use again in research, but would also recommend for future studies.

I found the Assessment of Language and Literacy (ALL) to be a useful measurement tool, as it was designed to assess a vast array of areas concerned with language and emergent literacy. In addition, the authors provide instructions in the ALL testing manual regarding approaches of assessing children who present with dialectal variations (Lombardino, Lieberman, 
$\&$ Brown, 2005). The authors also emphasized the importance of the tester being familiar with the dialectal variation presented in determining correctness of the response (Lombardino, et al., 2005), which speaks to their awareness of issues in testing regarding language variation. It is my hope that this tool is increasingly incorporated in future research.

The Matched-Guise Technique has been used in numerous previous studies (Edwards, 1977; Lambert, 1960; Loureiro-Rodrigues, Boggess, \& Goldsmith, 2012), however, the present study was the first to utilize this test with kindergarten-aged children. Consequently, adaptations were implemented, included the inclusion of a pictorial Likert scale with words describing each category of choice. There are some concerns of validity with the pictorial Likert scale with words, particularly with a sample of this age group, including image preference and word comprehension. Nonetheless, this is a test that I would use again in research. Further adaptations could be considered for future research with early childhood populations.

Adult measures provided ample methodological insights as well. The 5-point Likert scale used in the questionnaire to measure language use and attitudes yielded neutral responses from adult participants on some areas of testing, particularly with perspectives on child language attitudes. Therefore, use of a scale that did not allow for neutral responses, such as a 4-point scale, may have yielded more substantive responses form participants. Although the content of the questionnaire was adapted from a measure on language attitudes in Jamaica (Jamaica Language Unit, 2005), it appears to not be valid for this population in Canada. This may be true for other Jamaican populations of the diaspora, and should be altered in future investigations that will include these populations. The underlying reasons for this difference between Jamaican and diasporic contexts should also be investigated in future. 
The interview with adult participants yielded considerable variation in perspectives from respondents, generating a concern of the ability of the questions to capture this variation. In addition, I wondered if the order of presentation for questions in the interview had any impact on the responses obtained. For example, if I had presented questions regarding perceptions of educators' attitudes prior to questions regarding perceptions of children's ability to succeed academically, would the interviewees' responses be different? Consideration of these aspects of interviewing is of great importance in conducting research of this nature.

\section{Future Directions}

As a member of the Jamaican diaspora by descent and having experienced my own academic challenges in the past, this area of research is of particular interest to me. Therefore, the overall design of the study is subject to investigator bias, as it is likely that my positionality impacted my approach to this research investigation. At the same time, my unique perspective as a Jamaican Canadian offered within-group insights not available from those outside of the community. Ideally, future research could integrate both a within-group and an external perspective into culture-specific research.

Due to the small sample, specifically with the child data, reliable interpretations of results could not be presented. Instead, the current study offered an opportunity to explore the use of various measurement tools for use with a larger sample in future. Future research may examine similar issues related to children of their age groups beyond the stage of emergent literacy.

I encourage future investigators to move away from homogenous assumptions of race and delve further into factors related to race, such as culture, language, and identity. This paper contributes the novel focus of Jamaican Creole to the small but growing literature on the Jamaican diasporic experience broadly, and the Jamaican-Canadian and Caribbean-Canadian 
experience, more specifically. It would be interesting to perform a similar investigation with a larger sample that was more racially heterogeneous yet ethnically homogenous. Research should also consider the impact of culture and dialect for other Caribbean groups. Are other Jamaican immigrant groups in other areas of Canada, including those that do not reside in a metropolitan area, impacted by these issues in the same way? Lastly, it would be interesting to see the changes in language socialization patterns overtime. As the study goes beyond focusing on race, it addresses systemic issues with theoretically informed investigation and nonetheless contributes to the understanding of the interplay between race and culture in influencing aspects of learning.

Presented in this investigation are preliminary results based on questionnaires, assessments, and interview data and hence, should be interpreted with caution. This is a preliminary study to be extended, as data collection is still underway. Findings are inconclusive due to the small number of participants. Additionally, snowball sampling contributes to low generalizability of results. However, the findings highlight important issues concerning language, identity, and literacy development of Jamaican-Canadian children. The current investigation provides some insight on the relationship between language, identity, and literacy achievement of a group that is under-researched in Canada.

\section{Chapter 7: Conclusion}

Evidence of the underachievement of Black students in schools has existed for some time. However, using the term 'Black' to describe a group of students performing poorly in academics homogenizes and racializes a problem that is not racially-determined. In focusing on a specific cultural subgroup, the purpose of this sociolinguistic investigation was to determine the impact of dialect and cultural identity on literacy performance of Jamaican Creole speakers in Canada. However, in discussing members of the Caribbean diaspora, race and culture cannot be 
considered separately, as they are essential part of identity construction. Language is a medium through which identity is asserted, and culture is expressed and transmitted.

The relationship between dialect and language and literacy performance for Jamaican Canadian children remains to be determined with continued data collection. Parental language views influence their private language planning process where parents make language choices concerning use, purposes, and context of languages for their children. Similarly, the language views held by educators may influence. The language views held in wider society impact individual views of language and resulting practices related to language use.

Although not widely discussed by participants, incidents of differential treatment on the basis of race and language that persist in educational contexts remain to be addressed. The overarching goal of this investigation was to challenge race-based findings on academic achievement and address a systemic problem with a theoretically driven approach. This investigation provides unique contributions.

Although a disproportionate number of Black Canadian students are underachieving in Toronto schools, it appears that no one has performed a sociolinguistic exploration of this issue. The current investigation, therefore, provides a new perspective of Black academic underachievement and highlights the need for more research in this area. It appears that previous studies have not considered the relationship between Jamaican identity and Creole use in the Canadian context. This study was specifically aimed to investigate the role of Jamaican Creole in identity and achievement. More importantly, this investigation encourages the reconceptualization of preconceived beliefs regarding members of minority, cultural, and language groups in education. 


\section{Language, Literacy, and Culture Study}

\section{RYERSON
UNIVERSITY}

Is your family of Jamaican heritage?

Do you or your family members speak Jamaican

Creole/Patois/Patwa?

If you answered YES to any of the above questions, you may

be interested in participating in a study focused on language, literacy, and culture!

We are presently looking for children aged 5-6 and their parent/guardian/family member from the Greater Toronto Area (City of Toronto, Durham, Halton, Peel, York) to be a part of our study

What does this study involve?

Adult participants

-1 brief questionnaire ( 3 pages)

-Focus group (optional) (1.5 hour maximum)
Child Participants

- Language and Literacy evaluations (45 minutes maximum) - Literacy-based activity (15 minutes maximum)

\section{If interested, please contact Nicola Dove at nicola.dove@ryerson.ca or leave a message at (416) $979-5000$ ext. 7646}




\section{Appendix B \\ Consent Agreement \\ Ryerson University}

\section{Language socialization and early literacy achievement: A developmental sociolinguistic investigation of school-aged bidialectal English speakers}

Dear Parent/Guardian/Family Member,

You and your child are invited to participate in a research study that investigates aspects of language socialization and literacy achievement. Before you provide consent to voluntarily participate in this research study, it is important that you read the following information and ask as many questions as necessary to ensure that you understand what you will be asked to do.

Investigator: $\quad$ Nicola M. Dove

B.A. (Hons.), C.D.A., Reg. CDAAC, M.A. candidate

Department of Early Childhood Studies

Faculty of Community Services

Ryerson University

Supervisor: $\quad$ Dr. Kathleen Peets

B.A., M. Ed., E.Ed.

Department of Early Childhood Studies

Faculty of Community Services

Ryerson University

Purpose of the Study: I intend to explore the role of language in literacy achievement. I intend to focus my investigation on the English language and literacy development of bidialectical children, specifically children whose initial language exposure was Jamaican Creole.

Description of the Study: This study will explore children's use of Jamaican Creole and their language and literacy performance. More specifically, we are interested in the impact of dialect and cultural identity on pre-literacy skills development. I aim to recruit a total of 60 participants; 30 child participants between the ages of 5 and 6 years, and their parents/guardians/family members from Jamaican Creole-speaking families within the Greater Toronto Area. 
Procedures: You will be asked to complete a questionnaire containing single-select 5-point scale questions and open-ended questions. A subset of the parents/guardian/family members in this study will participate in a focus group. Participation in this focus group is voluntary.

You will sign the consent forms, and you or the investigator can read the assent document to the child participants. You will provide responses to questionnaire. The child will engage in the language evaluation, language and literacy assessment, and literacy activity. Breaks will be provided at your request or the request of the child.

Flexible scheduling arrangements will be offered to all participants.

An undergraduate student in Early Childhood Studies from Ryerson University will be available on an as-needed basis to care for siblings who are not part of the research study.

Detailed information and the expected duration of each procedure in a session with in this study are as follows:

1. Consent and assent provision and questionnaire provided (duration: as long as needed)

- You will be asked to read this consent form in its entirety. If participating in this research study, you will be asked to sign and date in the designated spaces located at the ends of this form.

- The assent form will be read to the child by either the investigator or you. If desired, the child can choose who will read their assent form for them. If participating in this research study, children will be asked to sign and date in the designated spaces located at the ends of this form

- A questionnaire will then be provided for you to complete.

2. Language evaluation (duration: 15 minutes maximum)

- The investigator will read instructions of the task to the child. Pictures will be shown to the child, and the child will be asked to label items and provide descriptive responses to picture items. Scores obtained by the investigator will be recorded on a score sheet.

3. Language and literacy assessment (duration: 30 minutes maximum)

- Task 1: the child will be asked to point to a picture item that represents the words provided by the investigator.

- Task 2: the investigator will present the child with a description of a picture. The child will be asked to describe similar pictures with similar grammatical features as used by the investigator.

- Task 3: the investigator will present the child with a word, and the child will be asked to eliminate a portion of the word. 
- Task 4: the investigator will read a story to the child. The child will be asked to retell the story presented.

\section{Literacy activity (duration: 15 minutes maximum)}

- Short stories will be read to the child. Following each story, the child will be asked to respond orally or in written form to 7 questions.

Discomforts/Risks: Minimal risks and discomforts will be experienced in this study.

The inconvenience associated with this research study is the time commitment required to participate. This may include the time required to travel to and from the Ryerson University Campus, and the duration of the study session (as outlined in the Procedures section of this document). The cost of travel to and from the Ryerson University Campus is also an inconvenience for participants.

During data collection, child participants may experience discomfort associated with performance test-taker anxiety. The investigator will provide positive and encouraging cues that make it clear to child participants that they are not being academically evaluated and the responses provided are confidential. Additionally, parents/guardians/family members may be present with the child during the language and literacy activities.

Child participants may reveal confidential parent-related or family-related information. This information will be kept confidential by the investigator, and will not be included for analysis in this research study.

Benefits of the Study: There are no direct benefits to the child or parent/guardian/family members for participating in this study.

The findings from this study will inform us about the relationship between language socialization and literacy achievement.

Incentives to Participate: You will have the opportunity to receive an incentive of up to $\$ 30$, depending of level participation in this study. Specifically, participants will be offered $\$ 10$ for completion of the parent questionnaire, $\$ 10$ for the involvement of their child in the study, and $\$ 10$ for focus group participation (optional).

Furthermore, you will be reimbursed for any public transit costs incurred. 
Children will be given a token gift (toy, less than $\$ 5.00$ value) and a certificate of participation for their involvement as a participant in this research study.

Costs for Participation: At present, the cost for participation includes transportation costs associated with visiting the Ryerson University campus. The principle investigator will cover any costs associated with public transportation. This will be a maximum cost of $\$ 6.00$ per participant in the form of Toronto Transit Commission (TTC) tokens. The TTC tokens will be provided by the investigator upon your arrival.

Voluntary Nature of Participation: Participation in this study is voluntary. Your choice of whether or not to participate will not influence your future relations with Ryerson University. If you decide to participate, you are free to withdraw your consent and to stop your participation at any time without penalty or loss of benefits to which you are allowed.

At any particular point in the study, you may refuse to answer any particular question or stop participation altogether. You can choose not to participate or you may withdraw from this study at any time without your choice affecting your relationship with Ryerson University.

Should you choose to withdraw from the study after completion, all your data will be destroyed, paper information will be shredded, and audio files will be excluded. If you choose to withdraw from the study after completion, please contact Nicola Dove via email no later than September $30^{\text {th }}, 2014$. After this date, your data cannot be withdrawn.

Confidentiality: All information obtained from participants will remain confidential. Raw data and identifying participant information will be stored in a confidential manner. Data from each parent/guardian/family member will be connected to the data of the child. Each data set will be coded. Codes and identifiers will be stored separately from the data in a secure location.

All information provided from participants will be stored in locked cabinets and on secure electronic files. We will ensure that only the investigator and supervisor will have access to this information. If the results from this study are published, identifying information of all participants will not be shared.

Consent forms and participant data will be kept for maximum 2 years. After this period, all data will be destroyed, paper information will be shredded, and audio files will be permanently deleted. 
Questions about the Study: If you have any questions about the research study now, please ask. If you have questions later about the research, you may contact Nicola Dove. Please feel free to contact the person listed below at any point during the duration of the study.

\author{
Nicola M. Dove \\ nicola.dove@ryerson.ca \\ 416-979-5000 ext. 7646 (leave a message)
}

If you have questions regarding your rights as a human subject and participant in this study, you may contact the Ryerson University Research Ethics Board for information.

\author{
Research Ethics Board \\ c/o Office of the Vice President, Research and Innovation \\ Ryerson University \\ 350 Victoria Street \\ Toronto, ON M5B 2K3 \\ 416-979-5042
}

Note to Parents: Assent for your child will accompanied by this parental consent form. The investigator will read assent form aloud to the child. If preferred, you may read the assent form aloud to the child. This research will not be undertaken without the informed written consent of the parent(s) or guardian(s) of each child participant, as well as consent from the child.

\title{
Agreement:
}

Your signature below indicates that you have read the information in this agreement and have had a chance to ask any questions you have about the study. Your signature also indicates that you agree to be in the study and have been told that you can change your mind and withdraw your consent to participate at any time. You have been given a copy of this agreement.

You have been told that by signing this consent agreement you are not giving up any of your legal rights.

Are you interested in participating in a focus group at a later point in time? (childcare available)

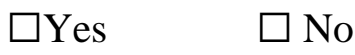


Name of Parent/Guardian (print)

Signature of Parent/Guardian

Name of Investigator (print)

Signature of Investigator
Name of Child (print)

Date

Date 
Appendix C

\section{Assent}

Ryerson University

Hello, my name is Nicola Dove. You Can call me Nicola. I want to tell you about our research study. I would like to know if you want to be in our research study. We want you to ask any questions that you have. You can ask questions any time.

\section{What is a research study?}

$A$ research study is a fun way to learn about something new. We ask questions and then we search for the answers.

\section{Why are we doing this research study?}

We want to know more about speaking and reading for children who are just like you. We want to know how much children like hearing their home language and what this does for children's reading.

\section{Why do we want you to be in this research study?}

We want you to be in our research study because you live in Canada. You also have parents who were born in Jamaica or you were born in Jamaica. You hear your parents speaking their language. We want to know how much you like hearing this and what this does for your reading.

\section{What will happen if I want to be in this research study?} We will ask you to answer some questions and do some talking. You will also listen to some stories and answer some questions.

What will happen if I do not want to be in this research study? That will be OK. If you do not want to be in this research study, tell Nicola. You can say NO at any time. You can choose not to be in 
this study whenever you want.

What will happen if my parents want me to be in this research study, but I don't want to be in this research study?

If your parents say that you can be in this study, but you don't want to be in this study, that will be OK. Tell Nicola. You Can say NO at any time. You can choose not to participate in this study whenever you want.

\section{Could bad things happen if I join this research study?}

We will try our best to make sure that bad things will not happen. Some of the questions might be hard to answer. If you do not want to be asked anymore questions, you can tell me and we will stop.

\section{What else should I know about this research?}

If you do not want to be in this research study, tell Nicola. You Can say NO at any time. You Can even say YES now and NO later on. If you do not want to be in this research study, you do not have to be. If you want to stop, please tell Nicola.

Thank you for reading all about our research study. You Can ask Nicola any questions that you have, at any time. If you want to ask Nicola any questions after today, you can ask your parent/guardian to email her at nicola.dove@ryerson.ca

Do you want to be in our study? Circle one word. 
Write your name below. By writing your name, we can be sure that the answer to the first question came from you, and not from anyone else.

NAME:

DATE:

INVESTIGATOR: 


\title{
Appendix D \\ Consent Agreement \\ Ryerson University
}

\begin{abstract}
Language socialization and literacy achievement: A developmental sociolinguistic investigation of school-aged bidialectal English speakers
\end{abstract}

Dear

Thank you for participating in the first phase of our research. We are now moving to a second phase in which we would like to discuss your experiences in a focus group of parents. Please read the information provided here to determine if this is something that you would be willing to do.

Thank you very much for your consideration.

Investigator: $\quad$ Nicola M. Dove

B.A. (Hons.), C.D.A., Reg. CDAAC, M.A. candidate

Department of Early Childhood Studies

Faculty of Community Services

Ryerson University

Supervisor: $\quad$ Dr. Kathleen Peets

B.A., M. Ed., E.Ed.

Department of Early Childhood Studies

Faculty of Community Services

Ryerson University

Purpose of the Study: I intend to explore the role of language in literacy achievement. I intend to focus my investigation on the English language and literacy development of bidialectical children, specifically children whose initial language exposure was Jamaican Creole.

Description: The first phase of the study was related to children's use of Jamaican Creole and their language and literacy performance. In this focus group, we would like to hear from you and other parents about your experiences around Creole use and the educational system, and your opinions on the use of Creole as it relates to education. The subjects of this focus group will 
include parents, guardians, or family members of Canadian- and foreign-born monodialectical and bidialectical English-speaking children who have attended schools in Canada since Kindergarten and their language of educational instruction was in English.

Procedures: Participants will be asked to sign consent forms prior to participation.

The investigator will facilitate a group discussion. Questions concerning perceptions of their child's abilities to succeed academically, perceived attitudes of educators, and peer interactions will be included in the discussion.

During the group discussion, audiotaping will take place. Participants may request for audiotaping to be temporarily or permanently stopped at any time during the group discussion.

Discomforts/Risks: Minimal risks and discomforts will be experienced in this study.

It is anticipated that not all participants will feel comfortable with sharing their thoughts and opinions in a group discussion setting. To offset this, I will set a positive conversational tone. The will be sure to address each person in the group, and will moderate turn-taking to ensure an equal distribution of participation. I will also remind participants that the information shared in this focus group will remain confidential.

Participants may also experience discomfort as a result of sharing unpleasant memories with a group of individuals. The investigator will provide positive and encouraging cues to the participant during this time.

Benefits of the Study: Participants will not experience any direct benefits from participation in this study.

This focus group will provide you with an opportunity to share your perspective on aspects of your child's language and literacy development within the school.

Incentives to Participate: Adult participants have had the opportunity to receive an incentive of up to $\$ 30$, depending of level participation in this study. So far, you were offered $\$ 10$ for completion of the parent questionnaire, $\$ 10$ for the involvement of their child in the study. You will have the opportunity to receive $\$ 10$ for focus group participation. 
Snacks and drinks will be provided and in addition, the investigator will offer to share a summary of the findings of the overall study.

An undergraduate student in Early Childhood Studies program from Ryerson University will be available on an as-needed basis to care for children during the duration of the focus group.

Costs for Participation: At present, the cost for participation includes transportation costs associated with visiting the Ryerson University campus. The principle investigator will cover any costs associated with public transportation. This will be a maximum cost of $\$ 6.00$ per participant in the form of Toronto Transit Commission (TTC) tokens. The TTC tokens will be provided by the investigator upon your arrival.

Voluntary Nature of Participation: Participation in this study is voluntary. Your choice of whether or not to participate will not influence your future relations with Ryerson University. If you decide to participate, you are free to withdraw your consent and to stop your participation at any time without penalty or loss of benefits to which you are allowed.

At any particular point in the study, you may refuse to answer any particular question or stop participation altogether at any time and without explanation. You can choose not to participate or you may withdraw from this study at any time without your choice affecting your relationship with Ryerson University.

Should you choose to withdraw from the study after completion, all your data will be destroyed, paper information will be shredded, and audio files will be excluded. If you choose to withdraw from the study after completion, please contact Nicola Dove via email no later than December $31^{\text {st }}$, 2014. After this date, your data cannot be withdrawn.

Confidentiality: The investigator will maintain confidentiality of the data and will protect participant identity. However, the investigator cannot ensure that other participants in the focus group will do likewise thus, confidentiality cannot be guaranteed.

Raw data and identifying participant information will be stored in a confidential manner. All information provided from participants will be stored in locked cabinets and on secure electronic files. We will ensure that only the investigator and supervisor will have access to this information. If the results from this study are published, identifying information of all participants will not be shared. 
Consent forms and participant data will be kept for maximum 2 years. After this period, all data will be destroyed, paper information will be shredded, and audio files will be permanently deleted.

Questions about the Study: If you have any questions about the research study now, please ask. If you have questions later about the research, you may contact Nicola Dove. Please feel free to contact the person listed below at any point during the duration of the study.

\title{
Nicola M. Dove \\ nicola.dove@ryerson.ca \\ 416-979-5000 ext. 7646 (leave a message)
}

If you have questions regarding your rights as a human subject and participant in this study, you may contact the Ryerson University Research Ethics Board for information.

\author{
Research Ethics Board \\ c/o Office of the Vice President, Research and Innovation \\ Ryerson University \\ 350 Victoria Street \\ Toronto, ON M5B 2K3 \\ 416-979-5042
}

\section{Agreement:}

Your signature below indicates that you have read the information in this agreement and have had a chance to ask any questions you have about the study. Your signature also indicates that you agree to be in the study and have been told that you can change your mind and withdraw your consent to participate at any time. You have been given a copy of this agreement.

You have been told that by signing this consent agreement you are not giving up any of your legal rights. 
Name (print)

Signature

Date

Name of Investigator (print)

Signature of Investigator

Date 


\title{
Appendix E
}

\author{
Participant Information Form \\ Parent/Caregiver/Family Member Information \\ First Name: \\ Country of Birth: \\ Parish of birth (if applies): \\ If you were raised in a parish/town different than the parish/town of birth, please provide \\ details: \\ Last Name/Initial: \\ Number of years in Canada: \\ Town of birth (if applies):
}

Level of Education (please circle the one that applies):
a) Some high school education
b) Completed high school education
c) Some post-secondary education
d) Completed post-secondary education
e) Some/completed graduate education

Current occupation: 


\section{Child Information}

First Name:

Country of Birth:

Parish of birth (if applies):

Age:
Last Name/Initial:

Number of years in Canada:

Town of birth (if applies):

Indicate the child's current grade level:

Location of child's education (please circle the one that applies):

a) My child has attended all school in Canada/the GTA

b) My child has attended school mostly within Canada, but not in the GTA

c) My child has attended school mostly within North America

d) My child has attended school mostly within the Caribbean, but not in Jamaica

e) My child has attended school mostly in Jamaica 


\section{Language Questionnaire}

\section{INSTRUCTIONS:}

There are 4 sections in this questionnaire: Parent Language Use, Parent language Opinions, Child Language Use, and Child Language Opinions. In each of these sections, there are questions that require that you rate (on the left) each response (on the left) as they apply. Each question asks that you rate your responses on a 5-point scale. Please be sure to double-check these scales, as they vary from section to section. It is important that you do not consult your children when answering the questions related to your child's language use and attitude. Note: Standard English refers to the dialect of English spoken by Canadian speakers. Patois/Patwa refers to the variations of Jamaican Creole spoken by Jamaican speakers. If you have any questions, please feel free to contact Nicola Dove at nicola.dove@ ryerson.ca. Thank you.

\section{PARENT LANGUAGE USE:}

\begin{tabular}{|c|c|c|c|c|c|}
\hline \multicolumn{6}{|c|}{$\begin{array}{l}\text { Please circle the response that applies to the questions below } \\
1=\text { Never, } 2=\text { rarely, } 3=\text { occasionally, } 4=\text { almost all the time, } 5=\text { all the time }\end{array}$} \\
\hline 1. I understand Standard English & 1 & 2 & 3 & 4 & 5 \\
\hline 2. I understand Patois/Patwa & 1 & 2 & 3 & 4 & 5 \\
\hline 3. I speak Standard English at home & 1 & 2 & 3 & 4 & 5 \\
\hline 4. I speak Patois/Patwa at home & 1 & 2 & 3 & 4 & 5 \\
\hline $\begin{array}{l}\text { 5. I speak Standard English to my } \\
\text { child/children }\end{array}$ & 1 & 2 & 3 & 4 & 5 \\
\hline $\begin{array}{l}\text { 6. I speak Patois/Patwa to my } \\
\text { child/children }\end{array}$ & 1 & 2 & 3 & 4 & 5 \\
\hline $\begin{array}{l}\text { 7. I speak Standard English outside the } \\
\text { home }\end{array}$ & 1 & 2 & 3 & 4 & 5 \\
\hline 8. I speak Patois/Patwa outside the home & 1 & 2 & 3 & 4 & 5 \\
\hline
\end{tabular}

Please provide other contexts outside of your home where you speak Patois/Patwa: 
PARENT LANGUAGE OPINIONS:

\begin{tabular}{|c|c|c|c|c|c|}
\hline \multicolumn{6}{|c|}{$\begin{array}{c}1=\text { strongly disagree, } 2=\text { disagree, } 3=\text { neither agree/disagree, } 4=\text { agree, } 5=\text { strongly } \\
\text { agree } \\
\text { Please circle the response that applies to the questions below: When you hear a person } \\
\text { speaking Patois/Patwa and another person speaking Standard English... }\end{array}$} \\
\hline $\begin{array}{l}\text { 1. You think the person speaking } \\
\text { Patois/Patwa is more intelligent }\end{array}$ & 1 & 2 & 3 & 4 & 5 \\
\hline $\begin{array}{l}\text { 2. You think the person speaking Standard } \\
\text { English is more intelligent }\end{array}$ & 1 & 2 & 3 & 4 & 5 \\
\hline $\begin{array}{l}\text { 3. You think the person speaking } \\
\text { Patois/Patwa is more honest }\end{array}$ & 1 & 2 & 3 & 4 & 5 \\
\hline $\begin{array}{l}\text { 4. You think the person speaking Standard } \\
\text { English is more honest }\end{array}$ & 1 & 2 & 3 & 4 & 5 \\
\hline $\begin{array}{l}\text { You think the person speaking } \\
\text { Patois/Patwa is more educated }\end{array}$ & 1 & 2 & 3 & 4 & 5 \\
\hline $\begin{array}{l}\text { 6. You think the person speaking Standard } \\
\text { English is more educated }\end{array}$ & 1 & 2 & 3 & 4 & 5 \\
\hline $\begin{array}{l}\text { 7. You think the person speaking } \\
\text { Patois/Patwa is more friendly }\end{array}$ & 1 & 2 & 3 & 4 & 5 \\
\hline $\begin{array}{l}\text { 8. You think the person speaking Standard } \\
\text { English is more friendly }\end{array}$ & 1 & 2 & 3 & 4 & 5 \\
\hline $\begin{array}{l}\text { 9. You think the person speaking } \\
\text { Patois/Patwa has more money }\end{array}$ & 1 & 2 & 3 & 4 & 5 \\
\hline $\begin{array}{l}\text { 10. You think the person speaking Standard } \\
\text { English has more money }\end{array}$ & 1 & 2 & 3 & 4 & 5 \\
\hline $\begin{array}{l}\text { 11. You think the person speaking } \\
\text { Patois/Patwa is more helpful }\end{array}$ & 1 & 2 & 3 & 4 & 5 \\
\hline $\begin{array}{l}\text { 12. You think the person speaking Standard } \\
\text { English is more helpful }\end{array}$ & 1 & 2 & 3 & 4 & 5 \\
\hline
\end{tabular}


CHILD LANGUAGE USE:

\begin{tabular}{|c|c|c|c|c|c|}
\hline \multicolumn{6}{|c|}{$\begin{array}{l}\text { Please circle the response that applies to the questions below } \\
1=\text { Never, } 2=\text { rarely, } 3=\text { occasionally, } 4=\text { almost all the time, } 5=\text { all the time }\end{array}$} \\
\hline $\begin{array}{l}\text { 1. Your child understands Standard } \\
\text { English }\end{array}$ & 1 & 2 & 3 & 4 & 5 \\
\hline 2. Your child understands Patois/Patwa & 1 & 2 & 3 & 4 & 5 \\
\hline $\begin{array}{l}\text { 3. Your child speaks Standard English at } \\
\text { home }\end{array}$ & 1 & 2 & 3 & 4 & 5 \\
\hline $\begin{array}{l}\text { 4. Your child speaks Patois/Patwa at } \\
\text { home }\end{array}$ & 1 & 2 & 3 & 4 & 5 \\
\hline $\begin{array}{l}\text { 5. Your child speaks Standard English to } \\
\text { you }\end{array}$ & 1 & 2 & 3 & 4 & 5 \\
\hline 6. Your child speaks Patois/Patwa to you & 1 & 2 & 3 & 4 & 5 \\
\hline $\begin{array}{l}\text { 7. Your child speaks Standard English } \\
\text { outside the home }\end{array}$ & 1 & 2 & 3 & 4 & 5 \\
\hline $\begin{array}{l}\text { 8. Your child speaks Patois/Patwa outside } \\
\text { the home }\end{array}$ & 1 & 2 & 3 & 4 & 5 \\
\hline $\begin{array}{l}\text { 9. Your child speaks Standard English at } \\
\text { school }\end{array}$ & 1 & 2 & 3 & 4 & 5 \\
\hline $\begin{array}{l}\text { 10. Your child speaks Patois/Patwa at } \\
\text { school }\end{array}$ & 1 & 2 & 3 & 4 & 5 \\
\hline
\end{tabular}

Please provide other contexts outside of your home where your child speaks Patois/Patwa: 
CHILD LANGUAGE OPINIONS:

\begin{tabular}{|c|c|c|c|c|c|}
\hline \multicolumn{6}{|c|}{$\begin{array}{c}1=\text { strongly disagree, } 2=\text { disagree, } 3=\text { neither agree/disagree, } 4=\text { agree, } 5=\text { strongly } \\
\text { agree } \\
\text { Please circle the response that applies to the questions below: When your child hears a } \\
\text { person speaking Patois/Patwa and another person speaking Standard English... }\end{array}$} \\
\hline $\begin{array}{l}\text { 1. He/She thinks the person speaking } \\
\text { Patois/Patwa is more intelligent }\end{array}$ & 1 & 2 & 3 & 4 & 5 \\
\hline $\begin{array}{l}\text { 2. He/She thinks the person speaking } \\
\text { Standard English is more intelligent }\end{array}$ & 1 & 2 & 3 & 4 & 5 \\
\hline $\begin{array}{l}\text { 3. He/She thinks the person speaking } \\
\text { Patois/Patwa is more honest }\end{array}$ & 1 & 2 & 3 & 4 & 5 \\
\hline $\begin{array}{l}\text { 4. He/She thinks the person speaking } \\
\text { Standard English is more honest }\end{array}$ & 1 & 2 & 3 & 4 & 5 \\
\hline $\begin{array}{l}\text { 5. He/She thinks the person speaking } \\
\text { Patois/Patwa is more educated }\end{array}$ & 1 & 2 & 3 & 4 & 5 \\
\hline $\begin{array}{l}\text { 6. He/She thinks the person speaking } \\
\text { Standard English is more educated }\end{array}$ & 1 & 2 & 3 & 4 & 5 \\
\hline $\begin{array}{l}\text { 7. He/She thinks the person speaking } \\
\text { Patois/Patwa is more friendly }\end{array}$ & 1 & 2 & 3 & 4 & 5 \\
\hline $\begin{array}{l}\text { 8. He/She thinks the person speaking } \\
\text { Standard English is more friendly }\end{array}$ & 1 & 2 & 3 & 4 & 5 \\
\hline $\begin{array}{l}\text { 9. He/She thinks the person speaking } \\
\text { Patois/Patwa has more money }\end{array}$ & 1 & 2 & 3 & 4 & 5 \\
\hline $\begin{array}{l}\text { 10. He/She thinks the person speaking } \\
\text { Standard English has more money }\end{array}$ & 1 & 2 & 3 & 4 & 5 \\
\hline $\begin{array}{l}\text { 11. He/She thinks the person speaking } \\
\text { Patois/Patwa is more helpful }\end{array}$ & 1 & 2 & 3 & 4 & 5 \\
\hline $\begin{array}{l}\text { 12. He/She thinks the person speaking } \\
\text { Standard English is more helpful }\end{array}$ & 1 & 2 & 3 & 4 & 5 \\
\hline
\end{tabular}




\section{Appendix F \\ Matched-Guise Test}

Participant \#:

Date:

Notes: 


\section{Do you think the man reading this story is smart?}

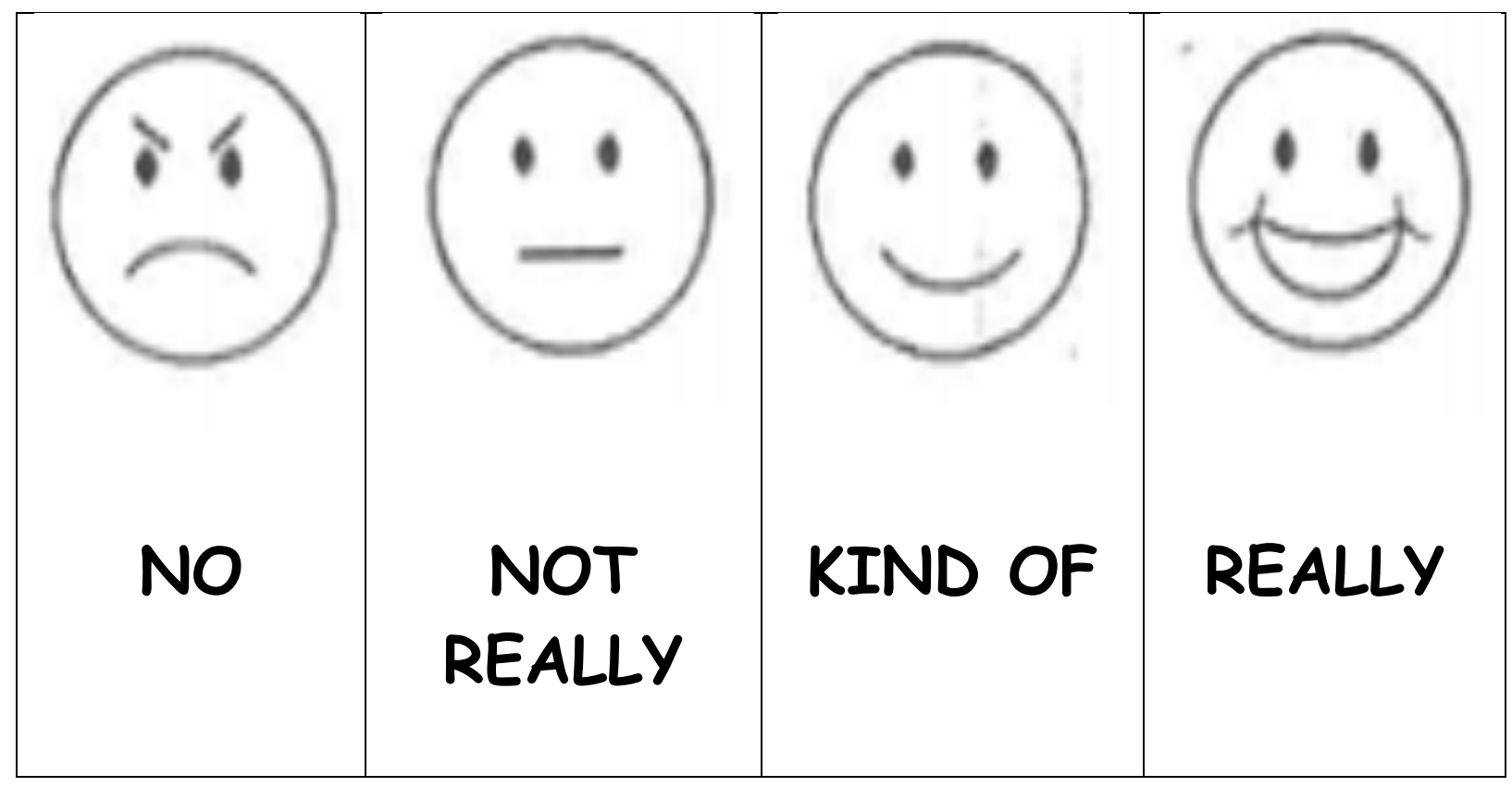


2. Do you think the man reading this story is kind?

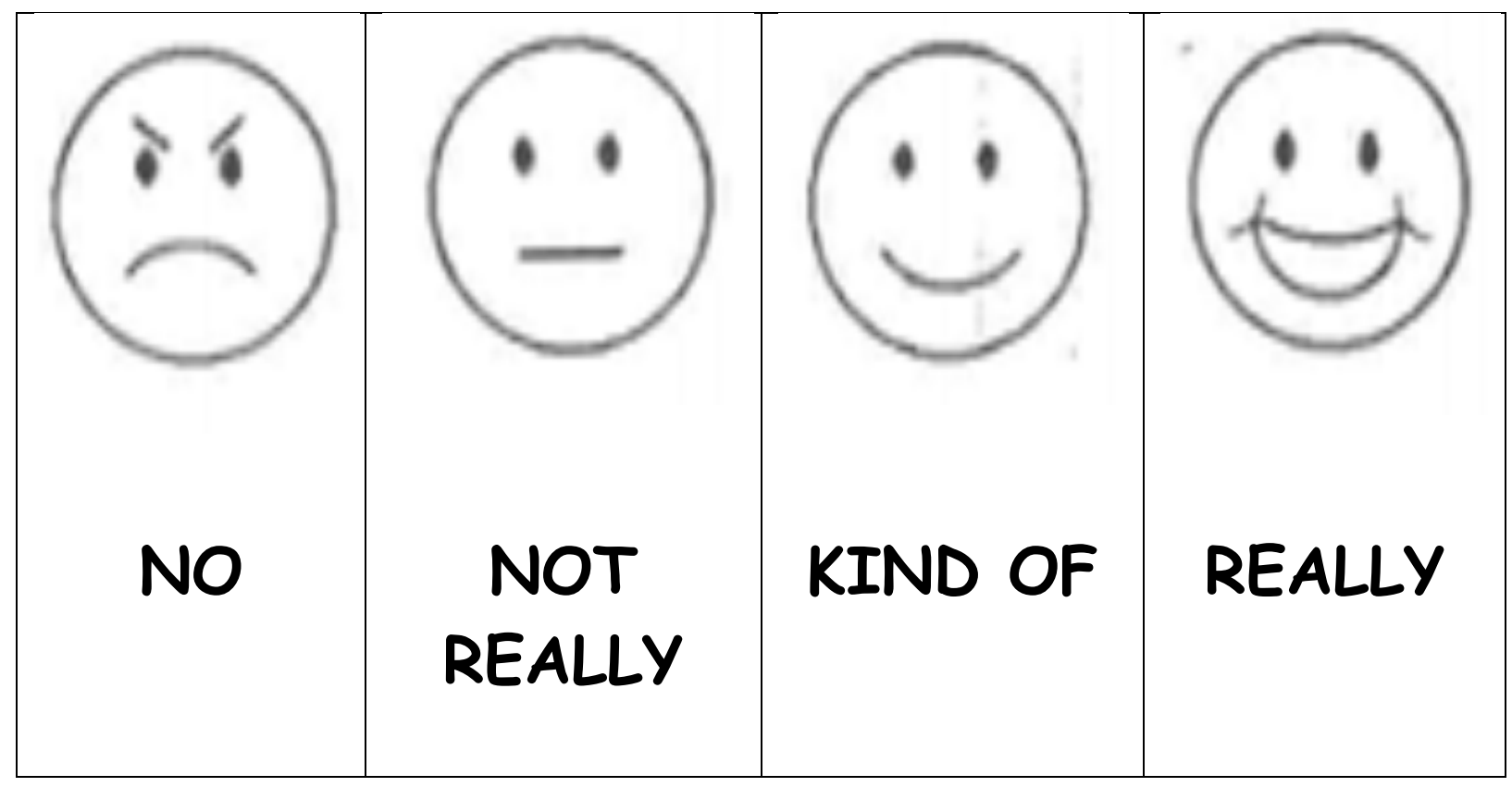


3. Do you think the man reading this story is nice?

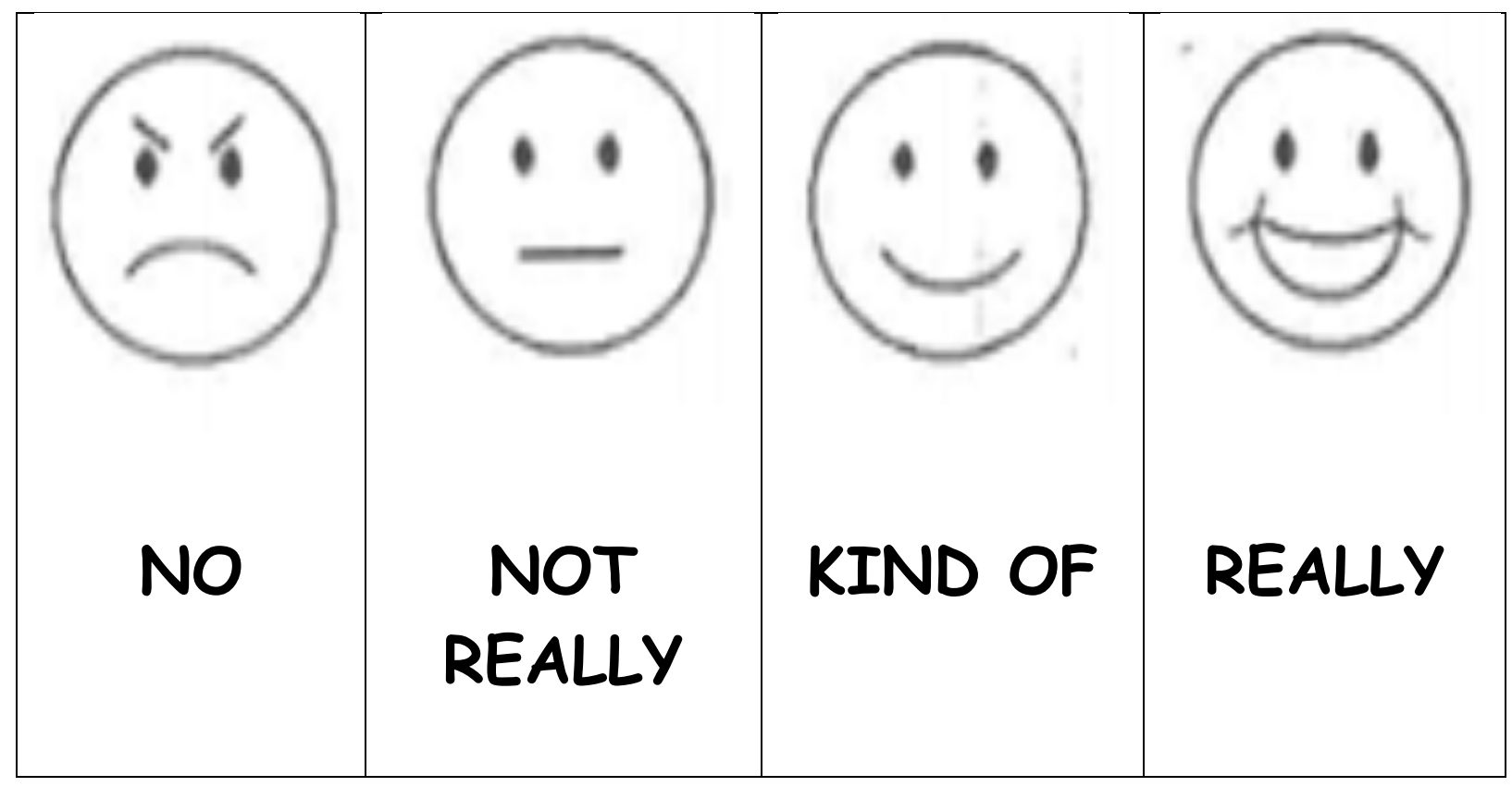




\section{Do you think the man reading this story is friendly?}

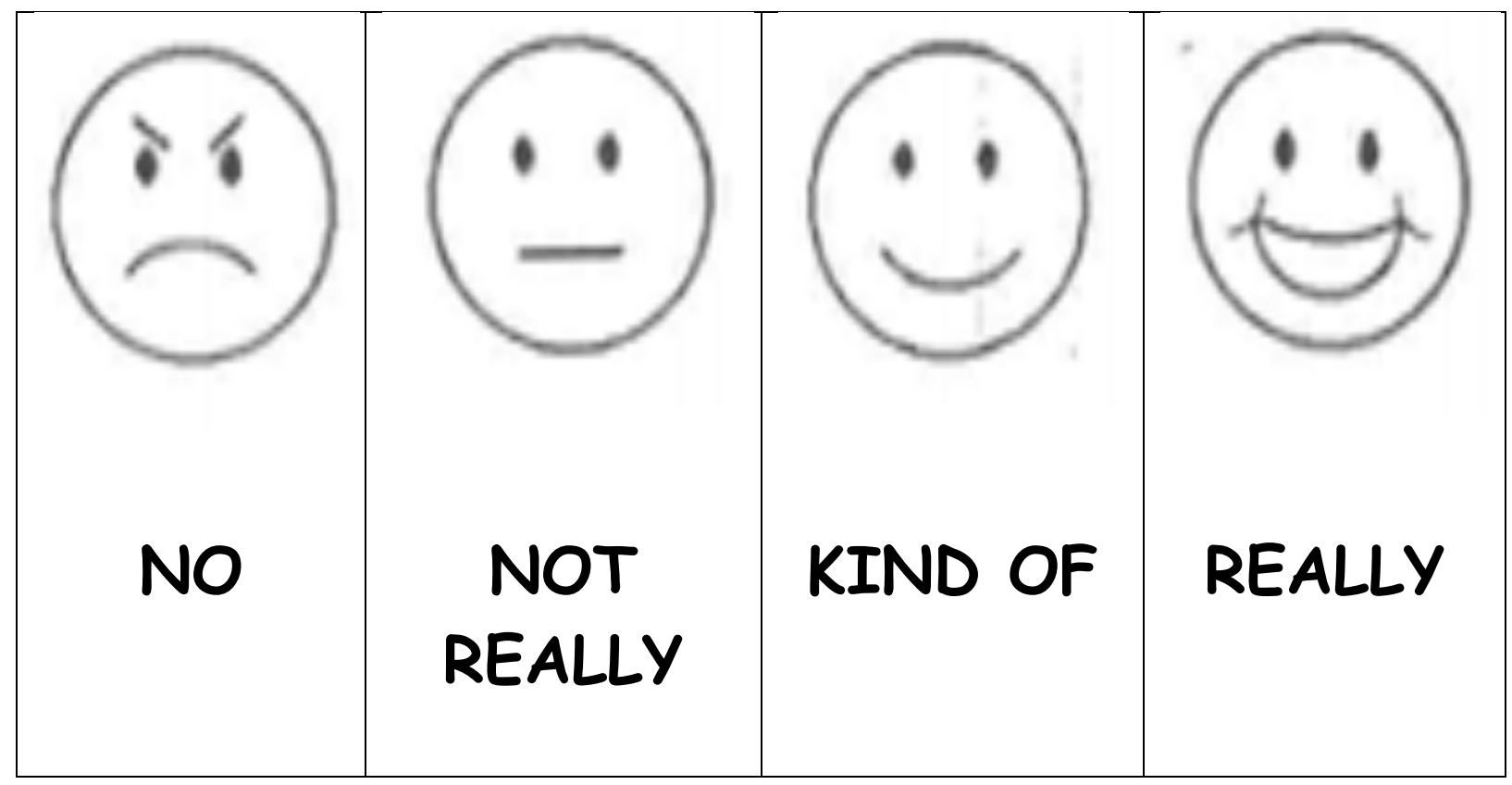




\section{Do you think the man reading this story is funny?}

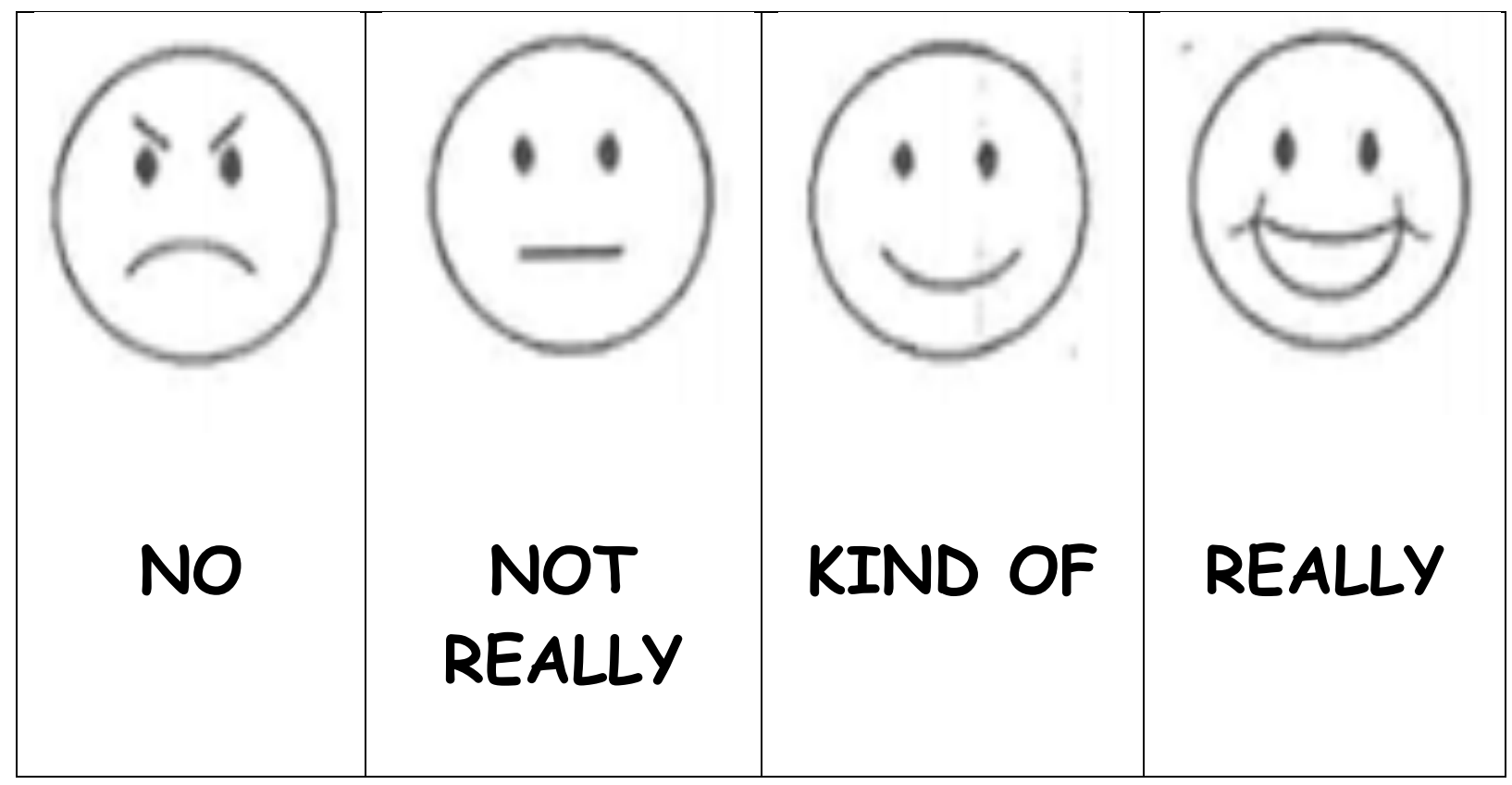


6. Do you think the man reading this story is polite?

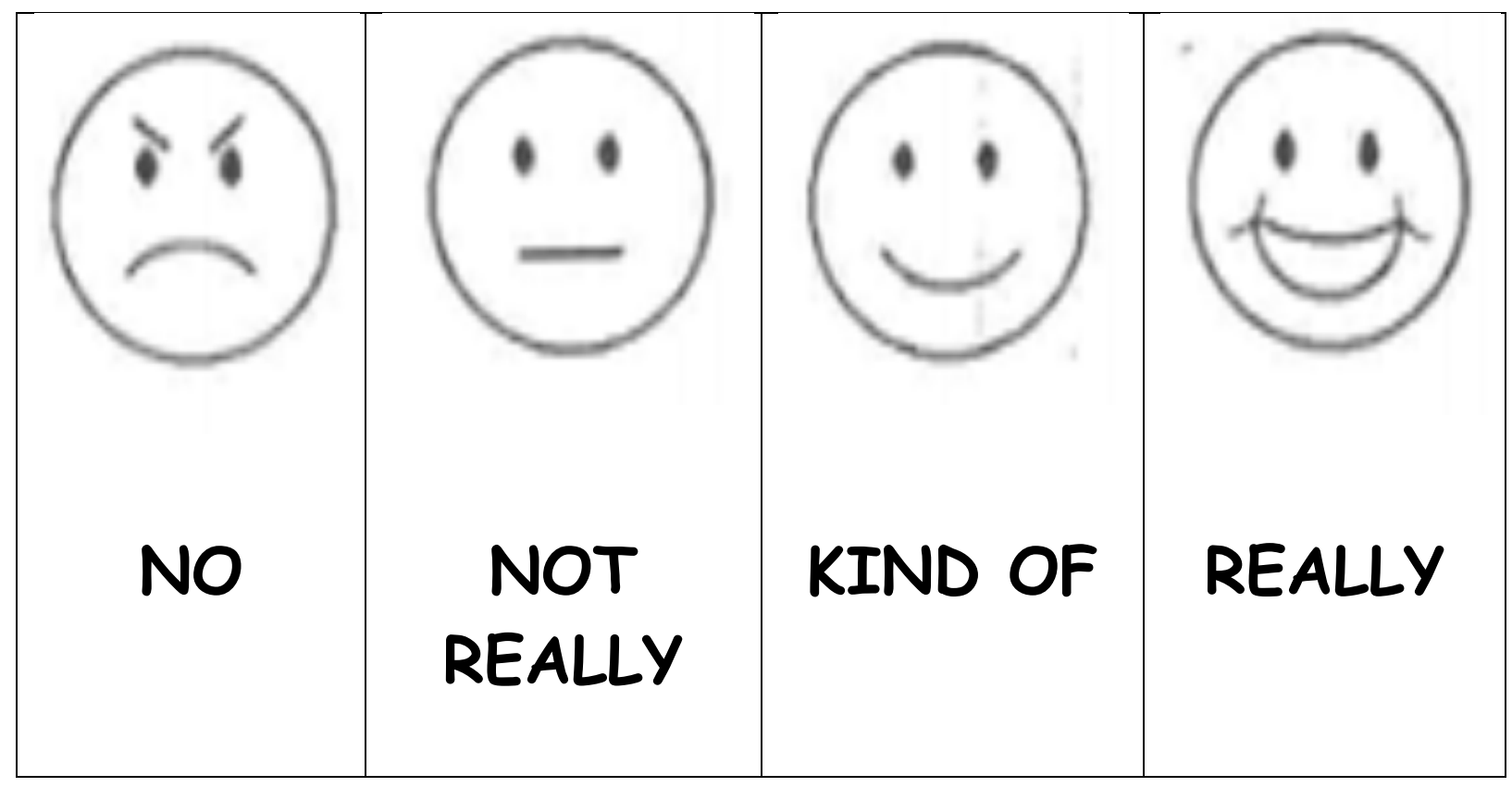




\section{Do you think the man reading this story works hard?}

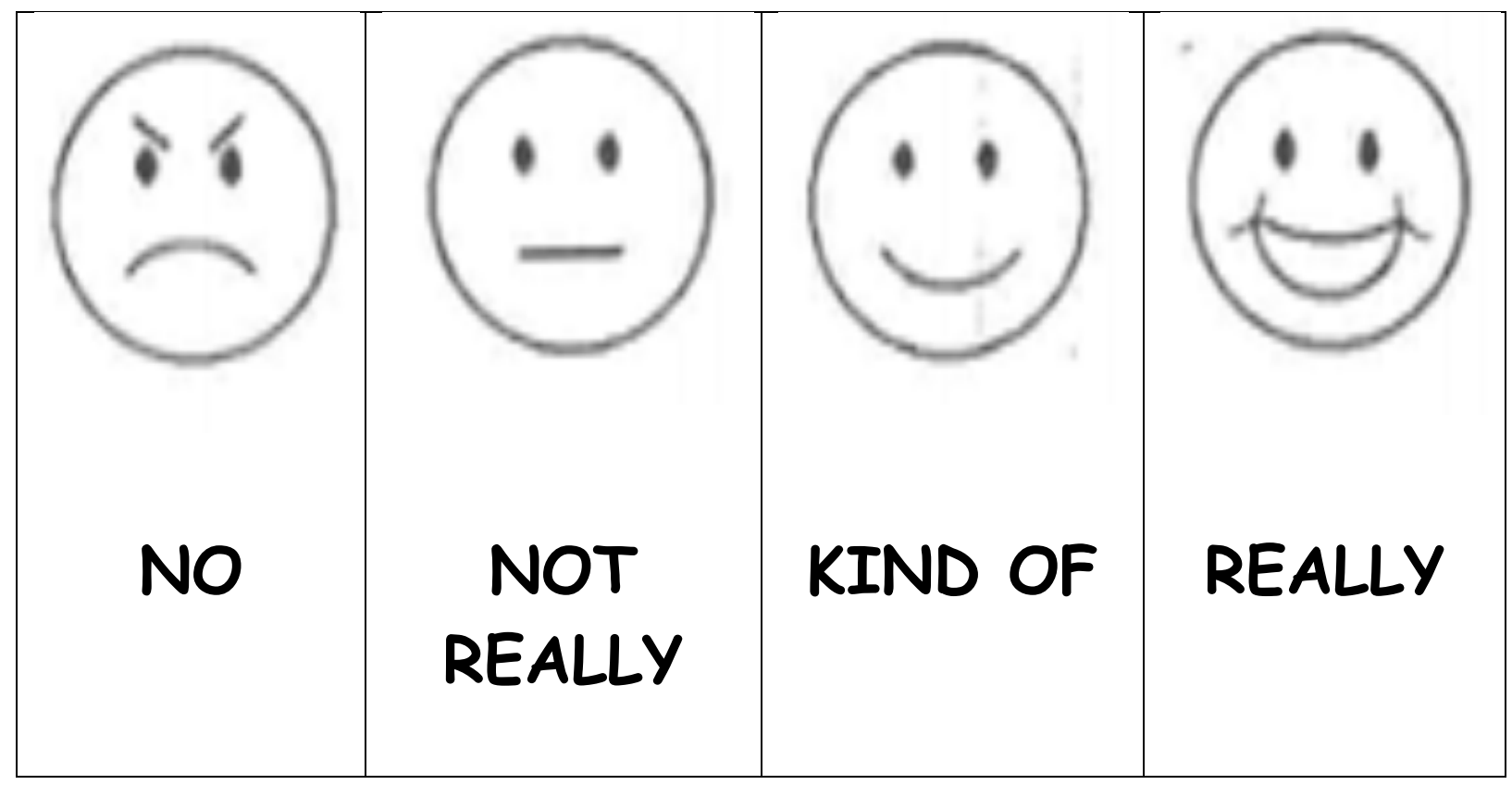




\title{
Appendix G
}

\section{Research Study Information Sheet}

\author{
Ryerson University
}

\section{Language socialization and literacy achievement: A developmental sociolinguistic investigation of school-aged bidialectal English speakers}

You and your child are being invited to participate in a research study that investigates aspects of language socialization and literacy achievement. This document provides information about this research study. You are invited to ask as many questions as needed prior to making a decision about participating in this study.

Investigator: $\quad$ Nicola M. Dove

$$
\begin{aligned}
& \text { B.A. (Hons.), C.D.A., Reg. CDAAC, M.A. candidate } \\
& \text { Department of Early Childhood Studies } \\
& \text { Faculty of Community Services } \\
& \text { Ryerson University }
\end{aligned}
$$

Supervisor: $\quad$ Dr. Kathleen Peets

B.A., M. Ed., E.Ed.

Department of Early Childhood Studies

Faculty of Community Services

Ryerson University

Purpose of the Study: I intend to explore the role of language in the literacy achievement. I intend to focus my investigation on the English language and literacy development of bidialectal children, specifically children whose initial language exposure was Jamaican Creole.

Description of the Study: This study will explore children's use of Jamaican Creole and their language and literacy achievement. More specifically, we are interested in the impact of dialect and cultural identity on pre-literacy skills development. I aim to recruit a total of 60 participants; 30 child participants between the ages of 5 and 6 years, and their parents/guardians/family members from Jamaican Creole-speaking families within the Greater Toronto Area.

Procedures: The parents/guardian/family members of the children will be asked to complete a questionnaire containing single-select 5-point scale questions and open-ended questions. A subset of the parents/guardian/family members in this study will participate in a focus group. Participation in this focus group is voluntary.

You will sign the consent forms, and you or the investigator can read the assent document to the child participants. You will provide responses to questionnaire. The child will engage in the language evaluation, language and literacy assessment, and literacy activity. Breaks will be provided at your request or the request of the child. 
Detailed information and the expected duration of each procedure in a session with in this study are as follows:

- Consent and assent provision and questionnaire provided (duration: as long as needed)

- You will be asked to read this consent form in its entirety. If participating in this research study, you will be asked to sign and date in the designated spaces located at the ends of this form.

- The assent form will be read to the child by either the investigator or you. If desired, the child can choose who will read their assent form for them. If participating in this research study, children will be asked to sign and date in the designated spaces located at the ends of this form

- A questionnaire will then be provided for you to complete.

- Language evaluation (duration: 15 minutes maximum)

- The investigator will read instructions of the task to the child. Pictures will be shown to the child, and the child will be asked to label items and provide descriptive responses to picture items. Scores obtained by the investigator will be recorded on a score sheet.

3. Language and literacy assessment (duration: 30 minutes maximum)

- Task 1: the child will be asked to point to a picture item that represents the words provided by the investigator.

- Task 2: the investigator will present the child with a description of a picture. The child will be asked to describe similar pictures with similar grammatical features as used by the investigator.

- Task 3: the investigator will present the child with a word, and the child will be asked to eliminate a portion of the word.

- Task 4: the investigator will read a story to the child. The child will be asked to retell the story presented.

4. Literacy activity (duration: 15 minutes maximum)

- Short stories will be read to the child. Following each story, the child will be asked to respond orally or in written form to 7 questions.

Discomforts/Risks: Minimal risks and discomforts will be experienced in this study.

During data collection, child participants may experience discomfort associated with performance anxiety. The investigator will provide positive and encouraging cues that make it clear to child participants that they are not being academically evaluated and the responses provided are confidential. Additionally, parents/guardians/family members may be present with the child during the language and literacy activities.

Child participants may reveal confidential parent-related or family-related information. This information will be kept confidential by the investigator, and will not be included for analysis in this research study. 
For participants who choose to be a part of the focus group, it is anticipated that not all participants will feel comfortable with sharing their thoughts and opinions in a group discussion setting. To offset this, I will set a positive conversational tone. The will be sure to address each person in the group, and will moderate turn-taking to ensure an equal distribution of participation. I will also remind participants that the information shared in this focus group will remain confidential.

Participants may also experience discomfort as a result of sharing unpleasant memories with a group of individuals. The investigator will provide positive and encouraging cues to the participant during this time.

Benefits of the Study: There are no direct benefits to the child or parent/guardian/family members for participating in this study.

The findings from this study will inform us about the relationship between language socialization and literacy achievement.

For participants who choose to partake in a focus group, this research will provide parents/guardian/family members with an opportunity to share their perspectives on aspects of their child's language and literacy development within the school.

Incentives to Participate: Adult participants will have the opportunity to receive an incentive of up to $\$ 30$, depending of level participation in this study. Specifically, you will be offered $\$ 10$ for completion of the parent questionnaire, $\$ 10$ for the involvement of their child in the study, and $\$ 10$ for focus group participation (optional).

Furthermore, you will be reimbursed for any public transit costs incurred ( $\$ 6.00$ in the form of tokens).

Children will be given a token gift (toy, less than $\$ 5.00$ value) and a certificate of participation for their involvement as a participant in this research study.

Flexible scheduling arrangements will be offered to all participants.

For those who choose to be part of the focus group, snacks and drinks will be provided and in addition, the investigator will offer to share a summary of the findings of the overall study.

An undergraduate student in Early Childhood Studies from Ryerson University will be available on an as-needed basis to care for siblings who are not part of the research study. Additionally, an undergraduate student in Early Childhood Studies program from Ryerson University will be available on an as-needed basis to care for children during the duration of the focus group. 
Voluntary Nature of Participation: Participation in this study is voluntary. Participants will not be paid to participate in this study. Your choice of whether or not to participate will not influence your future relations with Ryerson University. If you decide to participate, you are free to withdraw your consent and to stop your participation at any time without penalty or loss of benefits to which you are allowed.

At any particular point in the study, you may refuse to answer any particular question or stop participation altogether. You can choose not to participate or you may withdraw from this study at any time without your choice affecting your relationship with Ryerson University.

Note to Parents: Assent for child participants accompanied by parental consent form, which the investigator will read aloud to the child. This research will not be undertaken without the informed written consent of the parent(s) or guardian(s) of each child participant.

Thank you for your interest in this research study!

If you have any additional questions, please feel free to contact Nicola Dove by email at nicola.dove@ ryerson.ca or by phone at 416-979-5000 ext. 7646 (leave a message). I look forward to hearing from you again. 


\title{
Appendix $\mathbf{H}$
}

\section{Focus Group Script \\ Ryerson University}

\author{
Language socialization and literacy achievement: A developmental sociolinguistic \\ investigation of school-aged bidialectal English speakers
}

\section{Opening}

Prior to beginning the focus group, rapport will be established with members by greeting and engaging in conversations unrelated to topics.

I will introduce the focus group discussion by stating the following:

Hello everyone, thank you for taking the time to be a part of this focus group. The opinions expressed in this focus group will remain confidential. The purpose of this focus group is to get your perspectives on language attitudes regarding Jamaican Creole (Patois) as they relate to your child's education. Everything you say here will be kept anonymous and seen only by myself and my academic advisor. Small segments or quotes may be used anonymously in the research paper that I write, and may be published in an academic journal, always maintaining full confidentiality. Your opinions will be treated in confidence among the investigators of this project for the purpose of perceptions and language attitudes in relation to academic performance. All responses provided will remain anonymous.

I will ensure that the participants understand the nature of this focus group by providing the purpose and motivation behind this discussion. I will also share other details concerning the expected time, and will address any concerns the participants may have prior to the discussion. I will state the following:

I would like to ask you some questions about your child's language and literacy development. I am interested in any thoughts you have about language and literacy in school, and if you think success in these areas is affected by the use of Jamaican Creole or not.

To start the discussion, I will say:

Thank you, again for taking the time to talk about your child's experiences in education and I want you to feel completely comfortable to say whatever is on your mind - there are no right or wrong opinions. This is a safe space, and anything said will remain confidential and anonymous.

\section{Body}


The following questions are the topics of focus for this discussion, and the questions that will be used to guide the discussion.

\section{Topic A: Language Use}

1. Do you speak Jamaican Creole at home with your child?

2. Why did you choose to speak/not speak Jamaican Creole with your child?

3. Does your child speak Jamaican Creole at home as well?

4. What were your reasons for teaching your child how to speak (and not just simply understand) Jamaican Creole?

5. What were your reasons for not teaching your child how to speak Jamaican Creole?

6. Other than home, where does your child speak Jamaican Creole?

7. Why did you choose to speak/not speak Jamaican Creole with your child?

8. Is your child allowed to use Jamaican Creole with their non-Jamaican friends? If your child does not speak Jamaican Creole, would you allow your child to use Jamaican Creole with their non-Jamaican friends if they could? Why?

9. Do you think it is appropriate for your child to speak Jamaican Creole at school?

10. Do you think it is appropriate for your child to speak Jamaican Creole in the classroom?

\section{Topic B: Perceptions of children's ability to succeed academically}

1. Do you believe that your child's language or language background has any relation to his/her academic performance?

2. Do you feel that your child's language or language background is having a positive impact on his/her success in school?

3. Do you feel that your child's language or language background is having a negative impact on his/her success in school?

4. Do you think your child's academic efforts will be perceived positively due to their language or cultural background?

5. Do you think your child's academic efforts will be perceived negatively due to their language or cultural background?

6. Should Jamaican Creole be incorporated into the classroom activities?

7. If Jamaican Creole were incorporated into the classroom activities, do you feel that this would help or hurt your child's academic performance?

\section{Topic C: Perceptions of educators' attitudes}

1. Have any of your child's teachers discussed any problems or difficulties that your child may have with language? What were they, specifically?

2. Do you feel that your child has been treated differently, positively or negatively, by teacher(s) due to his/her language or cultural background in comparison students from other cultural or language backgrounds?

3. Have you felt that you were treated differently, positively or negatively, by your child's teacher(s) due to your language or cultural background in comparison parents from other cultural or language backgrounds? 
During the discussion, participants will be encourages to expand on yes/no responses. Follow-up questions will be posed concerning examples or further explanation.

\section{Closing}

In closing, the researcher will thank the participants for their time. The following will be said:

Thank you for taking the time to be a part of this focus group. The information provided will be valuable to my research study. Before ending this session, are there any questions of concerns that you may have? Please feel free to express your questions and concerns to me via email at nicola.dove@ryerson.ca. Thank you, again. Have a great evening everyone. 


\section{Appendix I}

\section{Inclusion/Exclusion Checklist \\ Ryerson University}

\begin{tabular}{|l|l|l|}
\hline Questions & \multicolumn{2}{l|}{ Responses } \\
\cline { 2 - 3 } & Yes & No \\
\hline 1. Do you and your family currently live in the Greater Toronto Area (GTA)? & & \\
\hline 2. Was your child born in Canada? & & \\
\hline 3. Was your child born in Jamaica? If yes, indicate age that the child came to Canada: & & \\
\hline 4. Do you speak Jamaican Creole/Patois/Patwa? & & \\
\hline 5. Do you speak Jamaican Creole/Patois/Patwa to your child (frequently/infrequently)? & & \\
\hline 6. Does your child speak Jamaican Creole/Patois/Patwa? & & \\
\hline 7. Does your child understand Jamaican Creole/Patois/Patwa? & & \\
\hline 8. Is your child between the ages of 5 and 6 years? & & \\
\hline 9. Does your child presently attend school in Canada? & & \\
\hline 10. Has your child received educational instruction in English since Kindergarten? & & \\
\hline $\begin{array}{l}\text { 11. Has your child experienced any present of previous difficulties with language? (ie: } \\
\text { "late talker") }\end{array}$ & & \\
\hline
\end{tabular}




\section{Appendix J}

The following chart was retrieved from First Years Professional Development (2011) at the University of North Carolina-Chapel Hill Division of Speech and Hearing Sciences.

Presented in the chart are patterns of initial language acquisition (L1) for children according to the acquisition of sounds. This chart outlines the order in which each sound is acquired (vertically displayed in graph) and the expected age range by which each sound is acquired (horizontal displayed in graph). It is important to note that this chart is a general guideline used in the field of speech and language sciences.

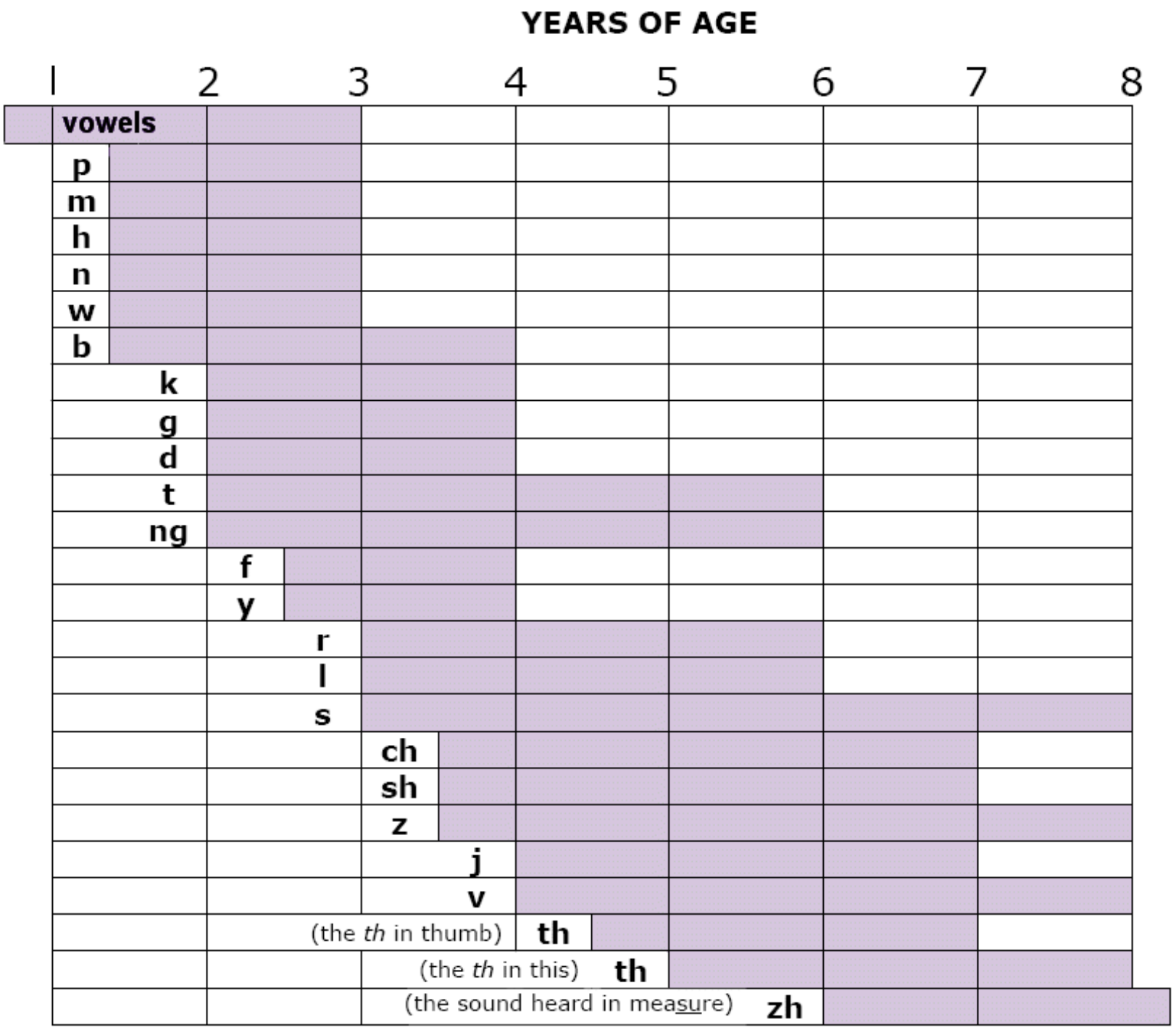




\section{Appendix K}

\section{Interview with Ann}

Date of interview: August $11^{\text {th }}, 2014$

Note: For the purposes of maintaining anonymity and protecting the privacy of all participants, pseudonyms replaced all participant names in reports of the data.

Topic A: Language Use

Investigator: Okay. So the first question is: Do you speak Jamaican Creole or Patois at home with your child?

Ann: On occasion, yes.

Investigator: $\quad$ Okay, and why did you choose to speak it with your child?

Ann: It's just something that I grew up with so it's almost like a force of habit so at home my mom spoke patois to me and I've just grown up around it so I end up speaking it.[a]

Investigator: $\quad$ Okay. Does your child speak Patois at home as well?

Ann: $\quad$ Not often. She will say a few words but she doesn't speak it often.[b]

Investigator: Okay. What were your reasons for teaching your child how to speak Patois and not just simply understand Patois?

Ann: Because that is my heritage[c]. It's something that she hears from other family members so she can understand it and she can understand when other people who are in the family are around and they're speaking[d] so it's almost like a tradition I guess.

Investigator: Okay. Other than home, where does your child speak Jamaican Creole?

Ann: $\quad$ That's just it. She only speak a few words at home.[e]

Investigator: Okay, and would you say that's because there's a lack of maybe

Jamaicans in her outside circle or there's no opportunities?

Ann: It's mostly the lack of friends who... at school who speak Patois as well[f].

Investigator: Okay, Okay. Is your child allowed to use Patois with their non-Jamaican friends, if she chose to?

Ann: If she's speaking in a playground, [g] I don't see a problem with it.

Investigator: Why don't you see a problem with it?

Ann: As long as she's... it's not as if it's rude[h] or... it's the same as the way there are some people of other heritage, let's just say people who can speak a different language who speak it amongst their peers outside of the home who share the same nationality or who share the same heritage and as long as it is not offending anyone else or they're not doing it in a way so that other people can't understand what they're saying around them, I don't see a problem with it. [i]

Investigator:

Okay, do you think it is appropriate for your child to speak Jamaican

Creole at school?

Ann:

Not when she's in class, I don't think it's appropriate[j][k].

Investigator:

Oh you don't think it's appropriate in the classroom? 
Ann: $\quad$ Yes.

Investigator: What about outside the classroom though? And any other school environment outside the classroom?

Ann: I think, I don't see any problem with it. As long as it's not offensive[1]. It's not like she would ever use any rude words or inappropriate words. It's just speaking in a different dialect, so I don't see a problem if she were to use it on the playground.

Investigator: And you said you don't think it's appropriate for the classroom?

Ann: $\quad$ No.

Investigator: Why not?

Ann: If they are teaching them how to speak in English and she's learning how to write in certain English, just so that it doesn't come out it in any of her... especially at this age, $i$ think just for them to continue to develop literature in the English language, I think it would be better for her not to do it in the classroom. [m]

Topic B: Perceptions of children's ability to succeed academically

Investigator: Okay. Do you believe that your child's language or language background has any relation to her academic performance?

Ann: No.

Investigator: Could you elaborate on that?

Ann: $\quad$ She does extremely well in her language components in school. She's actually exceed the outcome in that area so I definitely don't see any type of barrier that's been placed.

Investigator: $\quad$ So you feel that it may have had a positive impact on her academic performance in school, possibly?

Ann: $\quad$ Well, yeah, if anything it would be a positive because if she's exceeding the outcome then I'm not sure exactly as to what it is. I mean i know she does a lot of talking outside of school and inside of school so I'm not sure what the contributing factor is but the fact that she is exceeding the outcome in that area, that could very well have something to do with it.

Investigator: What about her overall success in school... Do you feel that her language or language background has a positive or negative impact on her success in school?

Ann: $\quad$ Yeah, definitely. I think not just her but just even any other different type of language that somebody may speak at home or something that has recognizing 2 different... whether[n] it's languages which is ways to say something or whether it's just even a different dialect and still be able to perform all the work that they have at school and for them to be able to differentiate between the two and exactly what they need to put down on paper not just say, i think it's definitely a positive.

Investigator: Do you think your child's academic efforts will be perceived positively due to their language or cultural background?

Ann: $\quad$ I don't know if that is what people would attribute it to, but there isn't very many studies or any testing really that would be able to attribute her dialect at home or her having a different language to her academic success, but I personally just think that whenever a child is able to do more than one thing and they're still able to let's just say give whatever it is that they need to give for their school work and differentiate what they do at school from what they do at home, then I think it's always a positive to be able to have that sort of social skill that 
even to allow them to...especially in such a multicultural society, i mean i think it's definitely a positive.

Investigator: Do you think your child's academic efforts will ever be perceived negatively due to their language or cultural background?

Ann: If she wasn't doing well, I think... I could see it being perceived by other as being a negative attribute to her not doing well in school[o].

Investigator: Now earlier you said that you don't think it would be appropriate for Patois to be incorporated in the classroom or for your child to use Patois in the classroom, but do you feel that it's appropriate for Patois to be incorporated in classroom activities?

Ann: Can you elaborate on that?

Investigator: $\quad$ Like maybe, if there was a language activity for English class, for example, and the teacher decided, "okay, to be representative of the different cultures present in the classroom, let me incorporate different languages in this specific activity"... So you've got Urdu, French, and Jamaican Patois... would it be appropriate? Should it be incorporated in classroom activities?

Ann: $\quad$ I think it would be definitely... I'm an advocate when it comes to exploring different cultures in the classroom, especially because Canada is so[p] multicultural so yeah if there was an activity, I think that would be great to get to experience different cultures and I think that may also take away some of the stigma associate with it if they did more things like that to show that it's not a negative thing... people who speak Patois or people who speak Chinese or whatever it may be.

Investigator: If Jamaican Creole were incorporated into the classroom activities, do you feel that this would help or hurt your child's academic performance?

Ann: $\quad$ I don't think it would do anything either way, just because she is already exposed to it. I could see it more serving a purpose for the people who are not exposed to it, so it would break the stigma, but I don't see it having an effect on her because she's already familiar with it. She's already close to it.

\section{Topic C: Perceptions of educators' attitudes}

Investigator: Have any of your child's teachers discussed any problems or difficulties that your child may have with language? You were saying that your child does well in language, but has there ever been any discussion about problems or any difficulties ever with any teachers Ann:

Well, they always say that she talks too much, but not any difficulties per se but very vocal.

Investigator: Do you feel that your child has been treated differently, positively or negatively, by teacher(s) due to his/her language or cultural background in comparison students from other cultural or language backgrounds?

Ann: $\quad$ For sure[q]. Not at her current school, but I had to remove her from the school she was at last year based on the way she was being treated because of the fact that she was Black and there was a lot of racist things that was going on at the school, so I had to remove her from the school based on that. So it definitely exists.

Investigator: When you say racist things, maybe just give a... you don't have to describe the specifics, could you give an example?

Ann: $\quad$ Well, she was starting school and I was able to on my lunch period, I was able to go there just to kind of check up on her. This was her first year starting school, and I was realizing that none of the kids were playing with her and this is something that I brought up to 
the teachers. I brought it up to the principals, and what they told me is because the school is more than $90 \%$ of a[r] specific cultural background and obviously being Black, she was definitely in the minority. There was only a few other Black kids in the entire school and also just a few other Caucasian kids in the school and I was just told "well it's because they share the same language why the other kids aren't playing with her"

Investigator: Oh, wow.

Ann: $\quad$ So this is something that they try to... I took it to the actual school district and this is a problem that has been happening a lot. They've actually incorporated a certain survey that goes out to every single parent in the district which is primarily based on discrimination based on race and cultural backgrounds that they conduct because it is such a big problem.

Investigator: $\quad$ Oh my goodness, in the entire district?

Ann: In the entire district.

Investigator: Have you spoken to any other parents that have brought up the same

issues?

Ann: I have spoken to one other parent who was having the same... one of the other Black kids that was in the same school actually, she was having the same issue.

Investigator: In the same school?

Ann: $\quad$ Yes, but her kids are in a different grade.

Investigator: Wow, so it's the general school climate, then.

Ann: Yes!

Investigator: $\quad$ Wow. Okay, and the last question: Have you felt that you were treated differently, positively or negatively, by your child's teacher(s) due to your language or cultural background in comparison parents from other cultural or language backgrounds?

Ann: I would say probably just at that same school. The only experience that I had, I just felt like it was a problem that was obviously going on in the school for a bit of time. So to me, just that alone is them treating me different.[s]

Investigator: Oh, I see. When you brought up the issue to them, did you feel that they were attentive or did they not understand the problem?

Ann: $\quad$ On, no, no. They definitely understood it because it was obviously

something that has happened before but they were pretty much saying that there was not much that they could do about it[t].

Investigator: Oh my goodness.

Ann: $\quad$ Although I did get a different response from the school district when I spoke to the trustees and stuff from the board.

Investigator: They were more receptive to changing things?

Ann: $\quad$ No, they were more receptive to the problem and they were more accommodating to say that they would definitely look into it and do a further investigation on it and things like that

Investigator:

these issues?

Ann:

Okay, but in your child's current school, you're not really experiencing

Investigator:

Ann:

No. No. No.

Would you say that the school has a more diverse student body?

backgrounds.

Yes, they do. They do. They definitely do have more diverse cultural 
Investigator: Would you say that different cultures are celebrated in the school? Or would you say that it is not even a discussion?

Ann: In her new school, I would say they do celebrate some of the other cultures in the school. They did recognize some of the Indian holidays and some of the Chinese holidays and they did recognize Black history month.

Investigator: Okay, so they celebrate the token holidays...

Ann: Yeah.

Investigator: $\quad$ Okay, well that's it for the interview. Thank you for your time.

Ann: $\quad$ No problem

[a]use driven by language socialization

[b]language socialization

[c]identity-related

[d]maintain group connectedness

[e]language socialization: established contexts of Patois use

[f]lack of opportunities to engage in Patois in community

[g]allowed to speak Patois with non-Jamaicans in informal setting

[h]rudeness a concern

[i]dialect use similar to bilingualism

[j]Creole not appropriate for classroom (prestige)

[k]Creole not beneficial in classroom

[1]rudeness/offensiveness a concern

[m]language interference of creoles in the classroom

[n]benefit of multiple languages

[o]bad school performance may be blamed on language/culture

[p]Canada's multiculturalism - should be represented in the classroom

[q]negative school climate

[r]lack of diversity

[s]differential treatment

[t]inaction of school staff 


\section{Interview with Hal}

Date of interview: August $13^{\text {th }}, 2014$

Note: For the purposes of maintaining anonymity and protecting the privacy of all participants, pseudonyms replaced all participant names in reports of the data.

Topic A: Language Use

Investigator: $\quad$ Do you speak Jamaican Creole at home with your child?

Hal: $\quad$ Yes.

Investigator: Why did you choose to speak Jamaican Creole with your child?

Hal: $\quad$ Due to the family settings. Older family members[a]. Just convenient.

Investigator: $\quad$ Does your child speak Jamaican Creole at home as well?

Hal: $\quad$ Yes.

Investigator: $\quad$ What were your reasons for teaching your child how to speak Jamaican

Creole?

Hal: Just to associate with her family members[b]. We have a lot of old school family members who haven't grown up in I guess Canada's or North America's modern terminology so they have to use these old words and little slangs for her to even communicate with her.

Investigator: Okay. Other than home, where does your child speak Jamaican Creole? Hal: $\quad$ Usually family events, outings, when we go out to dinner together. We go out to another family member's house. Around the same nationality people, like Jamaica day, stuff like that. Last year she was actually handing out flags so a lot of people that approached her were of Jamaican descent and I guess it rubs off. [c]

Investigator: $\quad$ Is your child allowed to use Jamaican Creole with their non-Jamaican

friends?

Hal: $\quad$ Yes.

Investigator: Why?

Hal: Just because of the sheer fact that it's nothing negative[d]. I mean, it's just like Canadian slang. If you say "what's up?" or "yo", that's North American terminology. If you say "wha gwan?", that's still proper terminology, it's just Jamaican slang instead of Canadian slang or north American slang.

Investigator: Do you think it is appropriate for your child to speak Jamaican Creole at school?

Hal: $\quad$ No. Not in class. [e]

Investigator: Okay, not in the classroom but outside the classroom?

Hal: $\quad$ Outside the classroom is totally fine, maybe the play yard or with her friends or whatever, but not to a teacher. Not to an authority figure.[f]

Topic B: Perceptions of children's ability to succeed academically

Investigator: Okay. Do you believe that your child's language or language background has any relation to his/her academic performance? 
Hal: $\quad$ No, I don't think so.

Investigator: Why not?

Hal: $\quad$ Just the sheer fact that I think that Patois adds another level to the actual education. I mean if you think of it this way, someone that speaks another language, they're considered bilingual. [i] So they can identify with someone speaking to them in their language. So it would be beneficial to her.

Investigator: Do you feel that your child's language or language background is having a positive impact on his/her success in school?

Hal: $\quad$ Yes, I do. The reason being she's able to communicate not only her own nationality, but with other people that have Caribbean accents and descents because there's other Caribbean countries other than Jamaica that do speak Patois.

Investigator: Okay, so you don't feel that your child's language or language background is having a negative impact on her success in school?

Hal: No.

Investigator: Do you think your child's academic efforts will be perceived positively due to their language or cultural background?

Hal: $\quad$ I don't think that the two would actually have a connection.

Investigator: $\quad$ So you don't think it would be perceived as either positive or negative?

Hal: $\quad$ No.

Investigator: Should Jamaican Creole be incorporated into the classroom activities?

Hal: $\quad$ No, I don't

Investigator: Why not?

Hal: $\quad$ Again, it's the same thing as slang. You wouldn't incorporate North

American slang into academics, so I think Patois should be treated as slang because that's what it is.

Investigator: If Jamaican Creole were incorporated into the classroom activities, do you feel that this would help or hurt your child's academic performance?

Hal: $\quad$ I think it would probably hurt it because I don't see why they would be incorporating that terminology and that type of language in the classroom. I don't think it would benefit either parties. Someone that speaks English or Someone that speaks Patois.

\section{Topic C: Perceptions of educators' attitudes}

Investigator: Have any of your child's teachers discussed any problems or difficulties that your child may have with language? What were they, specifically?

Hal: $\quad$ No.

Investigator: Do you feel that your child has been treated differently, positively or negatively, by teacher(s) due to his/her language or cultural background in comparison students from other cultural or language backgrounds?

Hal: $\quad$ Yes. Growing up, she went to...her preschool was predominantly an Asian school and I found that they were actually... because it was predominantly Asian, they actually geared towards accommodating the Asian language more than they would accommodate any other language which I found really weird. The teacher was Asian. I'd say maybe $50 \%$ of the class was Asian. So I would hear... like when I used to go pick her up, I would hear the teachers communicating with other kids in another language. And that kind of bothered me. I'm like, they're actually going out of their way to relate to other students a little bit more and maybe not 
relate to her as much because she's Standard English and she doesn't have any.. I'm not sure what language they were speaking, Chinese or whatever, but she wasn't able to relate to that. Investigator: $\quad$ So you felt that that was a negative thing for your child.

Hal: If not everyone is able to understand, she'd be completely left out.

Investigator: Okay. Did your daughter have any issues with that?

Hal: $\quad$ No, I don't think she noticed to be honest but it was just something that stood out to me.

Investigator: Has any other parents discussed any issues that they've had?

Hal: $\quad$ Similar parents were making similar comments. Like a younger Indian lady... she was actually picking her some up, and she'd make the same type of comments as well. She's like "listen to them speak in her mother tongue", and it was kind of... I wouldn't say offensive, but it's like you're giving a little bit more attention to those students because you're able to communicate with them because you're able to identify with their language. It feels kind of biased Investigator: Have you felt that you were treated differently, positively or negatively, by your child's teacher(s) due to your language or cultural background in comparison parents from other cultural or language backgrounds?

Hal: $\quad$ I think so yeah. More for my image. I'm a younger Black male and I always get perceived as that young party guy, I guess. So usually when they... when I go pick my daughter up, I get asked if I'm an uncle or brother, which I think is kind of offensive because I think of myself as a young man, not a brother or cousin or... I take offense to that sometimes. Investigator: Okay, but have you experienced any outward differential treatment in the school?

Hal: Actually, you know what, yeah. I was at an award show, funny enough, she had an award... a little ceremony and they actually had all the parents go up. I was wearing a hat and this was an outside event right? I had a baseball event, and I didn't think anything of it at the time but we were all getting together. All the parents were taking a picture with the kids in front of us and one of the parents turned to me and said "take your hat off". And I felt totally offended by that.[g]

Investigator: $\quad$ You felt that the comment was related to your racial or cultural background?

Hal: $\quad$ I think so, yeah. I think it was related to my racial and cultural background. I, I mean...I didn't find anything wrong with it. It was a hat. There was no profanity on it. It was a Toronto Blue Jays hat, so if anything, I'm representing for the city and for them to ask me to take it off, I felt offended. I was like...well is it because I'm black?

Investigator: Could it have been a generational thing? Generational differences in perceptions?

Hal: I think it could be a generational thing, but I more took it as...because I was Black. I was literally the only Black person at that ceremony. Like, when I looked around at all the parents, there was every race... White, Indian, Asian... and I was the only Black guy there. So, I felt offended by that. [h]

[a]group connectedness

[b]group connectedness

[c]contexts of use establish 
[d]positive view of Patois

[e]Patois has no place in the classroom

[f]Patois use allowed in informal settings-lack of prestige

[g]differential treatment

[h]perceived as differential treatment that was race-based

[i]bilingualism 


\title{
Interview with Cara and Dennis
}

\author{
Date of interview: August $14^{\text {th }}, 2014$
}

Note: For the purposes of maintaining anonymity and protecting the privacy of all participants, pseudonyms replaced all participant names in reports of the data.

\section{Topic A: Language Use}

Investigator: $\quad$ Do you speak Jamaican Creole at home with your child?

Dennis: I don't speak Patois at all to my children at home.

Investigator: Okay, and what about you Cara?

Cara: I do. Only when I'm frustrated and I need to get that expression out, it comes out usually... Yeah, in that way[a]

Investigator: $\quad$ So then, other than anger, is there any other reason that you choose to speak Patois to your child or children?

Cara: $\quad$ Sorry can you repeat that again.

Investigator: $\quad$ So then, other than anger, is there any other reason that you choose to speak Patois to your child or children?

Cara: $\quad$ No, there are no real pressing reasons... like I said, I think it just naturally kind of just comes out that way.

Investigator: Okay, and Dennis, why do you choose not to speak Patois with your children?

Dennis: $\quad$ More so, with my upbringing. My dad is from Jamaica, my mom born in England but grew up in Jamaica. So by family background, I'm familiar with Patois but it was nothing I was really geared towards speaking leading up to actually speaking it well. So I've never really gotten into the practice of it that why I never really gone and done it. The most I really ever do is outside of a house setting, joking around with maybe friends at very very very odd times, but that's more so why I don't really do it. [b]

Investigator: Do your children speak Patois at home?

Dennis: No.

Cara: No.

Investigator: Okay, so you guys haven't taught your children to speak Patois at all?

Cara: $\quad$ No, I've never taught them. I think it's more so our oldest son. He hears

like a phrase or a type of term, he may at the odd time throw it around

Dennis: Yeah.

Cara: $\quad$ And then the younger 2, they just kind of mock him or mimic him.

Investigator: $\quad$ Okay, would you say that your children understand Patois?

Dennis: Probably not. I wouldn't... I wouldn't think they really understand it at all. They probably hear it and... because they don't really hear it often, as well. So they wouldn't really be in tune with it at all.

Investigator: $\quad$ So other than home, if they were to speak Patois where would they speak

it?

Cara: $\quad$ If they did speak Patois? 


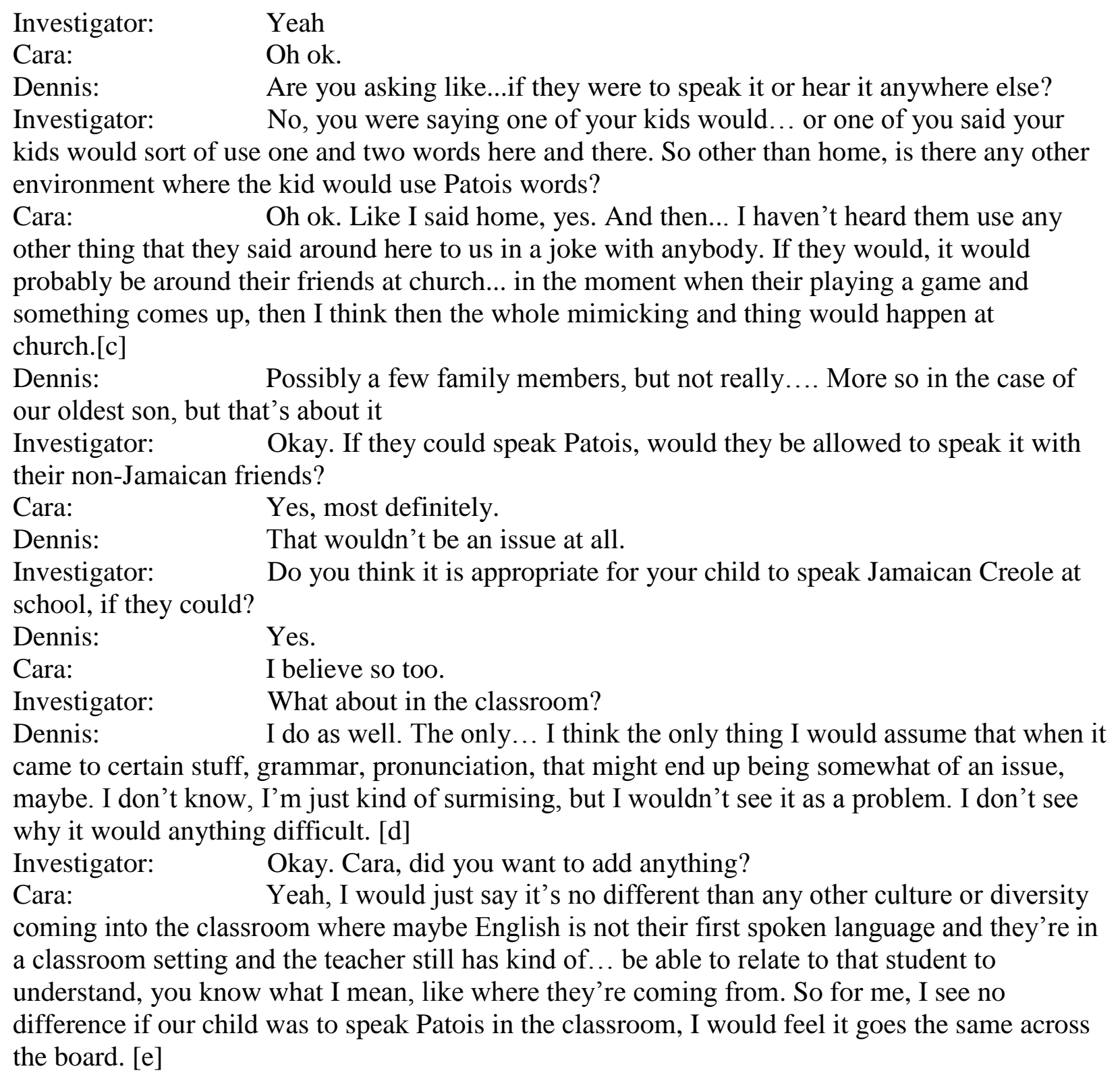

Topic B: Perceptions of children's ability to succeed academically

Investigator: Do you believe that your children's language or language background has any relation to their academic performance?

Cara: $\quad$ No. No. I'd have to say no.

Dennis: I'd have to say the same too, I don't think so either.

Investigator: Do you feel that your children's language or language background is having a positive impact on their overall success in school?

Dennis: $\quad$ Do you mean in general? Or in relation to... If they were growing up

more...

Investigator: Well, I'm referring to... let me rephrase the question... do you feel that their upbringing in hearing Patois, do you think it...hmmm.... do you think them being exposed 
to Patois in their early development has any positive influence on their overall success in school? Has language sort of helped them in school?

Cara: $\quad$ Okay. No. I mean, if they were exposed to Patois in any form and in any... whether it be minimal or whether it be in a magnitude of it, I don't think that would influence how successful they would be.

Dennis: $\quad$ Yeah, just to add to that, I don't think Patois is a learning issue.

Investigator: $\quad$ Okay, so you don't think it's positive or negative, both of you.

Cara: Yeah.

Dennis: I don't see it as any positive or negative. I think... if they grew up and we were speaking Patois all the time and that is what the predominantly learned and spoke I don't think they'd be any better off or any worse off than they would be as they are now not having Patois as our general conversation or anything like that.

Investigator: Do you think your child's academic efforts will be perceived positively or negatively due to their language or cultural background?

Investigator: $\quad$ (after long pause) Did you want me to rephrase that?

Cara: Yeah.

Dennis: $\quad$ Yeah. I'm thinking of a couple different things to add to that. I don't want to add to that inaccurately.

Investigator: Okay. I'll kind of split it up into two questions. So...Do you think coming from a Jamaican background or Patois background... do you think that people may perceived, may think that their... your child's efforts in school would be positively related to their language or cultural background?

Dennis: $\quad$ Are you saying... do you think that people would associate where their academic standing is with where their language background is coming from?

Investigator: Or cultural background, yes.

Dennis: That's a good question.

Cara: $\quad$ I don't think so.

Dennis: $\quad$ No, I don't think so.

Cara: No. She's trying to say that they would associate their cultural background to their academics?

Investigator: Yes

Cara: Or to their language?

Investigator: To their academics.

Cara: To their academics. Okay. No, I would say no with that.

Investigator: Okay. So you were saying before that Patois should not be a part of the classroom activities. Like yes, they can use it at school, but not specifically in the classroom, but if the teacher was to incorporate it in different activities...

Dennis: $\quad$ Sorry, I don't think that's what I was trying to say if that's how I communicated it.

Investigator: Okay.

Investigator: $\quad$ I think I was trying to say depending on the circumstance and what they were learning and at what point in time, it might seem to be... I don't know if it might seem to be perceived they're not, I guess, communicating something properly while they're using

Patois... [f] but I didn't mean it more so that it shouldn't be used. I don't think it's something that shouldn't necessarily be used but even if straight Patois was being used, I'm certain that it's..

teachers wouldn't be...They'd be kind of confused ... I'm of the opinion that with that confusion, 
they'd be inclined to believe that what the child is speaking to them isn't communicating properly which... that's not necessarily the case but that's how it would end up being perceived. So if i said it incorrectly before, I didn't mean to present it that way.

Investigator: Okay, and just to remind you guys, this will all be transcribed, like I'll listen to the recording over and over again, so like... all your answers will come out clearly then and my apologies if I remembered it incorrectly.

Dennis: $\quad$ Oh no no no. I just wanted to clarify.

Investigator: $\quad$ Yeah, for sure. For sure. So just turning back to the classroom aspects of it, do you think that Patois should be incorporated in specific classroom activities?

Dennis: In general? Or...

Cara: Just a minute. No I don't think so.

Investigator: No? How come?

Cara: I would say no because it's not a necessity right now. I think.. I think if there was like... If there was... like if teachers were getting a lot of students from a Jamaican culture background and there was a greater or high need for it, then I would assume then that for sure they could incorporate something like that, but I think there's no real need right now. It wouldn't be necessary. That's my take on it. I know that children who have come directly from Jamaica to Canada and they're being put in to schools, automatically, they parents... well my friends who have that scenario where they brought up their children from Jamaica and they are now going to a Canadianized school that they.. At home they're teaching their Patois-speaking child proper English proper grammar and trying to teach them... You know, this is how you say things here so that people understand you. So, I don't know... I would think that they wouldn't need it, unless it's like a real need.

Investigator: $\quad$ Okay, and what about you Dennis?

Dennis: $\quad$ I would say I don't think it would be needed in schools as well. I really am just thinking where our culture. Communicating is not predominantly Patois it's just in, for lack of a better phrase, normal standard English that we communicate with regularly, and so... if this was Jamaica, completely different circumstance.

Investigator: Okay.

Dennis: $\quad$ Because xxxx people are going to speak patois or in that regard that would be sensible but then again you obviously wouldn't need anything additional for Patois over there because everyone speaks it so I think that's really a determining factor for whether or not, in my opinion, it would be needed. If it were not... If there were a whole bunch of places where it was really established that way, like some places that are French-speaking for example, so... French needs to be a requirement because we're in Canada but there's a lot of places that have that language-speaking predominantly... and if there are more areas where a specific language is being used, then it would make sense in my mind that that be brought in more so that it's being taught more. But for now, Patois is nowhere on that level for the most part, the way I see it. Investigator: Okay. If Patois were incorporated into the classroom activities, do you feel that this would help or hurt your child's academic performance?

Cara: I'm not too sure if it would help. I think it would help in a scenario if our children were playing other children who spoke Patois on a regular basis from their home and they can probably relate to on that level, but I don't think if it was incorporated in a classroom setting that it would benefit them in that sort of sense.

Dennis: I think... I don't think it would do any damage to them outside of maybe. Once again, with English. Mainly because they're younger. I'm thinking for example, in grade 4, 
that's when they start teaching French and introducing that language. Later where there's all those things like general basic learning with general English stuff... but I don't think it would change anything but maybe that area. I don't think there'd be a change in math necessarily because of learning Patois, or gym or anything like that per se[g]

\section{Topic C: Perceptions of educators' attitudes}

Investigator: Okay, so there's 3 more questions left. So the next 3 questions deal with educators attitudes. So the first question is have any of your child's teachers discussed any problems or difficulties that your child may have with language? What were they, specifically? Cara: $\quad$ Like on a... like, outside of Patois?

Investigator: $\quad$ Or in their language related subjects. Yeah, outside of Patois or related to Patois. Anything just language-related.

Cara: Okay, yeah for the twin for one of them, just sometimes for articulation, more so with pronunciation. For example, /1/ words he would say like... as opposed to 'lab', he'd say 'wab', so that's more for articulation, I would say, would be the language issues that we've had.

Investigator: Okay, but other than that nothing else has come up?

Dennis: No.

Cara: $\quad$ No, that's it.

Investigator: Okay. Do you feel that your children has been treated differently, positively or negatively, by teacher(s) due to his/her language or cultural background in comparison students from other cultural or language backgrounds?

Cara: That's a good question. I actually haven't felt that way until last year with our twins starting JK, and one of them really felt that the teacher was really targeting him a bit based on his language and his... and how he was. He's a lot of energy and stuff so in that sense, yeah, I felt lie she was targeting him a bit, but then I found out that she targeted certain students in general and she just wasn't a good teacher overall.

Investigator: When you say targeting, what do you mean?

Cara: She would call me every other day telling me of incidents he was in and nothing major. He wouldn't hurt anybody at the time, but it would be like... "Oh he pushed someone today", "oh he's doing this today", "oh he's impulsive"... and she would call me every other day to the point where I had to say to her "yeah can you stop calling me?" and then she would write it home in a book. [h]

Investigator: Oh my goodness. Wow.

Cara: Yeah.

Investigator: And you said there were other students that she targeted?

Cara: $\quad$ Yeah, other students of different cultures. So, I didn't feel like it was only me. Obviously for me as a mother or parent, I was like "oh wow it's only me", but then when I spoke to other parents then...I was saying to them, "I feel like she's doing this", they said "oh okay me too". So it was actually across the board. Certain kids she would just... I don't know what it is with her but...

Dennis: It really just seemed like she...we learned later on that she taught a higher grade class and so I think the transition was just ... what she was able to handle was children that were maybe a little bit more well-mannered because they were older than children who were younger, more rambunctious and I mean... you're dealing with 4 or 5 years olds, possible 6 year olds, so there's a difference in dealing with an 8 year old or a 9 year old[i] 
Investigator: Okay. Yeah.

Dennis: I think that was... outside of that I don't think there was anything specific

to the language or culture to say there was a specific target in that regard, but...yeah that was the experience that we had.

Investigator: Okay. I just... I have a few questions regarding the targeting because in my essay, I write about school climate. I just was to get a little bit more detail about that. Do you feel that... you said that it wasn't one specific group that was targeted? Or do you feel that it was students from a specific cultural or racial group?

Cara: Honestly, it was like she had no discrimination for anybody, really, at the end of the day.

Investigator: Okay.

Cara: $\quad$ There was a lady I speak to, we're really close... not really close but we have a good relationship and she's from India and her son was in my son's class and he's Indian and she would complain of the teacher doing the same thing. Not as extensive as for me but some similar... I have a friend I went to college with. She was Caucasian and her daughter... she said the same thing too that you know... the teacher would just... like when she come and pick up her daughter from school, the teacher would always have something negative to say about her daughter's day and stuff like that. So I know, okay, it was kind of across the board... I don't know what it was but yeah.

Investigator: Oh okay, it could've been what Dennis was saying, just the transition and everything...

Cara: I think that for sure, yeah. After realizing that.

Dennis: It felt really weird until we heard that and then it was like, okay put two and two together, and it really made sense. It helped us to have some type of understanding since it was really difficult to try to understand what was going on.

Investigator: Okay. So last question, have you felt that you were treated differently, positively or negatively, by your child's teacher(s) due to your language or cultural background in comparison parents from other cultural or language backgrounds?

Cara: No. Honestly, I think since our first son has been in school, all the teachers I felt have been excellent. They've been great. In general, I just think it's this one teacher here with one of our twins that I had an issue with, really. But apart from that, all of our kids' teachers have been really good. I have no issues with them.

Dennis: I would have to say the same. I've never had a disagreement with a teacher. I have never gotten any impression that it was because of my language or culture background

Cara: $\quad$ Yeah.

Dennis: It was just what we were talking about, we just didn't agree on. That's all. I have confidence saying that as well.

Investigator: Okay, thank you guys.

[a]use of JA creole

[b]language use/group connectedness

[c]contexts of use

[d]language interference

[e]recognition of classroom diversity

[f]perception of speakers of Patois 
[g]interference

[h]negative school climate

[i]insight on negative school climate 


\section{Interview with Ida}

Date of interview: August $15^{\text {th }}, 2014$

Note: For the purposes of maintaining anonymity and protecting the privacy of all participants,

pseudonyms replaced all participant names in reports of the data.

\section{Topic A: Language Use}

Investigator: $\quad$ Do you speak Jamaican Creole at home with your child?

Participant: $\quad$ No.

Investigator: $\quad$ Why did you choose to not to speak Patois with her?

Participant: $\quad$ Because she won't understand. Too much explanation.[a]

Investigator: Okay, so she doesn't speak i at home then?

Participant: No.

Investigator: but she understands it?

Participant: I'm not sure to what level she'll understand it. I'd imagine she might understand a little but I don't think so. She won't understand.

Investigator: $\quad$ So, if she doesn't speak it at home, I'm guessing she doesn't speak it anywhere else?

Participant: No.

Investigator: If she could speak Patois, would you allow your child to use Jamaican Creole with their non-Jamaican friends?

Participant: Allow her to do that?

Investigator: Yeah.

Participant: I can't imagine they'd understand either. Like it would be like... ok she spoke that, but would they understand?

Investigator: $\quad$ Do you think it would be appropriate for your child to speak Patois at school, if she could?

Participant: $\quad$ No. Not at school because it's going to be all about the same thing...

Others not understanding what she's saying. [b]

Investigator: What about in the classroom?

Participant: No.

Topic B: Perceptions of children's ability to succeed academically

Investigator: Do you believe that your child's language or language background has any relation to her academic performance?

Participant: No.

Investigator: $\quad$ Do you feel that your child's language or language background is having a positive impact on her success in school?

Participant: Jamaican Patois?

Investigator: Yes.

Participant: No.

Investigator: Do you feel that your child's language or language background is having a negative impact on her success in school? 
Participant: I imagine if there were to have.... if she were to speak Patois in school and not being understood, then it might have had a negative impact, but she doesn't. [c]

Investigator: Okay, do you think her academic efforts will be perceived positively due to their language or cultural background?

Participant: Repeat that.

Investigator: Do you think her academic efforts will be perceived positively due to their language or cultural background?

Participant: I guess that would depend on... well some people would probably stigmatize you because of certain... but we hope that it wouldn't. I don't know. That's a difficult one to answer. It shouldn't. I hope it wouldn't, but who knows.

Investigator: Do you think your child's academic efforts will be perceived negatively due to their language or cultural background?

Participant: $\quad$ Yeah. No, yeah it's true. I think it would be more negative because you know, right away they put you in a category. [d]

Investigator: Do you think Patois be incorporated into the classroom activities?

Participant: $\quad$ I think so.[e]

Investigator: Really?

Participant: $\quad$ Yes.

Investigator: Why?

Participant: Because I think we're living in a diverse community and everbody should be just like any other culture, language or whatever. I think we should all learn to get along with everybody else and understand that okay, not because we speak differently or...we're the same.

[f]

Investigator: If Patois were to be incorporated into the classroom activities, do you feel that this would help or hurt your child's academic performance?

Participant: I would think it would help because at least they'd know that okay, that's a part of her background.[g]

Topic C: Perceptions of educators' attitudes

Investigator: Have any of your child's teachers discussed any problems or difficulties that your child may have with language?

Participant: $\quad$ No, not so far and she's six now. So hopefully not.

Investigator: Do you feel that she has been treated differently, positively or negatively, by teacher(s) due to his/her language or cultural background in comparison students from other cultural or language backgrounds?

Participant: $\quad$ No, I can't say I am aware of that.

Investigator: Okay. Have you felt that you were treated differently, positively or negatively, by your child's teacher(s) due to your language or cultural background in comparison parents from other cultural or language backgrounds?

Participant: No.

[a]language use

[b]against classroom use

[c]potential negative impact

[d]negative perception based on language/culture 
[e]incorporation in classroom

[f]multiculturalism

[g]dialect use bot bad in education 


\section{Appendix L}

\section{Responses}

Psuedonyms of Participants 1223456789101112

\begin{tabular}{|c|c|c|c|c|c|c|c|c|}
\hline Ann & 33 & 33 & 33 & 33 & 33 & 3 & 3 & 3 \\
\hline Bob & 33 & 42 & 23 & 34 & 42 & 3 & 3 & 4 \\
\hline Cara & 11 & 43 & 32 & 23 & 33 & 1 & 1 & 3 \\
\hline Dennis & 33 & 33 & $33:$ & 33 & 33 & 3 & 3 & 3 \\
\hline Eve & 33 & 33 & 33 & 33 & 33 & 3 & 3 & 3 \\
\hline Fran & 21 & 32 & 22 & 22 & 22 & 2 & 2 & 3 \\
\hline Gail & $\begin{array}{ll}1 & 1 \\
\end{array}$ & \begin{tabular}{l|l}
3 & 1
\end{tabular} & 11 & $\begin{array}{ll}1 & 1\end{array}$ & 11 & 1 & 1 & 1 \\
\hline $\mathrm{Hal}$ & 42 & 32 & 22 & 12 & 23 & 2 & 1 & 2 \\
\hline Ida & 33 & 22 & 23 & 32 & 22 & 1 & 1 & 2 \\
\hline
\end{tabular}

For original questions, see Appendix E (Parental Language Views). 


\section{References}

Aboud, F. E., \& Doyle, A. B. (1995). The development of in-group pride in Black Canadians. Journal of Cross-Cultural Psychology, 26(3), 243-254

Ager, D. E. (1999). Identity, insecurity and image: France and language. Clevedon, UK: Multilingual Matters.

Aguiar, L. L. M., McKinnon, A., \& Sookraj, D. (2011). Repertoires of racism: Reactions to Jamaicans in the Okanagan Valley. BC Studies, 168, 65-79.

Akers (1981). Phonological variation in the Jamaican continuum. Ann Arbor, MI: Karoma Publishers, Inc.

Allahar, A. L. (2010). The political economy of 'race' and class in Canada's Caribbean Diaspora. American Review of Political Economy, 8(2), 54-86.

Baffoe, M. (2011). Navigating two worlds: New identity constructions as determinants for successful integration of new black immigrant and refugee youth in canadian society. Journal of Social Sciences, 7(4), 475-484.

Baker, C. (2006). Foundations of bilingual education and bilingualism. North York, ON: Multilingual Matters, Ltd.

Bakker, P., Daval-Markussen, A., Parkvall, M., Plag, I. (2011). Creoles are typologically distinct from non-creoles. Journal of Pidgin and Creole Languages, 26(1), 5-42. doi:10.1075/jpcl.26.1.02bak

Benwell, B., \& Stokoe, E. (2006). Discourse and identity. Edinburgh: Edinburgh University Press.

Bentolila, A. (1987). Haitian Creole: A challenge for education. Diogenes, 35(137), 73-87. 
Berry, J. W. (1984). Multicultural policy in Canada: A social psychological analysis. Canadian Journal of Behavioural Science, 16(4), 353-370.

Best, C. T., Tyler, M. D., Gooding, T. N., Orlando, C. B., \& Quann, C. A. (2009). Development of phonological constancy toddlers' perception of native-and Jamaican-accented words. Psychological Science, 20(5), 539-542.

Bialystok, E., \& Peets, K. (2010). Bilingualism and cognitive linkages: Learning to read in different languages. In M. Shatz \& L. Wilkinson (Eds.), The education of English language learners: Research to practice (133-151). New York: Guildford Press.

Bialystok, E., Luk, G., Peets, K. F., \& Yang, S. (2010). Receptive vocabulary differences in monolingual and bilingual children. Bilingualism: Language and Cognition, 13(4), 525-531. DOI: 10.1017/S1366728909990423.

Boatswain, S. J., \& Lalonde, R. N. (2000). Social identity and preferred ethnic/racial labels for Blacks in Canada. Journal of Black Psychology, 26(2), 216-234.

Bolton, K., \& Kachru, B. B. (Eds.). (2006). World Englishes: Critical concepts in linguistics (Vol. 2). New York, NY: Taylor \& Francis.

Brathwaite, O. (2010). The role of the school curriculum to obliterate anti-Black racism. Our Schools, Our Selves, 19(3), 305-326.

Brown-Blake, C. (2008). The right to linguistic non-discrimination and Creole language situations The case of Jamaica. Journal of Pidgin and Creole Languages, 23(1), 32-74.

Carpenter, K. \& Devonish, H. (2010). Swimming against the tide: Jamaican Creole in education. In B. Migge, I. Léglise \& A. Bartens, (Eds.), Creoles in education: An appraisal of current programs and projects (167-181). Philadelphia, PA: John Benjamins. 
Chavous, T. M., Bernat, D. H., Schmeelk-Cone, K., Caldwell, C. H., Kohn-Wood, L., \& Zimmerman, M. A. (2003). Racial identity and academic attainment among African American adolescents. Child Development, 74(4), 1076-1090.

Chioneso, N. A. (2007). (Re) expressions of African/Caribbean cultural roots in Canada. Journal of Black Studies, 39(1), 60-84.

Clacher, A. (2004). The construction of Creole-speaking students' linguistic profile and contradictions in ESL literacy programs. TESOL Quarterly, 38(1), 153-165.

Codjoe, H. M. (2001). Fighting a 'Public Enemy' of Black academic achievement - the persistence of racism and the schooling experiences of Black students in Canada. Race, Ethnicity and Education, 4(4), 343-375.

Coelho, E. (1991). Caribbean students in Canadian schools, Book 2. Toronto, ON: Pippin Publishing.

Colour of Poverty Campaign - Colour of Change Network. (2011). Racial justice report card for Ontario. Retrieved from http://www.ocasi.org/downloads/Ontario\%20Racial\%20Justice\%20Report\%20Card\%202 011.pdf

Cumming, A. (2013). Multiple dimensions of academic language and literacy development. Language Learning, 63(1), 130-152. DOI: 10.1111/j.1467-9922.2012.00741.x

Cummins, J. (1997). Minority status and schooling in Canada. Anthropology \& Education Quarterly, 28(3), 411-430.

DeCamp, D. (1961). Social and geographic factors in Jamaican dialects. In Le Page, R. B., Creole Language Studies (61-84). London, UK: Macmillan. 
De Fina, A. (2007). Code-switching and the construction of ethnic identity in a community of practice. Language in Society, 36(3), 371-392.

DeGraff, M. (2005). Linguists' most dangerous myth: The fallacy of Creole Exceptionalism. Language in Society, 34(04), 533-591

Delpit, L. (2006a). Other people's children: Cultural conflict in the classroom. New York, NY: The New Press.

Delpit, L. (2006b). What should teachers do? Ebonics and culturally responsive instruction. Dialects, Englishes, creoles, and education, 93-101.

Deuber, D. (2009). 'The English we speaking': Morphological and syntactic variation in educated Jamaican speech. Journal of Pidgin and Creole Languages, 24(1), pp. 1-52.

Deuber, D., \& Hinrichs, L. (2007). Dynamics of orthographic standardization in Jamaica Creole and Nigerian Pidgin. World Englishes, 26(1), 22-47.

Dion, K. L., \& Kawakami, K. (1996). Ethnicity and perceived discrimination in toronto: Another look at the personal/group discrimination discrepancy. Canadian Journal of Behavioural Science, 28(3), 203-213. doi:http://dx.doi.org/10.1037/0008-400X.28.3.203

Dragasevich, D. (2012). The Canadian ethnocultural council and evolving multiculturalism. Canadian Ethnic Studies, 43/44(3-1), 227-234.

Dunn, R. (1993). Learning Styles of the Multiculturally Diverse. Emergency Librarian, 20(4), 24-32.

Edwards, J. R. (1977). Students' reactions to Irish regional accents. Language and Speech, 20(3), 280-286. 
Ellemers, N., \& Haslam, S. A. (2012). Social identity theory. In P. van Lange, A. Kruglanski, \& T. Higgins (Eds.). Handbook of theories of social psychology, (pp. 379-398). London, UK: Sage.

Ferguson, B., Tilleczek, K., Boydell, K., Rummens, J. A., Cote, D., \& Roth-Edney, D. (2005). Early school leavers: Understanding the lived reality of student disengagement from secondary school. Final Report submitted to the Ontario Ministry of Education.

First Years Professional Development Program. (2011). Speech sound development chart [Electronic image]. Retrieved from http://www.firstyears.org/c4/u2/sound.htm

Gardiner, H. W., \& Kosmitzki, C. (2011). Lives across cultures: Cross-cultural human development. Boston, MA: Allyn and Bacon.

Garcia, O. \& Bartlett, L. (2007). A speech community model of bilingual education: Educating Latino newcomers in the USA. The International Journal of Bilingual Education and Bilingualism, 10(1), 1-25.

Gordon, M. K. \& Zinga, M. K. (2012). "Fear of stigmatization”: Black Canadian youths' reactions to the implementation of a Black-focused school in Toronto. Canadian Journal of Educational Administration and Policy, (131), 1-37.

Hall, M. L. (2010). Re-constituting place and space: Culture and communication in the construction of a Jamaican transnational identity. The Howard Journal of Communications, 21(2), 119-140.

Harry, O. G. (2006). Jamaican Creole. Journal of the International Phonetic Association, 36(1), 125-131. DOI: 10.1017/S002510030600243X

Henry, A. (1993). Missing: Black self-representations in Canadian educational research. Canadian Journal of Education, 18(3), 206-222. 
Henslin, J. M., Glenday, D., Duffy, A., \& Pupo, N. (2007). Sociology: A down-to-earth approach (4th ed.). Toronto, ON: Pearson Education, Inc.

Howard, J. A. (2000). Social psychology of identities. Annual review of sociology, 26, 367-393.

Irvine, A. (2004). A good command of the English language: Phonological variation in the Jamaican acrolect. Journal of Pidgin and Creole Languages, 19(1), 41-76.

Jamaica Language Unit. (2005). The language attitudes survey of Jamaica. University of the West Indies. Retrieved from http://www.mona.uwi.edu/dllp/jlu/projects/survey.htm

Joseph, J. \& Kuo, B. C. H. (2009). Black Canadians' coping response to racial discrimination. Journal of Black Psychology, 35, 78-101. doi:10.1177/0095798408323384

Khan, M. (2013). English as lingua franca: a linguistic imperialism? Retrieved from http://www.dawn.com/news/1028971/english-as-lingua-franca-a-linguistic-imperialism

Kouwenberg, S., Jones, B., McLean, N., Scott, J., Anderson-Brown, W., Barrett, T., Dean, S., De Lisser, T. Havenol, D., Forbes, M., France, A., Jones, B., \& Gordon, L. (2011). Linguistics in the Caribbean: Empowerment through creole language awareness. Journal of Pidgin and Creole Languages, 26(2), 387-403. doi:10.1075/jpcl.26.2.06kou

Labov, W. (2010). Unendangered dialect, endangered people: the case of African American Vernacular English. Transforming Anthropology, 18(1), 15-27.

Labov, W. (1968). The reflection of social processes in linguistic structures. Readings in the sociology of language, 240-251.

Lambert, W. E., Hodgson, R. C., Gardner, R. C., \& Fillenbaum, S. (1960). Evaluational reactions to spoken languages. The Journal of Abnormal and Social Psychology, 60(1), 44-51. 
Le Page, R. B. (1988). Some premises concerning the standardization of languages, with special reference to Caribbean Creole English. International Journal of the Sociology of Language, 71, 25-36.

Lombardino, L. J., Lieberman, R. J., Brown, L. C. (2005). Manual: Assessment of literacy and language. San Antonio, TX: Harcourt Assessment, Inc.

Loureiro-Rodriguez, V., Boggess, M. M., \& Goldsmith, A. (2013). Language attitudes in Galicia: using the matched-guise test among high school students. Journal of Multilingual and Multicultural Development, 34(2), 136-153.

Mair, C. (2002). Creolisms in an emerging standard: Written English in Jamaica. English World-wide, 23(1), 31-58.

Migge, B. (2007). Code-switching and social identities in the Eastern Maroon community of Suriname and French Guiana. Journal of Sociolinguistics, 11(1), 53-73.

Millar, R. M. (2007). Trask's historical linguistics (2nd ed.). London: Saffron House.

Morgan, M. H. (2014). Speech communities. Cambridge: Cambridge University Press.

Mousa, A. I. (2014). Acquisition of the Labio-Dental Fricative/v/in English L2 and Jamaican Creole: A Comparative Study. International Journal of English Linguistics, 4(1), 60-69.

Mousa, A. (1994). The Interphonology of Saudi Learners of English (Unpublished doctoral dissertation). University of Essex.

Mühleisen, S. (2005). Introduction: Creole languages in creole literatures. Status and standardization. Journal of Pidgin and Creole Languages, 20(1), 1-14.

Nieuwenhuys, O. (2013). Theorizing childhood(s): Why we need postcolonial perspectives. Childhood, 20(1), 3-8. 
Organization for Economic Cooperation and Development (OECD). (2012) Connecting with Emigrants: A Global Profile of Diasporas. OECD Publishing. doi: 10.1787/9789264177949-en

Paradis, J., Genesee, F., \& Crago, M. B. (2011). Dual language development and disorders: A handbook on bilingualism and second language learning (2nd ed.). Baltimore, MD: Paul H. Brookes Publishing Co., Inc.

Pavlenko, A. (2004). 'Stop doing that, Ia komu skazala!': Language choice and emotions in parent_child communication. Journal of Multilingual and Multicultural Development, 25(2-3), 179-203.

Peets, K., \& Milburn, T. (2012) Emergent literacy in preschoolers: processes underlying listening comprehension. Poster presented at the $19^{\text {th }}$ Annual Meeting of the Society for the Scientific Study of Reading, Montreal, Canada.

Plaza, D. (2006). The construction of a segmented hybrid identity among one-and-a-half-generation and second-generation Indo-Caribbean and African Caribbean Canadians. Identity, 6(3), 207-229.

Plaza, D. (2004). Disaggregating the Indo-and African-Caribbean migration and settlement experience in Canada. Canadian Journal of Latin American and Caribbean Studies, 29(57-58), 241-266.

Pearson, B. Z., Velleman, S. L., Brant, T. J., \& Charko, T. (2009). Phonological milestones for African American English-speaking children learning mainstream American English as a second dialect. Language, Speech \& Hearing Services in Schools, 40(3), 229-244.

Phenice, L. A., \& Griffore, R. J. (2000). Social identity of ethnic minority families: An ecological approach for the new millennium. Michigan Family Review, 5(1), 29-40. 
Pigott, R. (2011). Jamaica's Patois bible: The word of God in creole. BBC News Magazine. Retrieved from http://www.bbc.com/news/magazine-16285462

Piller, I. (2001) Private language planning: The best of both worlds?. Estudios de Sociolinguistica, 2(1), 61-80.

Polinsky, M., \& Kagan, O. (2007). Heritage languages: In the 'wild' and in the classroom. Language and Linguistics Compass, 1(5), 368-395.

Reynolds-Keefer, L., Johnson, R., Dickenson, T., \& McFadden, L. (2009). Validity issues in the use of pictorial Likert scales. Studies in Learning, Evaluation Innovation and Development, 6(3), 15-24.

Royal Commission on Learning. (1994). For the love of learning: Report of the Royal Commission on Learning; Vol. 4 Making it happen. Toronto: Queen's Printer for Ontario.

Schecter, S. R., \& Bayley, R. (2004). Language socialization in theory and practice. International Journal of Qualitative Studies in Education, 17(5), 605-625.

Schecter, S. R., \& Bayley, R. (1997). Language Socialization Practices and Cultural Identity: Case Studies of Mexican-Descent Families in California and Texas. Tesol Quarterly, $31(3), 513-541$.

Schneider, E. W., \& Wagner, C. (2006). The variability of literary dialect in Jamaican creole: Thelwell's The Harder They Come. Journal of Pidgin and Creole languages, 21(1), 45-96.

Schwartz, S. J., Luyckx, K., \& Vignoles, V. L. (Eds.). (2011). Handbook of identity theory and research. New York, NY: Springer. 
Seymour, H. N., Roeper, T. W., \& de Villers, J. (2003). Examiner's manual: Diagnostic evaluation of language variation screening test. San Antonio: Pearson, Inc.

Siegel, J. (1999a). Creoles and minority dialects in education: An overview. Journal of Multilingual and Multicultural Development, 20(6), 508-531.

Siegel, J. (1999b). Stigmatized and Standardized Varieties in the Classroom: Interference or Separation?*. Tesol Quarterly, 33(4), 701-728.

Smith, A., Schneider, B. H., \& Ruck, M. D. (2005). “Thinking about makin' it”: Black Canadian students' beliefs regarding education and academic achievement. Journal of Youth and Adolescence, 34(4), 347-359. doi:10.1007/s10964-005-5759-0

Smith-Edwards, A. (2013, November 21). Oral test in English language by 2016. Jamaica Information Service. Retrieved from http://jis.gov.jm/oral-test-english-language-2016/ Statistics Canada. (2011). Immigration and ethnocultural diversity in Canada. Retrieved from http://www12.statcan.gc.ca/nhs-enm/2011/as-sa/99-010-x/99-010-x2011001-eng.cfm

Terry, N. (2012). Examining relationships among dialect variation and emergent language skills. Communication Disorders Quarterly, 33(2), 67-77. DOI: 10.1177/1525740110368846

Thompson, P., \& Bauer, E. (2003). Evolving Jamaican migrant identities: Contrasts between Britain, Canada and the USA. Community, Work \& Family, 6(1), 89-102.

Toronto District School Board. (2013). English as a second language/English literacy development. Retrieved from http://www.tdsb.on.ca/HighSchool/YourSchoolDay/EnglishasaSecondLanguage.aspx University of the West Indies. (2014). The Jamaica Language Unit (Background). Retrieved from http://www.mona.uwi.edu/Dllp/jlu/about/index.htm 
Watson-Gegeo, K. A. (2004). Mind, language, and epistemology: Toward a language socialization paradigm for SLA. The Modern Language Journal, 88(3), 331-350.

Weiss, R. S. (1995) Learning from strangers: The art and method of qualitative interview studies. New York: The Free Press.

Whinnom, K. (1971). Linguistic hybridization and the 'special case' of pidgins and creoles. In D. Hymes (Ed.), Pidginization and creolization of languages, 91115. Cambridge: Cambridge University Press.

Wigglesworth, G., Billington, R., \& Lakes, D. (2013). Creole speakers and standard language education. Language and Linguistics Compass, 7(7), 388-397.

DOI:10.1111/Inc3.12035

Winford, D. (1997). Re-examining Caribbean English Creole Continua. World Englishes, 16(2), 233-279.

Woodall, R. (2007). (Re)Thinking my '-Ness': Diaspora Caribbean Blacks in the Canadian Context. Shibboleths: A Journal of Comparative Theory, 1(2), 120-126.

Wotherspoon, T. (2009). The sociology of education in Canada (3rd ed.). Toronto: Oxford University Press.

Wright, B. L. (2011). I know who I am, do you? Identity and academic achievement of successful African American male adolescents in an urban pilot high school in the United States. Urban Education, 46(4), 611-638.

Wurm, S. A. (1987). Change of languages as a result of decay and change of culture. Diogenes, 35(137), 39-51. doi:10.1177/039219218703513703

Yinger, J. (1985). Ethnicity. Annual Review of Sociology, 11(1), 151-180. doi:10.1146/annurev.soc.11.1.151 